UNIVERSIDADE DE SÃO PAULO - USP

MARCOS HENRIQUE MARÇAL CAMILLO

\begin{abstract}
AVALIAÇÃO DE UMA METODOLOGIA PARA RESTABELECIMENTO DE ENERGIA BASEADA EM ALGORITMOS EVOLUTIVOS MULTI-OBJETIVOS NO SISTEMA DE DISTRIBUIÇÃO DE ENERGIA ELÉTRICA DA COPEL NA CIDADE DE LONDRINA
\end{abstract}





\section{AV ALIAÇÃO DE UMA METODOLOGIA PARA RESTABELECIMENTO DE ENERGIA BASEADA EM ALGORITMOS EVOLUTIVOS MULTI-OBJETIVOS NO SISTEMA DE DISTRIBUIÇÃO DE ENERGIA ELÉTRICA DA COPEL NA CIDADE DE LONDRINA ${ }^{1}$}

Dissertação apresentada à Escola de Engenharia de São Carlos, da Universidade de São Paulo, como parte dos requisitos para obtenção do Título de Mestre em Ciências pelo Programa de Engenharia Elétrica

Área de concentração: Sistemas Elétricos de Potência

Orientador: Prof. João Augusto Bosco London Junior

São Carlos

2013

\footnotetext{
${ }^{1}$ Trata-se da versão corrigida da dissertação. A versão original se encontra disponível na EESC/USP que aloja o Programa de Pós Graduação de Engenharia Elétrica.
} 


\section{AUTORIZO A REPRODUÇÃO TOTAL OU PARCIAL DESTE TRABALHO, POR QUALQUER MEIO CONVENCIONAL OU ELETRÔNICO, PARA FINS DE ESTUDO E PESQUISA, DESDE QUE CITADA A FONTE.}

C183a Avaliação de uma metodologia para restabelecimento de energia baseada em algoritmos evolutivos

multi-objetivos no sistema de distribuição da COPEL na cidade de Londrina / Marcos Henrique Marçal Camillo; orientador João Augusto Bosco London Junior. São Carlos, 2013.

Dissertação (Mestrado) - Programa de Pós-Graduação em Engenharia Elétrica e Área de Concentração em Sistemas Elétricos de Potência -- Escola de Engenharia de São Carlos da Universidade de São Paulo, 2013.

1. Algoritmos evolutivos multi-objetivos. 2 . Representação nó-profundidade. 3. Reconfiguração de redes. 4. Sistemas de distribuição de grande porte. I.Título. 


\section{FOLHA DT. IULGA.ME.TTO}

Candidato: Tengenliciro MARCOS IIENRIQUE MARGAL CAMILLO.

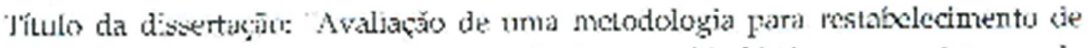
encrgin jaseada en algoritmos emblutivos nulti-obetivos no sistema de

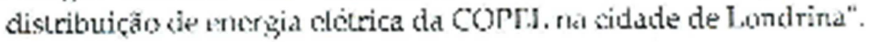

Wala da détra: $12 ; 09 / 20: 3$

Comissão Juigadorn:

Resultado:

Prol. Assoc. Joân Bosco Augusto London Júnior (Orientador) Escola de Fngenha ria de Säo Carke; EESC;

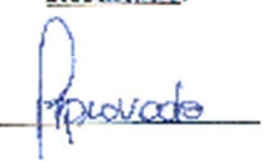

Prof. Dr. Madson Cortes de Almeida

Arsinasez

(Universichecte Listadual de CatpinasiLINICANT)

Prof. Ascrciado Alexandre Cláudio Botazzo Detbem

APROVINO

(Institut: ale Ma.cmática e ComputajäniliCMC)

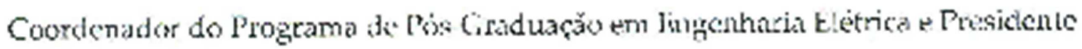
da Curnissáo de l'ós-Graduaţio:

Frof. Titular Denis Vinicius Coury 



\section{DEDICATÓRIA}

Aos meus filhos Gabriel e Ana Luiza e a todos que acreditaram neste trabalho. 



\section{AGRADECIMENTOS}

A Deus, criador de todas as coisas e fonte de inspiração, conhecimento e amor. Ao meu orientador João Bosco pela paciência, orientação, conhecimento e apoio. Agradeço também pelas críticas construtivas e debates sobre os assuntos desta dissertação.

À minha esposa Carol, por todos os momentos cedidos, pelo apoio sempre presente, pelo carinho e motivação. Sem sua insistência dificilmente eu teria chegado até aqui. Aos meus pais Carlos e Cidinha pela educação, formação, suporte e pela base através da qual se iniciou este trabalho.

À Laura e Pedro, por toda disponibilidade, consideração e ajuda.

Ao Professor Maciel, por acreditar no meu trabalho e me apresentar ao corpo docente da USP.

Aos meus filhos Gabriel e Ana Luiza que certamente sentiram minha falta durante as viagens para São Carlos e demais momentos dedicados ao mestrado.

Aos meus irmãos Guto e Hugo e todos familiares que participaram e incentivaram esta caminhada.

Aos amigos da COPEL, em especial aos Srs. Marcel e Rodrigo, pelas dicas, orientações e auxílio. Aos meus gerentes e superiores pelas liberações e compreensão da importância deste trabalho.

À COPEL, por acreditar no trabalho de Pesquisa e Desenvolvimento e fornecer toda estrutura necessária para sua realização.

À Escola de Engenharia de São Carlos (EESC/USP) por todo o suporte necessário para o desenvolvimento desta dissertação.

Por fim, a todos aqueles de alguma maneira participaram deste mestrado e apoiaram sua realização. 



\section{LISTA DE FIGURAS}

Figura 1. llustração de um Sistema de Distribuição ..............................................10

Figura 2. Chave Seccionadora Unipolar (SU) …….........................................11

Figura 3. Chave Tripolar isolada a óleo........................................................12

Figura 4. Exemplo de Posto de transformação na distribuição ................................13

Figura 5. Exemplo de Banco de Capacitores alocado em uma subestação ..............14

Figura 6. Exemplo de um grafo .................................................................. 18

Figura 7. SDR com 4 alimentadores representado através de grafo........................20

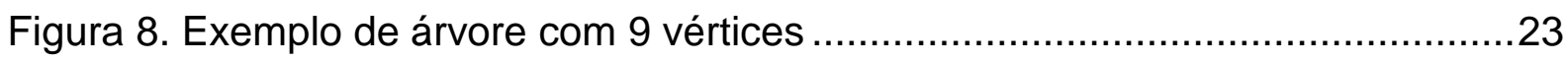

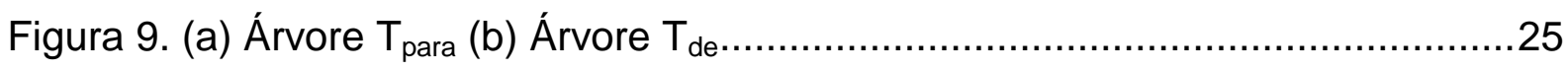

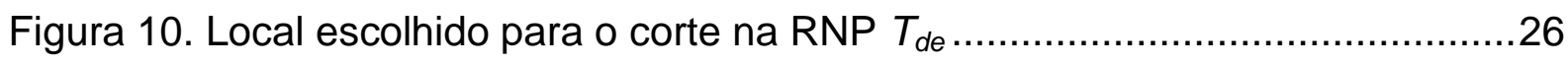

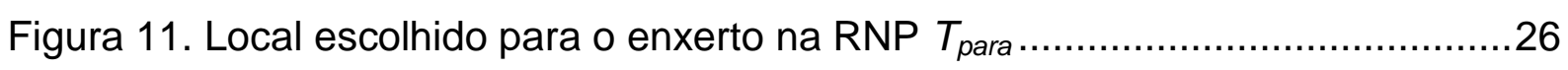

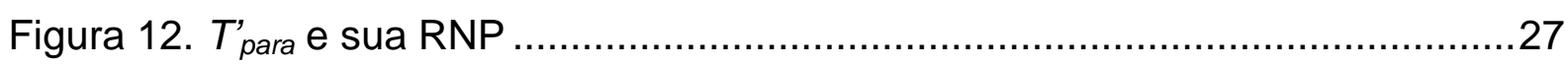

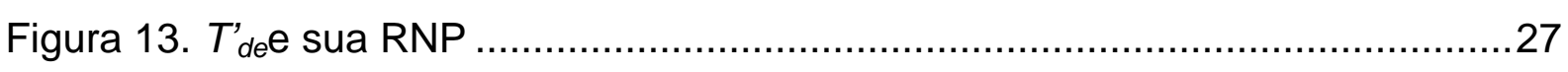

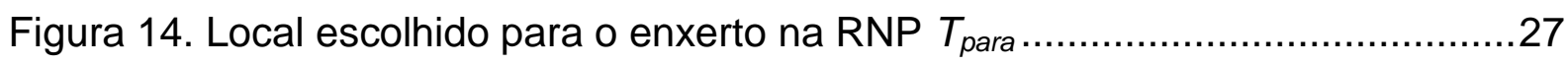

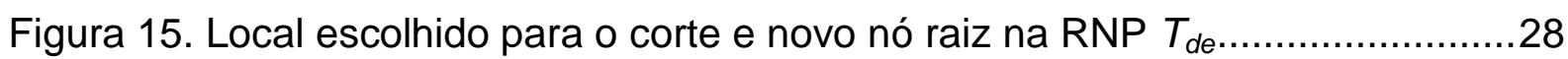

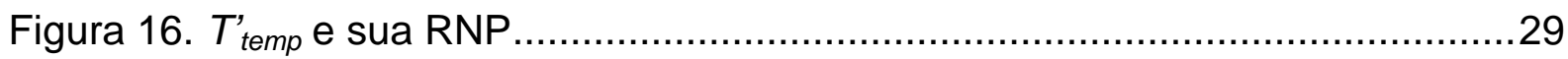

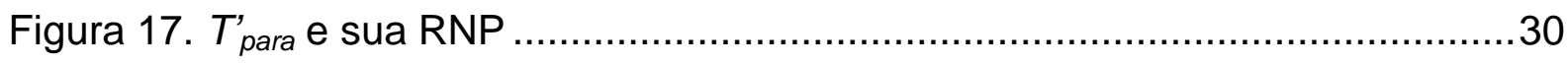

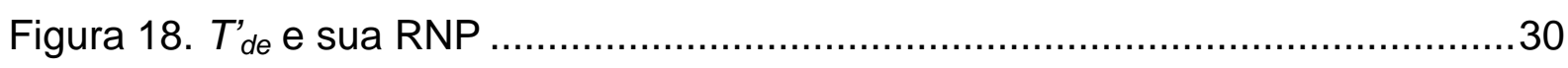

Figura 19. Exemplo de mutação em indivíduos binários ............................................34

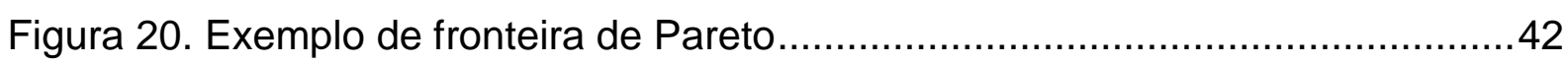

Figura 21. Soluções de Pareto-ótimas locais e globais (fonte: [48]).........................44

Figura 22. Diferentes distribuições de soluções na fronteira de Pareto (fonte: [48]) . 45

Figura 23. Ordenação por não-dominância (fonte: [57]).........................................49

Figura 24. Esquema para uma iteração do NSGA-II (fonte: [57]) ............................51

Figura 25. Diagrama unifilar de um circuito alimentador .......................................56

Figura 26. Exemplo de SRD com 02 (dois) alimentadores.....................................58

Figura 27. SRD exemplo com destaque para o "Setor 07" .......................................59

Figura 28. Operações necessárias para isolar o setor em falta ...............................64

Figura 29. Configuração proposta para isolação e restabelecimento..........................65

Figura 30. Cálculo das manobras: configuração inicial ............................................68

Figura 31. Configuração após alterações iniciais $(y)$..........................................69

Figura 32. Cálculo das manobras: configuração 2 .............................................70 


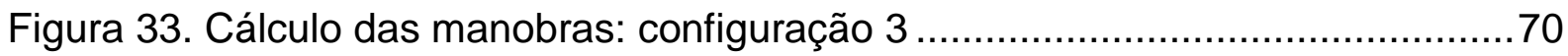

Figura 34. Exemplo de SDR a ser modelado (modelo COPEL) .............................78

Figura 35. Exemplo dos setores de um SDR qualquer (modelo Intermediário).........80

Figura 36. Representação Proposta para o SDR da Figura 34 (modelo USP)...........80

Figura 37. SDR de Londrina antes da ocorrência da falta.....................................81

Figura 38. Alimentador $59 \mathrm{em}$ falta - Chaves para isolamento do defeito .................83

Figura 39. Alimentador $59 \mathrm{em}$ falta - Chaves para restabelecimento e opções ........84

Figura 40. Fronteiras de Pareto obtidas para o SDR de Londrina............................86

Figura 41. Representação Gráfica do indivíduo da geração inicial ............................86

Figura 42. Representação Gráfica das alternativas para gerar o indivíduo inicial.....87

Figura 43. Representação Gráfica do indivíduo da geração 54.452 .........................89

Figura 44. Representação Gráfica do indivíduo da geração 3.768 ........................91

Figura 45. Representação Gráfica do indivíduo da geração 12.493 .......................92

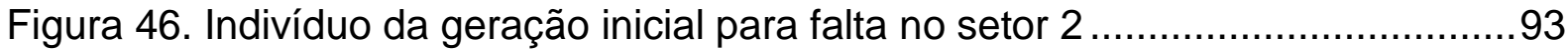

Figura 47. Indivíduo da geração inicial para falta no setor $1784 \ldots \ldots \ldots \ldots \ldots \ldots \ldots \ldots \ldots \ldots . . .96$

Figura 48. Representação Gráfica do indivíduo da geração 16.434 ......................97

Figura 49. Representação Gráfica do indivíduo da 2ª Simulação, Geração 7.408....98 


\section{LISTA DE TABELAS}

Tabela 1. Grau de cada um dos nós do grafo apresentado na Figura 6 .................19

Tabela 2. Tabelas e indivíduos de um exemplo de AEMT ...................................47

Tabela 3. Tabelas e indivíduos de um exemplo de AEMT após reprodução .............48

Tabela 4. Manobras de chaves: Caso 1 ...........................................................66

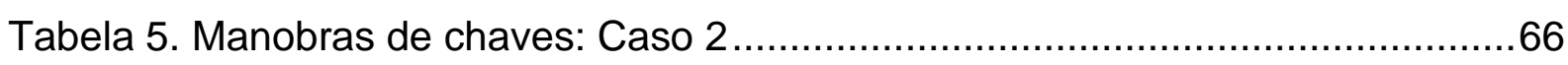

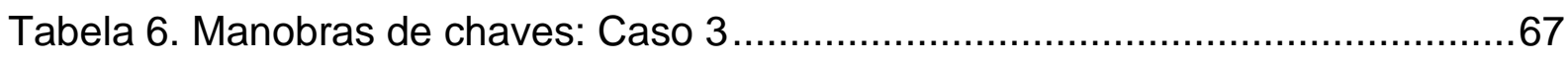

Tabela 7. Exemplo de seleção dos indivíduos da tabela 2 do AEMT-H (geração I) ..73

Tabela 8. Exemplo de seleção dos indivíduos da tabela 2 do AEMT-H (geração I) ..73

Tabela 9. Características do indivíduo da $1^{\text {a }}$ geração para o sistema em estudo .....84

Tabela 10. Número de manobras obtidos no SDR de Londrina................................85

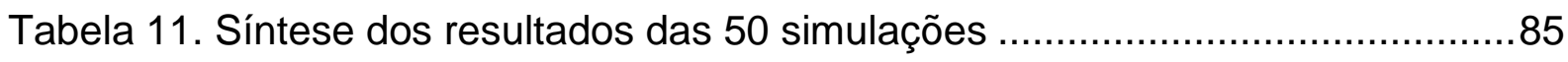

Tabela 12. Resultados do indivíduo da geração54.452 …………....................... 89

Tabela 13. Resultados desde a geração inicial até a do indivíduo $54.452 \ldots \ldots \ldots \ldots \ldots . . . .90$

Tabela 14. Características do indivíduo da $1^{\text {a }}$ geração para falta no setor 1784 ......94

Tabela 15. Síntese dos resultados das 50 simulações para a falta no setor 1784 ....95

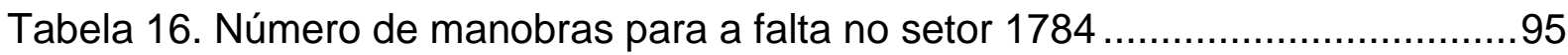

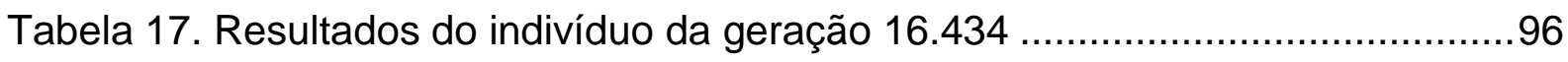

Tabela 18. Resultados desde a geração inicial até a do indivíduo $16.434 \ldots \ldots \ldots \ldots \ldots . . .97$

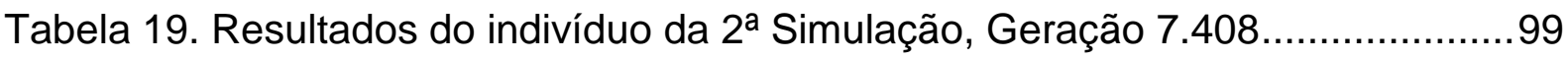





\section{LISTA DE ABREVIATURAS E SIGLAS}

AEs Algoritmos Evolutivos

AG Algoritmo Genético

AEMO Algoritmo Evolutivo "Multi-Objetivo"

AEMT Algoritmo Evolutivo Multi-objetivo em Tabela

AEMT-H Algoritmo Evolutivo Multi-objetivo em Tabela com heurística

BC Banco de Capacitor

BT Busca Tabu

BTR Busca Tabu Reativa

CAO do inglês Change Ancestor Operator

CE Computação Evolutiva

CF Chave Fusível

CO Chave a Óleo Tripolar

COD Centro de Operação da Distribuição

DEC Duração equivalente por consumidor

DIC Duração individual por consumidor

DMIC Duração máxima individual por consumidor

EEs Estratégias Evolutivas

FEC Frequência equivalente por consumidor

FIC Frequência individual por consumidor

GA Chave Tripolar com Isolação a Gás e Operação "Automática"

GM Chave Tripolar com Isolação a Gás e Operação Manual

LA Chave Fusível Laminada

MOGA do inglês "Multiple Objective Genetic Algorithm"

MOMGA do inglês "Multi-Objective Messy Genetic Algorithm"

MOO Otimização Multi-Objetivo

MOOP Problema de Otimização Multi-Objetivo

MPF Modelo Pai-Filho

NA Normalmente Aberta

NF Normalmente Fechada

NPGA do inglês "Niched-Pareto Genetic Algorithm"

NR Chave a Óleo Monopolar

NSGA-II do inglês "Elitist Non-Dominated Sorting Genetic Algorithm" 
OR Chave Omni Rupter

PAES do inglês "Pareto-Archived Evolutionary Strategy"

PAO do inglês Preserve Ancestor Operator

PE Programação Evolutiva

PESA do inglês "Pareto Envelope-Base Selection Algorithm"

PG Programação Genética

PPES do inglês "Predator-Prey Evolutionary Strategy"

REMOEA do inglês "Rudolph's Elitist Multi-Objective Evolutionary Algorithm"

RNP Representação Nó-Profundidade

RT Regulador de Tensão

SA do inglês "Simulated Anneling"

SDR Sistema de Distribuição Radial

SE Subestação

SF6 Hexafluoreto de Enxofre

SOD Sistema de Operação da Distribuição

SPEA do inglês "Strenght Pareto Evolutionary Algorithm"

SU Chave Seccionadora Unipolar

TF Transformador de Força

TGA do inglês "Thermodynamical Genetic Algorithm"

USP Universidade de São Paulo

VEJA do inglês "Vector Evaluated Genetic Algorithm"

WBGA do inglês "Weight Based Genetic Algorithm"

$\epsilon$-MOEA do inglês " $\epsilon$-dominance Multi-Objective Evolutionary Algorithm" 


\section{SUMÁRIO}

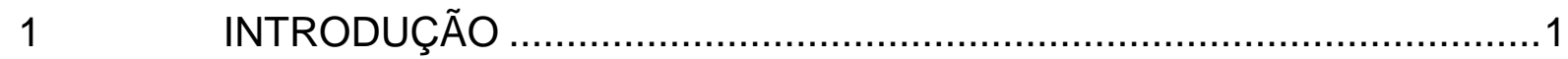

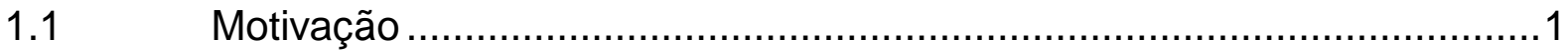

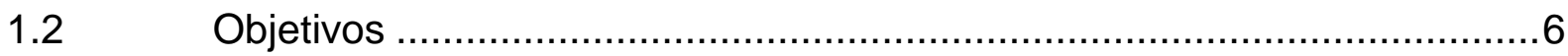

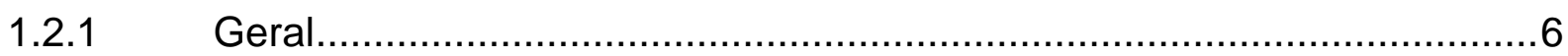

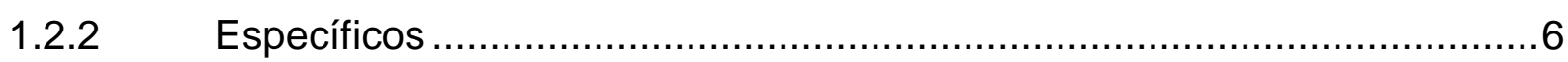

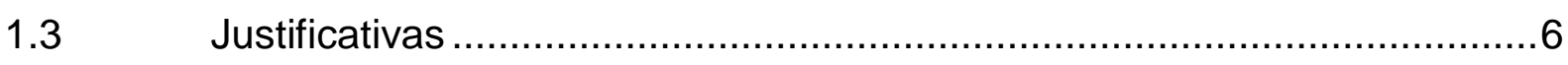

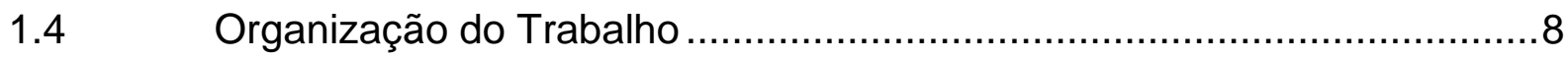

2 RESTABELECIMENTO DE ENERGIA EM SISTEMAS DE

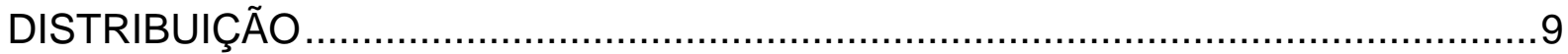

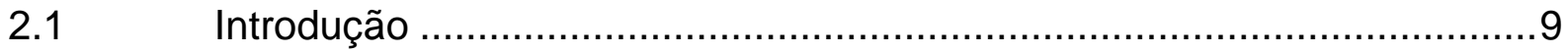

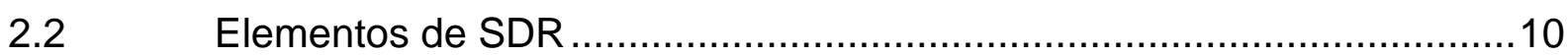

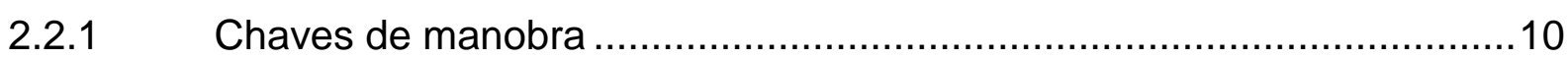

2.2.2 Trecho primário ........................................................................12

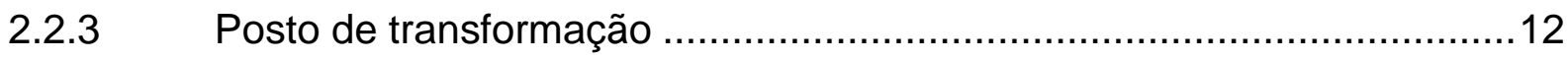

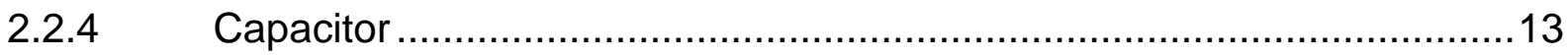

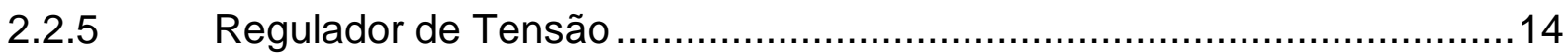

2.3 O problema de Restabelecimento de Energia em SDR ........................14

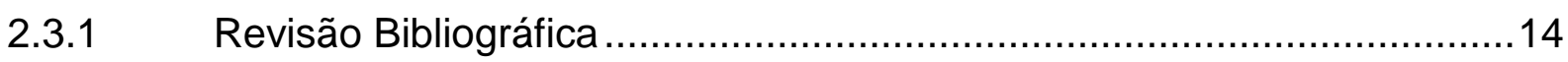

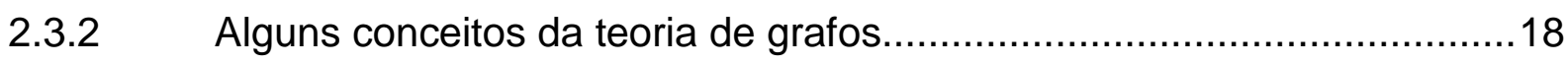

2.3.3 Representação de SDRs através de grafos .......................................20

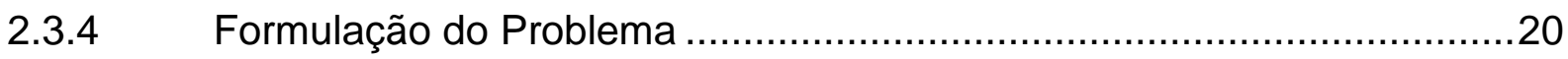

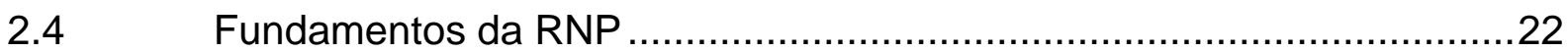

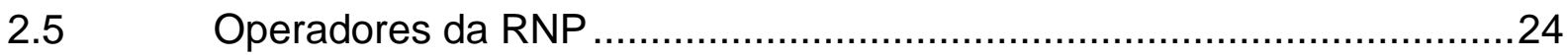

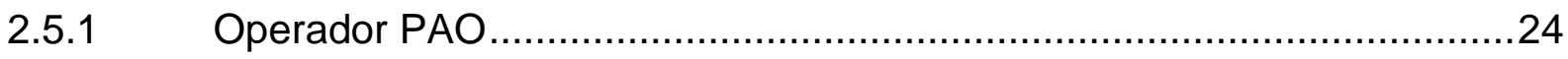

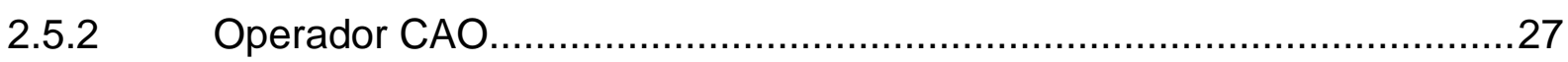

3 FUNDAMENTOS DE ALGORITMOS EVOLUTIVOS E DE OTIMIZAÇÃO

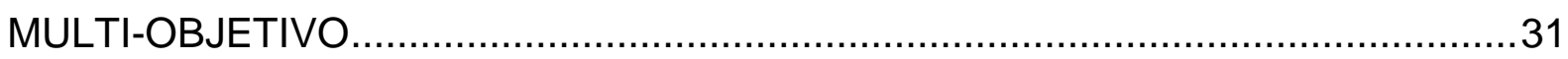

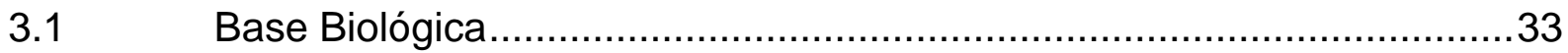

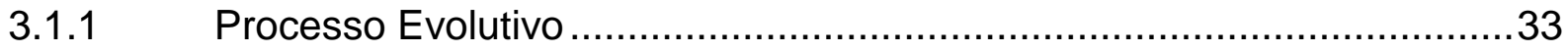

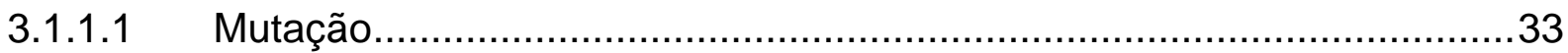

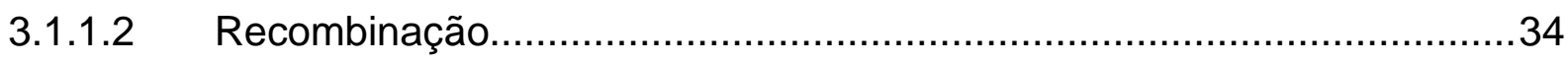

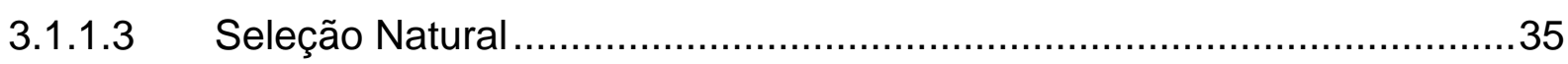




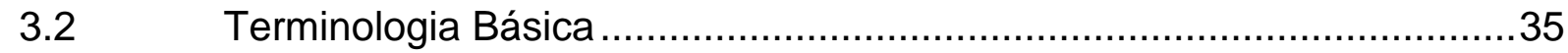

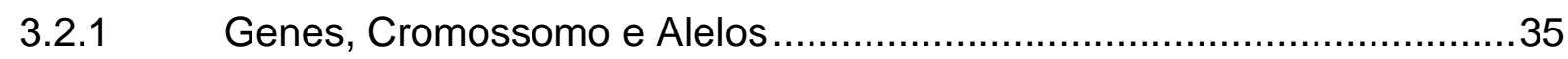

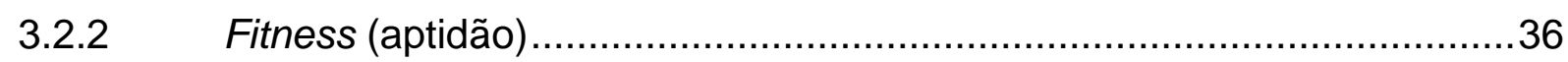

3.2.3 Pais, Operadores de Reprodução e Descendentes ...............................36

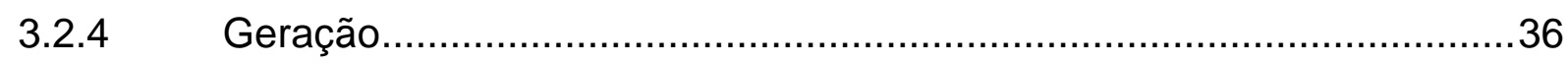

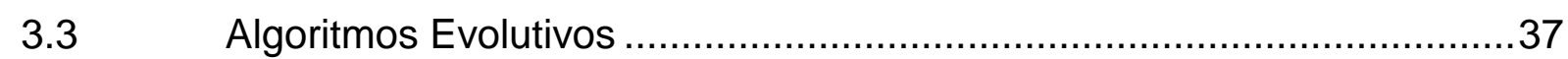

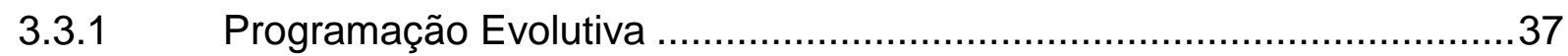

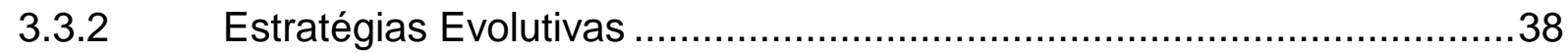

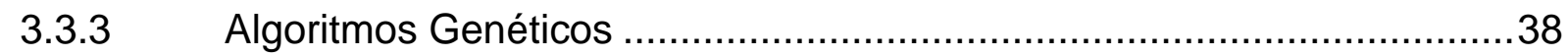

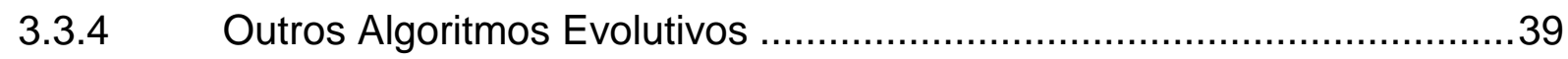

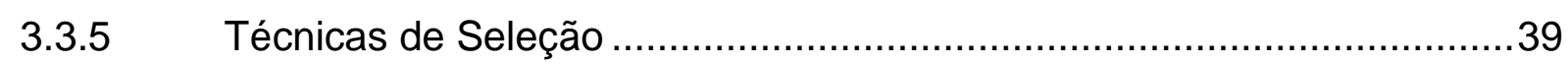

3.4 Algoritmos Evolutivos para Otimização Multi-Objetivo ..........................40

3.4.1 Problemas de otimização Multi-Objetivo ..............................................40

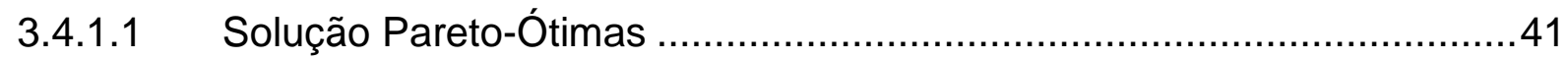

3.4.1.2 Dominância de Pareto: Definição e Propriedades ...................................43

3.4.2 Metas em otimização Multi-Objetivo ................................................ 44

3.4.3 Diferenças entre Otimização Multi-Objetivo e Mono-Objetivo ..................45

3.5 Algoritmos Evolutivos base do AEMT-H..........................................46

3.5.1 Algoritmo Evolutivo Multi-objetivo em Tabela.....................................46

3.5.2 NSGAll: "Elitist Non-Dominanted Sorting Genetic Algorithm” ................48

4 METODOLOGIA PARA RESTABELECIMENTO DE ENERGIA EM SISTEMAS DE DISTRIBUIÇÃO BASEADA NA RNP E EM AEMO ….....................53

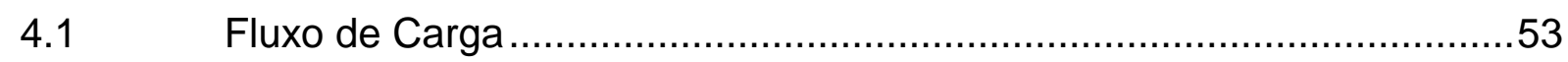

4.1.1 Método da Soma de Potência ………….........................................55

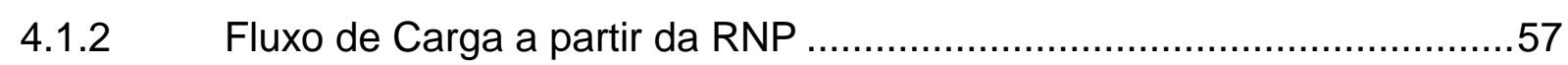

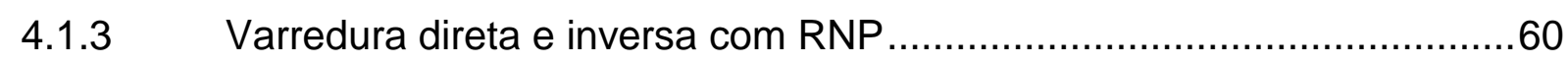

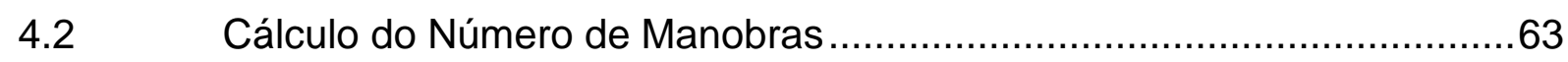

4.2.1 Exemplo ilustrativo de cálculo do número de manobras .........................67

4.3 Algoritmo Evolutivo em Tabelas com Heurística (AEMT-H) ....................71

5 PREPARAÇÃO DOS DADOS COPEL PARA APLICAÇÃO NO AEMT-H 76

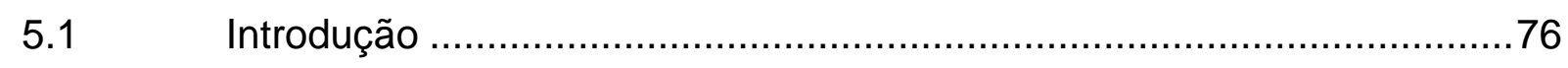

5.2 Base de dados da COPEL - Modelo COPEL.......................................76

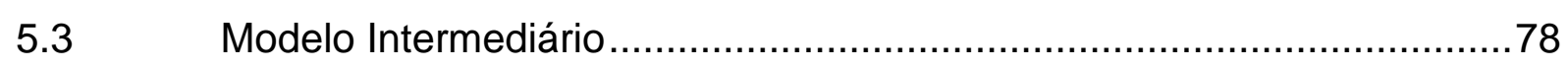




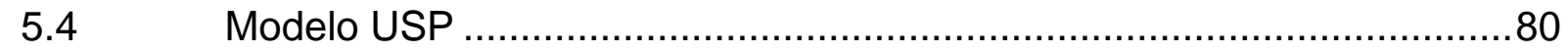

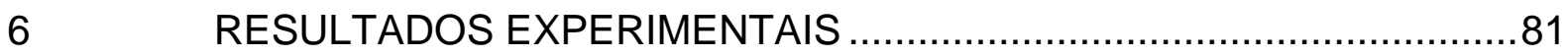

6.1 Simulações considerando Falta Única ………................................ 82

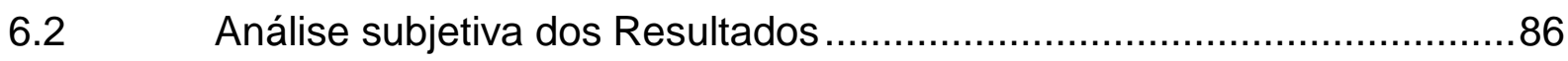

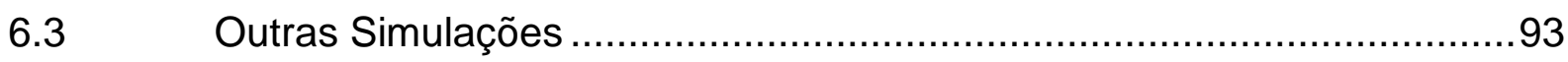

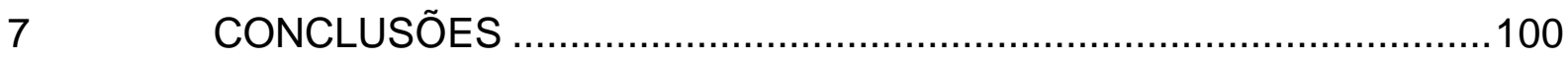

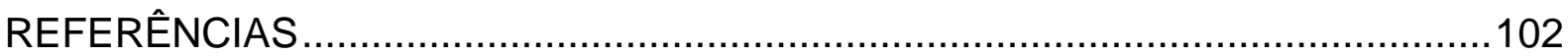





\section{RESUMO}

CAMILLO, M. H. M. Avaliação de uma metodologia para restabelecimento de energia baseada em algoritmos evolutivos multi-objetivos no sistema de distribuição da COPEL na cidade de Londrina. 2013. 129 pg.

Dissertação (Mestrado) - Escola de Engenharia de São Carlos, Universidade de São Paulo, São Carlos 2013.

Desenvolver um sistema de distribuição de energia confiável é certamente um desafio inerente aos profissionais do setor elétrico. Porém, os sistemas estão sujeitos a falhas e, sendo assim, o rápido restabelecimento traz a satisfação do cliente e reduz as compensações pagas pelas concessionárias de energia.

Neste contexto a presente dissertação visa avaliar a metodologia para restabelecimento de energia denominada AEMT-H que se baseia em algoritmos evolutivos multi-objetivo se na estrutura de dados chamada Representação NóProfundidade (RNP). Esta avaliação ocorrerá através da aplicação do AEMT-H para obtenção de planos de restabelecimento de energia após a ocorrência de faltas simples no sistema COPEL da cidade de Londrina. Os resultados gerados serão avaliados estatisticamente e ainda subjetivamente pelos profissionais do COD da concessionária.

Os algoritmos evolutivos têm apresentado resultados animadores para os problemas de restabelecimento de energia. Em especial, os resultados obtidos, quando da representação computacional de sistemas de distribuição de grande porte (com milhares de barras e chaves) através da RNP, possuem como característica o tempo de resposta da ordem de segundos, instigando a evolução das pesquisas para utilização desta metodologia inclusive em aplicativos de tempo real.

O sistema de Londrina possui 30.156 barras, 2.660 chaves "NF", 250 chaves "NA" e atende um universo de mais de 231.000 consumidores ligados diretamente ao sistema de 13,8kV ou, após os transformadores de distribuição, nas tensões de $220 \mathrm{~V}$ e $127 \mathrm{~V}$. Neste sistema estão presentes 6 subestações $138 \mathrm{kV} / 13,8 \mathrm{kV}$ e 64 circuitos alimentadores, totalizando uma capacidade de transformação de energia de 541,7MVA.

Palavras-chaves: restabelecimento de energia, sistema de distribuição de grande porte, Representação Nó Profundidade e Algoritmo Evolutivo Multi-objetivo. 



\begin{abstract}
CAMILLO, M. H. M. Evaluation of a methodology for service restoration based on multi-objective evolutionary algorithms for Copel distribution system in Londrina city. 2013. 129 pg. Master Thesis - Escola de Engenharia de São Carlos, Universidade de São Paulo, São Carlos 2013.

The development of a reliable distribution system is certainly a challenge to electrical industry professionals. However, these systems are subject to failures and thus the fast restoration brings customer satisfaction and reduces the compensation paid by the electricity utilities.

In this context, this dissertation aims to evaluate the methodology for service restoration called "AEMT-H", which is based on multi-objective evolutionary algorithms and in the data structure called Node Depth Encoding (NDE). This evaluation will occur by applying the "AEMT-H" to obtain service restoration plans considering the occurrence of simple faults in the COPEL system of the city of Londrina. The obtained results will bee valuated statistically and subjectively by professionals of the Distribution Operation Center.

It is important to highlight that Evolutionary algorithms have shown promising results to treat the service restoration problem in distribution systems. In particular, the results obtained when using NDE tocomputationally represent the electrical topology of large distribution systems (with thousand of buses and switchers) are very interesting in terms of time processing (in the order of seconds).

The system of Londrina has 30,156 buses, 2,660 switchers normally closed, 250 switchers normally opened and supplies a universe of more than 231,000 consumers connected directly to the system with voltage of $13.8 \mathrm{kV}$ or, after distribution transformers, with voltages of $220 \mathrm{~V}$ and $127 \mathrm{~V}$. This system contains 6 substations $138 \mathrm{kV} / 13,8 \mathrm{kV}$ and 64 feeders, and a installed power of 541.7MVA.
\end{abstract}

Keywords: service restoration, large-scale distribution system, Node Depth Encoding e Multi-Objective Evolutionary Algorithms. 



\section{INTRODUÇÃo}

\subsection{MOTIVAÇÃO}

No cenário atual das empresas concessionárias de energia elétrica brasileiras os desafios englobando a diminuição da quantidade de desligamentos têm consumido grande parte dos investimentos em novas tecnologias. É bastante comum observarmos mudanças nas redes aéreas de distribuição que, em tensões de 13,8 KV e 34,5 KV, recebem cabos "protegidos" ou, em algumas situações, cabos isolados, além dos sistemas com tensão de 220/127V, cujos cabos "nus", em sua maioria, estão sendo substituídos pelos "isolados - multiplexados". São observadas ainda soluções com aplicação dos conceitos de redes inteligentes (Smart Grids) como exemplos desta busca constante pela redução dos índices relacionados à continuidade no fornecimento da energia elétrica para o cliente final.

Infelizmente, por mais que se invista, é impossível pensarmos em uma rede completamente segura, principalmente devido às características operacionais e construtivas dos sistemas de distribuição atuais. Desta forma, as concessionárias de energia vêm realizando investimentos com intuito de diminuir a quantidade de consumidores que ficam sem energia, após a ocorrência de faltas permanentes, e também o tempo de desligamento destes consumidores. Como exemplo de investimentos ligados à diminuição dos trechos afetados pelos desligamentos ocasionados pelas faltas permanentes, tem-se a inclusão de religadores automáticos de trecho e chaves operáveis/manobráveis com carga e capazes de evidenciar a "passagem" do curto-circuito. Estas ações possibilitam uma melhoria tanto nos indicadores de quantidade de desligamentos (FEC - "frequência equivalente por consumidor" e FIC - "frequência individual por consumidor"), quanto nos de duração (DEC - duração equivalente por consumidor, DIC - duração individual por consumidor e DMIC - duração máxima individual por consumidor). Vale destacar que por motivos de segurança dos equipamentos e das pessoas, após a abertura do trecho "defeituoso", torna-se necessária a inspeção visual em busca da localização do defeito, isolação física do mesmo através da abertura de chaves normalmente fechadas (NFs) e posterior restabelecimento da parte "sã" do sistema através do fechamento de chaves normalmente abertas (NAs).

O processo de alteração da topologia de uma rede elétrica através da 
manobra de chaves NAs e NFs recebe o nome de Reconfiguração de Redes, que é uma ferramenta importante para tratamento de diversos problemas de operação e planejamento de Sistemas de Distribuição (SDs), como, por exemplo, o problema de restabelecimento de energia.

$\mathrm{Na}$ Companhia Paranaense de Energia Elétrica (COPEL) atualmente o processo de restabelecimento de energia elétrica do circuito alimentador afetado por uma ou múltiplas faltas permanentes é realizado pelos Operadores dos CODs, através da operação (abertura/fechamento) de chaves "automáticas" (com controle e comando remotos) e do posterior direcionamento das equipes de campo para inspeção do trecho desligado. Este direcionamento obedece às normas técnicas da concessionária sendo equacionado a partir da análise de uma série de variáveis, muitas vezes conflitantes e de difícil visualização pelo Operador. Devido a essa dificuldade de visualização das variáveis, à grande quantidade de soluções possíveis e ao tempo necessário para um ser humano determinar a solução ótima do problema, o processo de restabelecimento de energia fica baseado nas características pessoais de cada Operador. Lembrando que para um mesmo desligamento diversas soluções podem ser encontradas, podendo ainda, em alguns casos, nenhuma delas se aproximar da solução ótima.

Neste contexto a COPEL planeja investimentos visando a utilização do conceito de redes inteligentes para a elaboração automática de Planos de Restabelecimento de Energia (PREs) dos SDs. O objetivo de um dos projetos nessa linha é transformar a cidade de Curitiba em uma "cidade digital", com sistema de distribuição de energia elétrica totalmente automatizado, com a intensa aplicação de tecnologia de redes inteligentes. A ideia é automatizar a operação de todas as chaves e religadores, gerando assim redução no número de interrupções no fornecimento de energia elétrica e abreviando o tempo necessário ao restabelecimento dos serviços. Porém, para isso, faz-se necessário o desenvolvimento de aplicativos computacionais que possibilitem, de forma rápida e segura, o tratamento da grande quantidade de informações disponíveis no processo de elaboração dos PREs.

De uma forma geral, um PRE adequado envolve os seguintes objetivos:

$\checkmark$ Minimização do número de consumidores fora de serviço (sem energia);

$\checkmark$ Minimização do número de operações de chaveamento-manobras (busca-se reduzir o número de manobras basicamente por dois motivos: a operação 
frequente das chaves reduz a expectativa de vida útil das mesmas e quanto mais manobras, maior o tempo para executar o PRE, pois a maioria das chaves é operada manualmente);

$\checkmark$ Minimização do total de perdas resistivas por efeito Joule (quando não conflitar com os objetivos anteriores).

$\mathrm{E}$ deve obedecer às seguintes restrições de operação:

$\checkmark$ Manutenção da radialidade da rede;

$\checkmark$ Ausência de sobrecarga nos elementos da rede e das subestações (transformadores, barramento, etc);

$\checkmark$ Manutenção dos níveis de tensão dentro dos intervalos exigidos;

$\checkmark$ Determinação em tempo real (ser elaborado em um curto intervalo de tempo).

Conclui-se, então, que o problema de restabelecimento de energia em SDs, ou seja, o problema de obtenção de um adequado PRE após a ocorrência de faltas permanentes, pode ser abordado como um problema de otimização com múltiplas restrições e múltiplos objetivos, alguns dos quais conflitantes. Além disso, devido à grande quantidade de variáveis envolvidas nesse problema, ele está sujeito ainda ao fenômeno de explosão combinatória, que ocorre em razão de o espaço de busca de soluções possíveis aumentar exponencialmente com o número de variáveis. Em razão disso, a utilização de técnicas de programação matemática torna-se inviável [23, 29, 73, 74], e metas-heurísticas têm sido propostas como alternativas para resolver $\circ$ problema em questão, principalmente quando considerados SDs de grande porte.

Dentre as metas-heurísticas existentes, o Algoritmo Evolutivo (AE) tem sido a mais explorada [28-30, 73-75]. Destaca-se ainda que os AEs possuem um suporte relevante da literatura em problemas multi-objetivos [73, 76]. Entretanto, a maioria dos AEs desenvolvidos demanda um alto custo computacional (tempo de execução), quando aplicados em SDs de grande porte [23, 30].

De acordo com a literatura, o desempenho de um AE, para o tratamento de problemas de reconfiguração de redes em SDs de grande porte, é afetado principalmente pelos seguintes fatores [23, 28, 29, 30, 73, 75]:

$\checkmark$ Utilização de uma estrutura de dados inadequada, para representar computacionalmente a topologia elétrica dos SDs, reduzindo de forma significativa o desempenho do algoritmo; 
$\checkmark$ Os operadores genéticos normalmente utilizados não geram configurações radiais;

$\checkmark$ A conversão de um problema multi-objetivo, em um mono-objetivo, pela utilização de fatores de ponderação que penalizam a violação das restrições do problema.

Para reduzir o impacto destes fatores na solução do problema de restabelecimento de energia através de AEs, em [1], um grupo de pesquisadores da Universidade de São Paulo (USP) apresentou uma metodologia baseada em uma técnica de Algoritmo Evolutivo Multi-objetivo (AEMO) que faz uso da estrutura de dados denominada Representação Nó-Profundidade (RNP) [31], e de seus operadores de reprodução. Para tratar o problema multi-objetivo de forma mais adequada, essa metodologia trabalha em paralelo com várias subpopulações (conjunto de soluções do problema) armazenadas em tabelas. Dessa forma, os melhores indivíduos (melhores soluções do problema, isto é, configurações do SD) para cada característica do problema (número de manobras, perdas resistivas, queda de tensão, carregamento da rede e carregamento da subestação), são armazenados em suas respectivas subpopulações. Assim, um número maior de configurações é disponibilizado para o Operador decidir qual se adapta melhor ao problema da empresa. Dessa forma, tal metodologia permite o tratamento de SDs de grande porte (com milhares de barras, linhas e chaves), considerando todos os seus alimentadores e subestações.

Deve-se destacar que em relação aos métodos já desenvolvidos para reconfiguração de redes em SDs, o grande diferencial do método desenvolvido em [1], chamado de AEMO em Tabelas, é a utilização da RNP e de seus operadores genéticos de reprodução, que trazem as seguintes vantagens:

$\checkmark$ A RNP e seus operadores produzem exclusivamente configurações factíveis, isto é, redes radiais capazes de fornecer energia para todo o sistema. Observe que o termo "todo o sistema" significa todas as partes ligadas do sistema, pois, em algumas situações não é possível conectar uma área fora de serviço em razão da falta de chaves;

$\checkmark$ Em comparação com outras estruturas de dados, a RNP permite a geração de um número maior de configurações factíveis, num mesmo período de tempo, tendo em vista que a mesma apresenta uma complexidade computacional 
média de ordem $O(\sqrt{n})$, sendo $n$ o número de vértices do grafo, que no problema em pauta representam os setores de um SD;

$\checkmark$ Cada configuração gerada pela RNP e seus operadores genéticos possui todos os nós (ou barras) ordenados de acordo com uma relação conhecida como Modelo Pai-Filho (MPF), possibilitando, assim, a execução de um algoritmo de fluxo de carga de varredura direta e inversa de forma mais eficiente [21]. Trabalhando com outras estruturas de dados e operadores, antes de aplicar um fluxo de potência de varredura direta e inversa é necessário executar um algoritmo de ordenação, toda vez que uma nova configuração for gerada, para organizar os nós de acordo com o MPF.

Para validar o AEMO em Tabelas, em [1] foram apresentados vários testes utilizando o SD da cidade de São Carlos, São Paulo, que possuí 3.860 barras, 635 chaves, 3 subestações com dois transformadores com potência de 50 MVA e um transformador de 25 MVA e 23 alimentadores. Para demonstrar que o AEMO em Tabelas pode ser aplicado em SDs maiores que o SD da cidade de São Carlos, não incorrendo no problema de explosão combinatória, foram também apresentados testes utilizando aquele sistema aumentado, ou seja, com tamanho duplicado, quadriplicado e octuplicado.

Em [72] foram realizadas duas melhorias significativas no AEMO em Tabelas, que aumentaram a sua eficiência na exploração do espaço de busca. A primeira melhoria foi a inclusão de tabelas de soluções não-dominadas, que utilizam o conceito de dominância de Pareto para comparar duas soluções factíveis do problema [9], procedimento utilizado pelo AEMO denominado NSGAll (do inglês, Elitist Non-Dominated Sorting Genetic Algorithm). A segunda melhoria foi o desenvolvimento de uma heurística que visa restringir o espaço de busca e, consequentemente, obter soluções com menor número de manobras e que não violem os limites operacionais do sistema. Esse AEMO melhorado foi denominado AEMT-H (Algoritmo Evolutivo Multi-objetivo em Tabelas com Heurística).

Face ao exposto, a presente dissertação visa aplicar a metodologia chamada AEMT-H, apresentada em [72], ao sistema de distribuição da COPEL da cidade de Londrina (Paraná), avaliando os resultados gerados e consolidando as configurações propostas através de uma análise subjetiva de Operadores do COD da concessionária.

Para aplicação do AEMT-H no sistema da COPEL foi necessário um 
estudo do banco de dados da concessionária e uma implementação de adaptações convertendo o formato atual para o utilizado no programa desenvolvido pelo grupo de pesquisa da USP, que consiste da implementação da metodologia AEMT-H.

\subsection{OBJETIVOS}

\subsubsection{Geral}

- Visando uma melhoria dos indicadores de qualidade do serviço de distribuição de energia elétrica da COPEL, o objetivo principal deste trabalho é avaliar o desempenho da metodologia AEMT-H, desenvolvida em [72], para obtenção de PREs para o SD da cidade de Londrina.

\subsubsection{Específicos}

- Estudar a metodologia AEMT-H, bem como o correspondente programa computacional;

- Estudar o banco de dados de Georeferenciamento da COPEL, compreendendo todas as variáveis presentes e forma de representação do sistema;

- Estudar o modelo tipo barra-linha de representação dos dados utilizado pelo grupo de pesquisada USP e elaborar rotina para conversão dos dados do banco COPEL para este modelo;

- Aplicar os dados COPEL ao algoritmo apresentado em [72] e avaliar os resultados obtidos;

- Submeter as configurações apresentadas como resultado da metodologia à análise subjetiva dos Operadores do COD da COPEL.

\subsection{JUSTIFICATIVAS}

Conforme mencionado, atualmente o processo de restabelecimento de energia no sistema de distribuição da COPEL é amplamente dependente do desempenho e conhecimento dos Operadores dos CODs. Até o presente momento, não são utilizados sistemas inteligentes de apoio à tomada de decisão. Desta forma, 
cabe ao Operador a busca e análise dos diversos dados presentes neste processo. Importa destacar que diversas melhorias já foram implementadas no sistema de operação da distribuição (SOD) da COPEL, entre elas destacam-se:

$\checkmark$ Visualização gráfica dos circuitos alimentadores, sendo estes distinguidos por cores diferenciadas;

$\checkmark$ Facilidade de visualização dos equipamentos presentes nas redes de distribuição (chaves manobráveis com carga, chaves fusíveis, etc.);

$\checkmark$ Possibilidade de simulação da manobra a ser realizada, verificando os trechos que ficarão desligados após a conclusão da mesma;

$\checkmark$ Supervisão e comando de equipamentos disponibilizados nas subestações e redes de distribuição;

$\checkmark$ Criação de "planos de contingência estanques" para direcionar as ações no restabelecimento de energia caso o sistema não sofra qualquer alteração em relação à configuração original.

Contudo, vale ressaltar algumas dificuldades ainda encontradas no modelo atual de operação:

$\checkmark$ Não há cálculo em tempo real para verificação dos níveis de tensão no decorrer dos circuitos alimentadores;

$\checkmark$ Não há interação entre os sistemas computacionais utilizados pela COPEL, ou seja, o Operador deve acessar um sistema para pesquisar os dados das redes de distribuição, outro diferente para supervisão dos equipamentos telecomandados e outro ainda para buscar informações relativas aos "planos de contingência";

$\checkmark$ Com a constante redução das metas para os indicadores da qualidade do serviço aplicadas às concessionárias, as melhorias restritas à qualidade dos Operadores dos CODs não estão gerando os resultados necessários para o não pagamento de compensações;

$\checkmark$ O desgaste emocional e o nível de stress dos Operadores são elevados;

$\checkmark$ As chances de execução de manobras que infrinjam as normas técnicas de fornecimento de energia, principalmente em relação ao nível de tensão no ponto de entrega ao consumidor, são consideráveis. 
Ante o exposto, e o apresentado na seção 1.2 (Objetivos), acredita-se que este trabalho contribuirá de forma significativa para o início do processo de melhoria no atual SOD da COPEL, com soluções inteligentes que buscam resolver, ou pelo menos minimizar, algumas das dificuldades ainda encontradas no modelo atual de operação. Em complemento, o meio acadêmico poderá usufruir de dados de resultados reais da aplicação da metodologia proposta no sistema da concessionária.

\subsection{ORGANIZAÇÃO DO TRABALHO}

Os próximos capítulos desta Dissertação estão escritos da seguinte forma:

$\checkmark$ O capítulo 2 apresenta o problema de Restabelecimento de Energia em Sistemas de Distribuição. Inicialmente destacam-se os equipamentos presente no sistema e, em seguida, apresenta-se a formulação do problema e uma sucinta revisão bibliográfica. Finalizando o capítulo a estrutura de dados RNP e seus operadores são descritos em detalhes. Lembrando que essa estrutura de dados é utilizada pelo AEMT-H;

$\checkmark$ O capítulo 3 apresenta a teoria dos Algoritmos Evolutivos (AEs), a diferença entre problemas mono e multi-objetivos e ainda detalha AEs desenvolvidos para tratamento de problemas com múltiplos objetivos;

$\checkmark$ O capítulo 4 detalha metodologia AEMT-H, proposta em [72], que será validada neste trabalho no sistema da COPEL da cidade de Londrina;

$\checkmark$ O capítulo 5 apresenta a forma de armazenamento e composição da base de dados COPEL e o processo adotado para conversão dos mesmos para o modelo utilizado pelos pesquisadores da USP;

$\checkmark$ O capítulo 6 apresenta e analisa os resultados obtidos nas diversas simulações que foram executadas. Vale destacar que as análises foram realizadas com 0 auxílio de profissionais da Operação em Tempo Real da COPEL;

$\checkmark$ O capítulo 7 apresenta as conclusões finais do trabalho. 


\section{RESTABELECIMENTO DE ENERGIA EM SISTEMAS DE DISTRIBUIÇÃO}

\subsection{INTRODUÇÃO}

Uma das tarefas mais complexas e importantes para o bom desempenho de aplicativos computacionais utilizados no restabelecimento de energia em SDs a partir de manobras de chaves seccionadoras (processo conhecido como reconfiguração de redes) é a adequada representação do sistema elétrico. Essa representação deve buscar, na medida do possível, simplificações na malha elétrica (o que reduz a quantidade de barras e consequentemente a quantidade de combinações de configuração possíveis) sem comprometimento da qualidade dos cálculos realizados (que indicarão o carregamento e o nível de tensão no sistema). Dessa forma o primeiro passo para desenvolvimento de um aplicativo para restabelecimento de energia é conhecer os elementos do sistema, compreendendo suas características, informações e disposição no banco de dados específico. 0 sistema de distribuição pode ser dividido em:

- Sistema (ou Rede) de Distribuição Primária: também conhecido como sistema de distribuição de média tensão (MT), opera geralmente em redes radiais aéreas na tensão de 13,8 ou $34,5 \mathrm{kV}$. É projetado para possibilitar a transferência de blocos de cargas entre circuitos para o atendimento da operação em condições de contingências ou para manutenção preventiva e/ou corretiva. Esse sistema atende aos consumidores primários (industriais de médio porte, conjuntos comerciais, grandes hospitais, shopping centers etc.) e aos transformadores de distribuição que, por sua vez, suprem o SD Secundária ou de baixa tensão;

- Sistema (ou Rede) de Distribuição Secundária (ou Distribuição de Baixa Tensão - BT): geralmente opera com tensões de 220/127V ou 380/220V. Atende aos pequenos comércios, indústrias e aos consumidores residenciais. Essa parte do sistema de distribuição usualmente não conta com recurso para 0 atendimento de contingências.

A Figura 1 apresenta um Sistema de Distribuição dividido em Rede Primária e Secundária, onde SE é um barramento na subestação, TR é um transformador e S é uma chave seccionadora (as chaves preenchidas com a cor vermelha se encontram na posição NF enquanto as preenchidas em verde na 
posição NA).

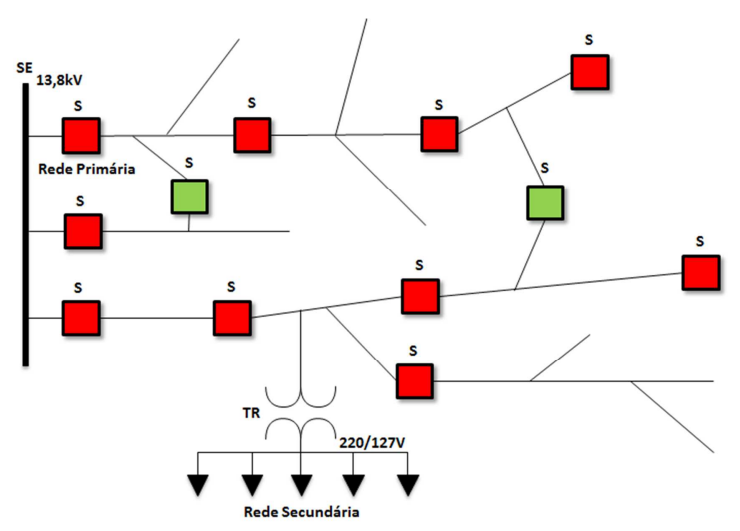

Figura 1. llustração de um Sistema de Distribuição

Este trabalho trata do problema de restabelecimento de energia em SDs Radiais (SDRs) de média tensão e suas seções estão organizadas da seguinte forma.

$\rightarrow$ Seção 2.2: recorda alguns dos elementos de SDRs, importantes para o processo de restabelecimento de energia;

$\rightarrow$ Seção 2.3: define o problema de restabelecimento de energia em SDRs, mostra como representar a topologia elétrica de SDRs através de grafo, trazendo ainda uma revisão bibliográfica sobre o tema;

$\rightarrow$ Seção 2.4: recorda os fundamentos da representação nó-profundidade.

$\rightarrow$ Seção 2.5: apresenta o detalhamento do funcionamento e implementação dos Operadores PAO e CAO.

\subsection{ELEMENTOS DE SDR}

\subsubsection{Chaves de manobra}

As chaves elétricas de manobra são dispositivos de manobra, destinados a estabelecer ou interromper a corrente em um circuito elétrico ou ainda "isolar" os circuitos da presença de tensão e corrente (principalmente quando da utilização em manutenções). São dotadas de contatos móveis e contatos fixos e podem ou não ser comandadas com carga. São ainda do tipo monopolar (operação de cada fase individualmente) ou tripolar (operação das três fases simultaneamente).

As chaves para operação sem carga são denominadas de chaves a seco 
e embora não interrompam qualquer corrente de carga, estas chaves podem interromper correntes de excitação de transformadores (a vazio), pequenas correntes capacitivas de linhas sem carga ou ainda pequenas correntes de carga (conforme características construtivas e estudos realizados no equipamento). Neste trabalho serão consideradas as chaves a seco do tipo seccionadores unipolares (SU's), omnirupter (OR) e chaves fusíveis laminadas (LA) (veja Figura 2).

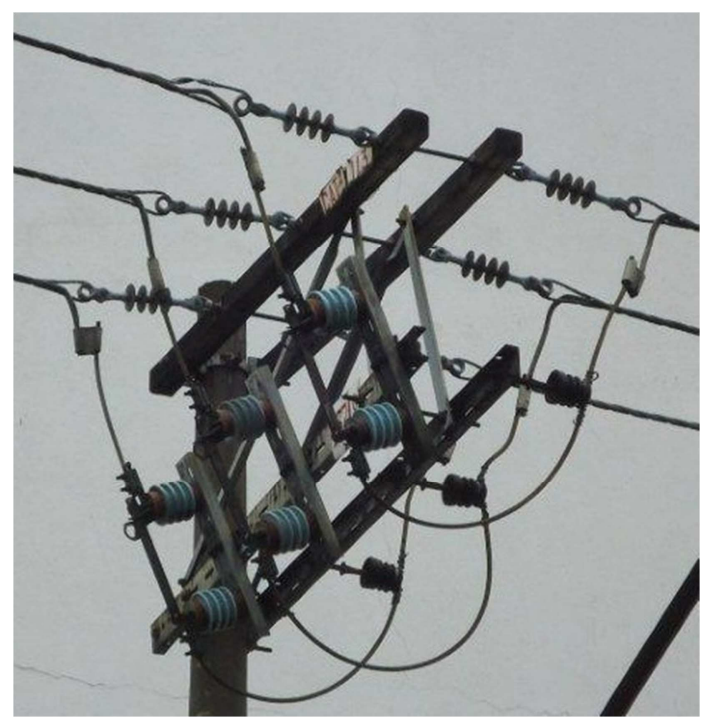

Figura 2. Chave Seccionadora Unipolar (SU)

As chaves para operação com carga são dispositivos dotados de meios de extinção do arco elétrico gerado pela interrupção abrupta das correntes de carga. Estes meios de extinção podem ser óleos isolantes, gás SF6 (Hexafluoreto de Enxofre), câmaras à vácuo, entre outros. Para este estudo serão consideradas as chaves operáveis sob carga do tipo chave a óleo tripolar (CO), chave a óleo monopolar (NR), chave tripolar com isolação a gás e operação manual (GM) e ainda chave tripolar com isolação a gás, controle e comando remotos (GA). A Figura 3 apresenta um exemplo de chave operável sob carga. 


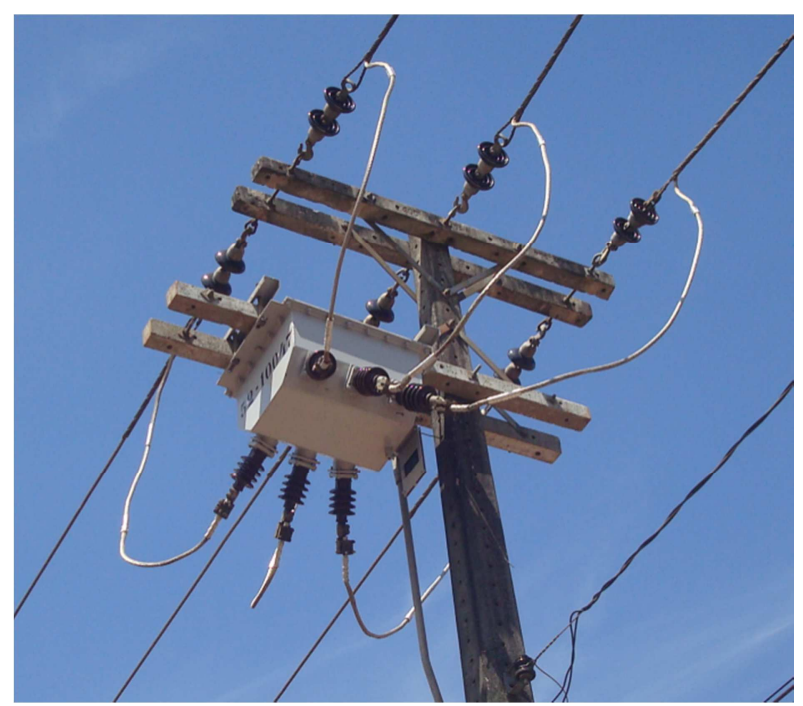

Figura 3. Chave Tripolar isolada a óleo

Quanto à posição normal as chaves de manobra podem ser classificadas em chaves NAs (quando a configuração original do circuito determina que a chave permaneça aberta) e em chaves NFs (quando a configuração original do circuito determina que a chave permaneça fechada).

\subsubsection{Trecho primário}

Trecho formado por condutores elétricos (cabos), responsáveis pela condução da corrente elétrica em tensão de 13,8kV ou 34,5kV. Estes trechos são localizados normalmente entre dois postes onde as demais estruturas são alocadas.

\subsubsection{Posto de transformação}

Postos dotados de transformadores responsáveis pela conversão da energia presente no trecho primário para a tensão de consumo do cliente final. Neste caso, os transformadores são equipamentos empregados para "abaixar" as tensões entre os subsistemas de um sistema elétrico. A Figura 4 apresenta um exemplo de posto de transformação.

O transformador é um equipamento conversor de energia eletromagnética, cuja operação pode ser explicada em termos do comportamento de um circuito magnético excitado por uma corrente alternada. Consiste de duas ou mais bobinas de múltiplas espiras enroladas no mesmo núcleo magnético 
(normalmente construído com placas metálicas), isoladas deste. Uma tensão variável aplicada à bobina de entrada (primário) provoca o fluxo de uma corrente variável, criando assim um fluxo magnético variável no núcleo. Devido a este é induzida uma tensão na bobina de saída (ou secundário). Não existe conexão elétrica entre a entrada e a saída do transformador.

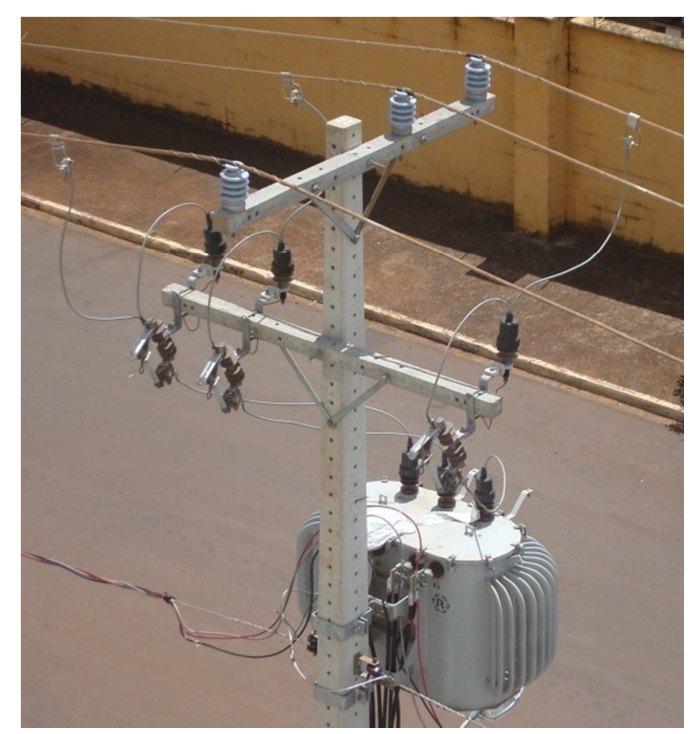

Figura 4. Exemplo de Posto de transformação na distribuição

\subsubsection{Capacitor}

Capacitores são fontes de energia reativa (conforme apresentado na Figura 5). Os objetivos de sua aplicação em sistemas de potência é a compensação de energias reativas produzidas por cargas indutivas ou reatâncias de linhas. Quando adequadamente utilizados permitem a obtenção de um conjunto de benefícios correlatos que incluem a redução de perdas de energia, correção dos perfis de tensões, controle dos fluxos de potência, melhoria do fator de potência e aumento da capacidade dos sistemas [2].

No escopo deste trabalho, os bancos de capacitores alocados nas redes de distribuição serão considerados apenas para os cálculos dos limites de tensão (haja vista não ser de praxe a operação destes equipamentos em manobras de recomposição de alimentadores). Por outro lado, os bancos de capacitores alocados nas subestações serão considerados também nos cálculos do controle de tensão na barra, podendo o algoritmo sugerir sua operação.

Os benefícios reais obtidos com a instalação de capacitores em sistemas de distribuição dependem das características dos equipamentos e da forma como é 
feita essa instalação. Especificamente, dependem do número e tamanho dos capacitores, de sua localização, do tipo (fixos ou chaveados) e do esquema de controle utilizado [2].

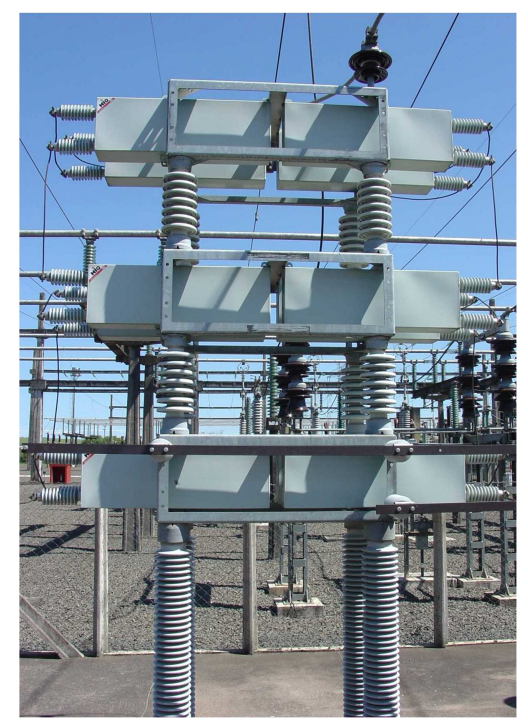

Figura 5. Exemplo de Banco de Capacitores alocado em uma subestação

\subsubsection{Regulador de Tensão}

A tensão ao longo de alimentadores é normalmente controlada por reguladores de tensão. Esses reguladores são auto-transformadores com tapes ou derivações em seus enrolamentos. Tipicamente, o regulador é usado para elevar ou abaixar a tensão por um intervalo de até $10 \%$. Um regulador pode ser operado em modo manual ou modo automático. No modo manual, a tensão de saída pode ser manualmente elevada ou abaixada no painel de controle do regulador. No modo automático, o mecanismo de controle do regulador ajusta os tapes para assegurar que a tensão monitorada mantenha-se dentro de certa faixa.

\subsection{O PROBLEMA DE RESTABELECIMENTO DE ENERGIA EM SDR}

\subsubsection{Revisão Bibliográfica}

As interrupções no fornecimento de energia nos SDRs são inevitáveis, isto em virtude da execução de obras de expansão, intervenções de manutenção preventiva em componentes da rede ou pela atuação de um dispositivo de proteção em decorrência de faltas permanentes. Desta forma, o agrupamento de 
vários pontos de carga em blocos separados por chaves, que operam no estado NA e NF, foi uma solução encontrada para melhorar a confiabilidade dos SDRs sem incorrer em gastos excessivos. Assim, a partir da reconfiguração da rede é possível a troca de carga entre os alimentadores em caso de interrupção em algum. Nessas situações, torna-se necessário um PRE que, conforme apresentado na seção 1.1, consiste basicamente em determinar um conjunto de manobras de chaves para restringir as interrupções à menor parte possível do sistema.

A reconfiguração de redes é uma ferramenta importante na automação dos SDRs, pois é um dos principais recursos para manutenção da qualidade e da confiabilidade do fornecimento de energia elétrica. Em condições normais de operação, também se pode utilizar a reconfiguração de redes para reduzir as perdas totais por efeito joule [3] e/ou para balanceamento de carga entre os alimentadores [4], aliviando os circuitos que estão com carregamento crítico. Nesse contexto, a reconfiguração permite a redução de queda de tensão [5] e alívio de trechos da rede com sobrecarga [6] (corrente elétrica em níveis acima do suportado pelos elementos).

Além disso, a reconfiguração de redes também pode ser aplicada na ocorrência de contingências com faltas permanentes [7, 8], sendo tal aplicação o foco principal desta dissertação. Nesse caso, após o setor (conjunto de barras e linhas sem a presença de chaves seccionadoras) em falta ter sido identificado e isolado pela atuação do sistema de proteção, faz-se necessário a elaboração de um PRE que identifique a melhor maneira de se restabelecer os setores "sãos" do sistema afetado (ver seção 1.1).

Ainda conforme explanado na seção 1.1, o problema de restabelecimento de energia em SDRs possui múltiplos objetivos, alguns conflitantes. Assim diversas técnicas para elaboração de PREs tem sido desenvolvidas, sendo que algumas das principais são apresentadas a seguir.

Em [13] desenvolveu-se um Algoritmo Genético (AG) paralelo para resolver problemas de restabelecimento de energia em SDRs. O problema é formulado de forma a minimizar a área fora de serviço e balancear o suprimento de cargas entre as subestações após uma falta ter sido identificada e isolada.

Fazendo uso de estratégias evolutivas [14], com uma definição fuzzy de objetivos conflitantes, em [15] foi desenvolvido um método para resolver o problema de restabelecimento de energia em SDRs. Considerou-se que o estado de operação 
normal permite o controle remoto das chaves, de bancos de capacitores e conexões de cargas. Assim, quando uma falta permanente ocorre, torna-se possível executar remotamente ações para restabelecer energia nas áreas afetadas. Para lidar com múltiplos objetivos, geralmente conflitantes, foram desenvolvidas estratégias baseadas em lógica fuzzy.

Em [16] Hsiao e Chien apresentaram um algoritmo híbrido combinando fuzzy com AG para resolver problemas de restabelecimento de energia. A formulação do problema contempla simultaneamente 5 objetivos a serem minimizados: total de carga deixada fora de serviço, número de operações de chaveamentos, queda de tensão nas barras, carregamento nas linhas e carregamento nos transformadores. Restrições envolvendo estrutura radial e sequência de operações de chaveamento também são incluídas na formulação do problema.

Em [17] foi desenvolvido um estudo comparativo entre 4 algoritmos heurísticos utilizados para restabelecimento de energia em SDRs: busca tabu (BT), busca tabu reativa (BTR), Simulated Anneling (SA) e Algoritmos Genéticos (AGs). A formulação do problema considerou: modelo de corrente constante, fonte de potência modelada como fonte de injeção de corrente (tensão na fonte conhecida), utiliza o conceito de setor (cada setor concentra um ponto de carga). O estudo foi realizado considerando o objetivo de encontrar, após a ocorrência de uma falta, planos que restabeleçam energia ao maior número de consumidores possível. Segundo os autores, para restabelecimento de energia não se pode afirmar qual estratégia seria mais efetiva, pois AGs podem realizar tanto busca local quanto global, enquanto SA, BT e BTR executam somente busca local. Por outro lado, AGs podem gerar muitas configurações infactíveis, elevando o tempo de processamento.

Um método híbrido para restabelecimento de energia e reconfiguração ótima de redes combinando AGs e BT foi proposto em [18]. A ideia é explorar os pontos fortes de ambas as técnicas, dando origem ao método denominado AGTabu. Realizaram-se testes para minimização de uma função objetivo contemplando dois casos: um com o custo total envolvendo a soma das perdas resistivas e o custo de interrupção e outro envolvendo somente o custo de perdas. Em todos os testes, o AG e o AG-Tabu encontraram a mesma solução, porém o AG-TABU exigiu menos iterações.

Tendo em vista que a reconfiguração de redes via AEs exige 
normalmente busca em grafo, pois a topologia elétrica dos SDRs são usualmente representadas através de grafos, o desempenho desses AEs torna-se fortemente dependente da forma com que as árvores de grafo são representadas no computador. Assim, buscando melhorar o desempenho dos AEs, para tratamento do problema de reconfiguração de redes, em [19] foi proposta uma nova codificação para SDRs, baseada em Cadeia de Grafos, de modo a melhorar o desempenho dos AEs. A partir dessa codificação, foram desenvolvidos operadores de reprodução não convencionais, que, a partir de uma configuração já existente, possibilitam a geração somente de configurações factíveis, isto é, configurações radiais que atendem a todos os consumidores, respeitando os limites de operação do sistema. Utilizando conceitos de grafos e partindo do princípio de que uma árvore de grafo pode ser representada por cadeias conectando a raiz às folhas, o conjunto de todas essas cadeias, armazenadas adequadamente, representa um alimentador de um SDR. Consequentemente, o conjunto de todos os alimentadores representa um sistema de distribuição completo. A técnica proposta pode ser aplicada em problemas multiobjetivos, utilizando sub-populações, de forma semelhante àquela empregada em [20]. Testes foram realizados em um SDR de grande porte, composto de 1471 barras, 249 chaves, 3 subestações e 23 alimentadores. Como restrições foram consideradas: queda de tensão, carregamento nas linhas e carregamento nos transformadores. A estrutura radial do SDR é sempre uma condição satisfeita no problema, pois os operadores de reprodução propostos geram apenas configurações factíveis. $\mathrm{O}$ artigo trata de uma falta por vez. Foram consideradas faltas em setores críticos da rede, isto é, que isolam completamente um alimentador. Vale destacar que a técnica foi aplicada ao problema de reconfiguração de SDRs, sendo testada em restabelecimento de energia, redução de perdas resistivas e planejamento de SDRs.

Em termos de estrutura de dados, no trabalho apresentado em [21], foi proposta uma nova codificação (do tipo conjunto de arestas), para tornar mínimas as perdas em SDRs, que garante, através do uso de operadores genéticos de recombinação, a geração somente de configurações radiais.

Em [1], o SDR foi representado computacionalmente através de uma nova estrutura de dados, denominada Representação Nó-Profundidade (RNP). A RNP é baseada nos conceitos de caminho e profundidade de nó em um grafo (árvore) e foi proposta em [22]. Conforme detalhado na seção 1.1, em [22] foram também 
desenvolvidos dois operadores que facilitam o manuseio dos dados armazenados na RNP, possibilitando a realização de poda e enxerto nas árvores armazenadas em RNPs.

Recentemente, as técnicas de AEMOs têm sido aplicadas para o problema de reconfiguração de redes em SDRs, com resultados que se mostram bastante promissores. Por exemplo, no trabalho desenvolvido em [8], aplicou-se a técnica NSGA-II (Elitist Non-Dominated Sorting Genetic Algorithm) [9, 23]. As regras de tomada de decisão contemplam a presença de consumidores prioritários e a presença de chaves controladas remota e manualmente. Resultados de testes do método proposto, denominado NSGA-II avançado, foram comparados com resultados do NSGA-II básico e de um AG tradicional.

Fazendo uso também da estrutura de dados RNP, bem como de uma versão modificada do NSGA-II, em [24] desenvolveu-se uma metodologia que possibilita a obtenção de PREs em SDRs de grande porte.

Para apresentar uma formulação matemática para o problema de restabelecimento de energia, via reconfiguração de redes, faz-se necessário rever alguns conceitos da teoria de grafos, isto em razão de os SDRs serem usualmente representados, computacionalmente, através de grafos.

\subsubsection{Alguns conceitos da teoria de grafos}

Um grafo $G(V, A)$ é definido pelo par $V$ e $A$, onde:

$\checkmark V$ - conjunto de vértices ou nós do grafo;

$\checkmark A$-conjunto de pares de nós não-ordenados: as arestas do grafo.

Se $u$ e $v$ são dois nós de um grafo e se o par $\{u, v\}$ é uma aresta denotada por $y$, diz-se que $y$ conecta $u$ e $v$, como pode ser visto na Figura 6 . Neste caso, a aresta $\{u, v\}$ é dita ser incidente ao nó $u$ e ao nó $v$.

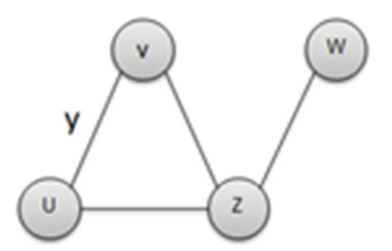

Figura 6. Exemplo de um grafo 
A ordem de um grafo $G$ é dada pelo número de elementos do conjunto de nós, ou seja, pelo número de nós de $G$; a ordem do grafo apresentado na Figura 6 é 4. O grau de um nó é dado pelo número de arestas que lhe são incidentes. A Tabela 1 informa o grau de cada nó do grafo apresentado na Figura 6.

Tabela 1. Grau de cada um dos nós do grafo apresentado na Figura 6

\begin{tabular}{|c|c|}
\hline Nó & Grau \\
\hline$w$ & 1 \\
\hline$u$ & 2 \\
\hline$v$ & 2 \\
\hline$z$ & 3 \\
\hline
\end{tabular}

Um caminho é uma sequência de nós, tal que de cada um dos nós exista uma aresta distinta, para o nó seguinte. Além disso, se nenhum dos nós no caminho se repete, o caminho é chamado de caminho simples ou cadeia. O comprimento do caminho é o número de arestas que o caminho usa. Dois caminhos são independentes se não tiverem nenhum nó em comum, exceto o primeiro e o último.

Se um caminho começa e acaba no mesmo nó, este caminho é chamado de ciclo. Um exemplo de ciclo é a sequência de arestas $\{u, v\},\{v, z\},\{z, u\}$ da Figura 6 , ou o caminho $\{u, v, z, u\}$ da mesma Figura 6 .

Um par de nós em um grafo é um par conexo, se existir um caminho entre eles. Um grafo $G(V, A)$ é um grafo conexo, se todo par de nós em $G(V, A)$ for um par conexo.

Diz-se que $H$ é um subgrafo conexo máximo de um grafo $G$, se o único subgrafo conexo contendo $H$ é o próprio $H$. Um subgrafo conexo $H$ máximo também é chamado de componente. Um grafo $G$ é conexo, se o número de seus componentes for igual a um.

Um grafo chama-se acíclico se não contém ciclos. Uma árvore é um grafo conexo acíclico. Seja $G(V, A)$ um grafo de ordem $n>2$; as propriedades seguintes são equivalentes, para caracterizar o grafo $G$ como uma árvore:

$\checkmark$ Gé conexo e acíclico;

$\checkmark G$ é acíclico e tem $(n-1)$ arestas;

$\checkmark G$ é conexo e tem $(n-1)$ arestas;

$\checkmark$ G é acíclico e por adição de uma aresta se cria um ciclo e somente um; 
$\checkmark$ G é conexo, mas deixa de sê-lo se uma aresta é eliminada (todas as arestas são pontes2).

$\checkmark$ Todo par de nós de $G$ é unido por uma e somente uma cadeia simples.

Um grafo formado por um conjunto de árvores é chamado de floresta. Logo, cada componente de uma floresta é uma árvore. No caso de uma floresta com apenas uma árvore, tem-se uma floresta conexa. Assim, uma árvore é uma floresta conexa.

É usual chamar um dos nós de uma árvore de nó raiz. Este nó, em geral, funciona como uma referência de onde se inicia a árvore. Um nó raiz pode ter grau maior ou igual a um.

\subsubsection{Representação de SDRs através de grafos}

A topologia elétrica de um SDR pode ser representada computacionalmente através de grafo. A Figura 7 mostra um SDR com 4 alimentadores. Cada barra (nó) do sistema representa um setor e as arestas interligando as barras são chaves seccionadoras. As arestas em linhas cheias representam as chaves $\mathrm{NF} e$ as arestas em linhas tracejadas representam as chaves NA. As barras 1, 2, 3 e 4 se encontram em uma subestação.

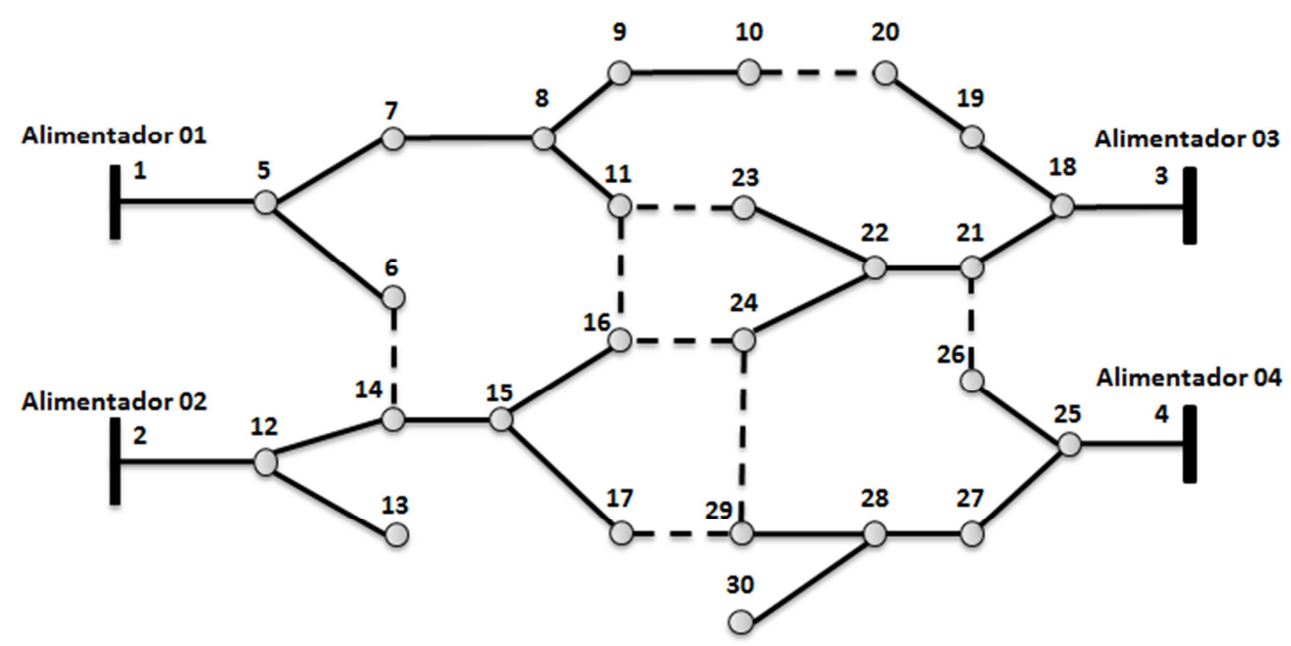

Figura 7. SDR com 4 alimentadores representado através de grafo

\subsubsection{Formulação do Problema}

A partir do que foi apresentado na subseção anterior, pode-se definir

\footnotetext{
${ }^{2}$ Uma aresta é dita ser uma ponte, se sua remoção provoca uma redução na conexidade do grafo.
} 
o problema de restabelecimento de energia em SDs via reconfiguração de redes da seguinte forma [72]:

$$
\begin{aligned}
& \text { Min. } \phi(G), \quad \psi\left(G, G^{0}\right) \quad \text { e } \quad \gamma(G) \\
& \text { Sujeito a }\left\{\begin{array}{l}
A x=b \\
X(G) \leq 1 \\
B(G) \leq 1 \\
V(G) \leq 0,1
\end{array}\right.
\end{aligned}
$$

em que:

$\checkmark$ G é uma floresta de grafo $^{3}$ representando uma configuração do SD;

$\checkmark \phi(G)$ é o número de consumidores fora de serviço em uma configuração $G$;

$\checkmark \Psi\left(G, G^{0}\right)$ é o número de operações de chaveamento necessárias para se obter uma configuração $G$ a partir da configuração $G^{0}$, na qual a área sob falta já está isolada;

$\checkmark \quad$ (G) são as perdas resistivas, em p.u., da configuração $G$;

$\checkmark A$ é a matriz incidência de $G$;

$\checkmark x$ é o vetor de correntes de linha na configuração $G$;

$\checkmark \quad b$ é um vetor contendo as correntes complexas nas barras de carga (com $b_{i} \leq 0$ ) ou as injeções de corrente nas barras das SEs (com $\left.b_{i}>0\right)$;

$\checkmark X(G)$ é o maior valor de carregamento da rede na configuração $G$, dado pela maior razão ${ }^{x_{j}} / \bar{x}_{j}$, onde $\bar{x}_{j}$ é um limitante superior de corrente, para cada corrente de linha $x_{j}$ em uma linha $j$;

$\checkmark B(G)$ é o maior valor de carregamento de SE na configuração $G$, dado pela maior razão $/ b_{s} / \bar{b}_{s}$, onde $\bar{b}_{s}$ é um limitante superior para cada injeção de corrente $b_{s}$ provida por uma SE $s$;

$\checkmark V(G)$ é o maior valor de queda de tensão em uma configuração $G$, dado pelo maior valor de $\left|v_{s}-v_{k}\right| / \delta$, onde $v_{k}$ é a magnitude de tensão, em p.u., na barra $k$, e $v_{s}$ é a magnitude de tensão, em p.u., na barra da subestação $s$ que alimenta a barra $k$, e $\delta$ é a máxima queda de tensão admissível.

O valor da corrente $x_{j}$ em cada linha $j$, bem como o valor da injeção de

\footnotetext{
${ }^{3} \mathrm{Em}$ problemas de reconfiguração de redes um SD pode ser convenientemente modelado por meio de uma floresta de grafo [19], nas quais as árvores representam os alimentadores, nós os setores e arestas as chaves de manobra.
} 
corrente $b_{s}$, em cada subestação $s$, e o valor da tensão $v_{k}$, em cada barra $k$, podem ser obtidos através de um fluxo de potência adequado para SDs, tendo as cargas modeladas segundo um modelo de carga também adequado. Em problemas de restabelecimento de energia em SDs, de uma forma geral, é possível utilizar o modelo de carga "corrente constante com a tensão" e, para permitir o cálculo de fluxo de potência, as barras devem ser ordenadas de acordo com uma relação MPF [19]. Essa ordenação permite que o fluxo de potência seja calculado segundo um método de varredura direta e inversa, sem a necessidade de fatoração de matrizes [70].

Quando AEs são empregados ao problema de restabelecimento de energia em SDRs, algumas modificações são realizadas na formulação apresentada anteriormente (equação 1). Nesse caso, a fim de penalizar as configurações de rede que violarem as restrições operacionais $(X(G), B(G)$ e $V(G))$, são inseridos fatores de penalidades [77]. Logo, o problema pode ser reformulado como a seguir:

Min. $\quad \phi(G), \quad \psi\left(G, G^{0}\right), \quad \gamma(G) \quad e \quad \omega_{x} X(G)+\omega_{b} B(G)+\omega_{v} V(G)$

$$
\text { Sujeito a }\left\{\begin{array}{c}
A x=b \\
\text { G seruma floresta }
\end{array},\right.
$$

em que $\omega_{x}, \omega_{b}$ e $\omega_{r}$ são pesos definidos em função do valor das restrições operacionais, da seguinte forma:

$$
\begin{aligned}
& \omega_{x}=\left\{\begin{array}{c}
A, \text { se } X(G)>1 \\
0, \text { caso contrário } ;
\end{array}\right. \\
& \omega_{b}=\left\{\begin{array}{c}
B, \text { se } B(G)>1 \\
0, \text { caso contrário } ;
\end{array}\right. \\
& \omega_{v}=\left\{\begin{array}{c}
C, \text { se } V(G)>1 \\
0, \text { caso contrário }
\end{array},\right.
\end{aligned}
$$

em que $A, B$ e $C$ são valores maiores do que zero.

\subsection{FUNDAMENTOS DA RNP}

Por se tratar de um conceito abordado em outros trabalhos, a apresentação da "Representação Nó-Profundidade" (RNP) ocorrerá com base nos textos contidos em [24], [31], [32] e [33].

A RNP será apresentada em função de sua utilização no AEMT-H, sendo 
esta representação de suma importância para a garantia da geração de soluções eletricamente factíveis e ainda para a rápida resposta do algoritmo garantindo uma performance adequada para a aplicação de tempo-real (ver seção 1.1).

A representação computacional para grafos do tipo floresta, RNP, baseiase nos conceitos de caminhos e de profundidade do nó em um grafo (árvore) [31]. Vale lembrar que a profundidade de um nó (ou vértice) num grafo é igual à distância deste nó até o nó raiz do grafo, distância esta correspondente ao número de nós existentes no caminho percorrido daquele nó ao nó raiz. A representação consiste, basicamente, de uma lista contendo os nós da árvore e suas respectivas profundidades, formando pares do tipo $\left(n_{i}, p_{i}\right)$, onde $n_{i}$ é o nó da árvore e $p_{i}$ a profundidade do nó.

O primeiro passo para armazenar uma árvore na RNP é escolher, de forma aleatória, um nó (vértice) para ser a raiz da árvore, o qual terá profundidade 0. A ordem dos pares dos demais vértices do vetor pode ser determinada por uma busca em profundidade [34] ou um percurso em pré-ordem para árvores [35, 36]. Em ambos os métodos, o processo deve iniciar pelo vértice definido como raiz.

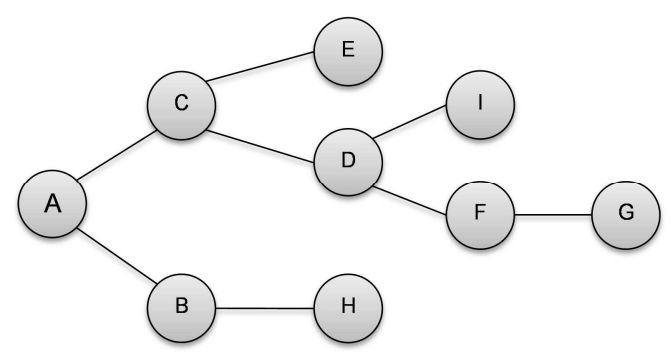

Figura 8. Exemplo de árvore com 9 vértices

No exemplo da árvore da Figura 8, foi escolhido nó $A$ como sendo o nó raiz (profundidade 0). A partir dele, utilizando o método de busca em profundidade, observa-se o caminho $(A, C)$, atribuindo-se, ao nó $C$, a profundidade 1 . Em seguida, pelo mesmo método, observa-se o caminho $(C, E)$ e, ao nó $E$, é atribuída a profundidade 2. Como não existem outros caminhos para o nó $E$, retorna-se para o nó $C$ e se observa o segundo caminho envolvendo este nó: $(C, D)$. Assim, para o nó $D$, é atribuída a profundidade 2 . Em seguida, observa-se o caminho $(D, I)$ e, ao nó lé atribuída a profundidade 3 e assim sucessivamente até a "passagem" por todos os caminhos presentes na referida árvore chegando à RNP descrita abaixo.

$$
\mathrm{T}=\left[\begin{array}{c}
\text { nó } \\
\text { profundidade }
\end{array}\right]=\left[\begin{array}{ccccccccc}
A & C & E & D & I & F & G & B & H \\
0 & 1 & 2 & 2 & 3 & 3 & 4 & 1 & 2
\end{array}\right]
$$


Uma alternativa interessante para implantação computacional da RNP é a utilização de listas encadeadas. Esta alternativa facilita tanto na construção de representações (tendo em vista a quantidade desconhecida de elementos que serão gerados), quanto na operação de corte ("poda") e inclusão ("enxerto") de elementos nas árvores de grafo armazenadas nas RNPs.

Para representar uma floresta possuindo " $n_{A}$ " árvores, teremos um conjunto de " $n_{A}$ " RNPs. Assim, a estrutura de dados da floresta pode ser facilmente implementada, utilizando ponteiros e matrizes, onde cada ponteiro indica os pares $\left(n_{i}, p_{i}\right)$, ou seja, nó e sua profundidade na árvore da floresta.

A fim de gerar novas florestas, a partir de uma floresta inicial representada computacionalmente através de RNPs, em [31] foram propostos dois operadores com características de operação distintas, porém produzindo resultados similares. Estes operadores foram chamados de PAO (Preserve Ancestor Operator) e CAO (Change Ancestor Operator) e produzem novas árvores $T^{\prime}$ quando aplicados à outras árvores $T$ de uma mesma floresta. Na prática, ao se aplicar o PAO (ou CAO) em uma determinada árvore de uma floresta (composta por duas ou mais árvores), o que se realiza é a transferência de uma sub-árvore de uma árvore $T_{d e}$ para uma outra árvore $T_{\text {para }}$. Ao aplicar o PAO, a raiz da sub-árvore cortada $T_{d e}$ será também a raiz desta sub-árvore na árvore $T_{\text {para }}$. Ao aplicar o $C A O$, a sub-árvore cortada terá um novo nó raiz, que poderá ser qualquer nó da sub-árvore cortada diferente da raiz original. Essa é a diferença básica entre PAO e CAO [33].

\subsection{OPERADORES DA RNP}

\subsubsection{Operador PAO}

O Operador PAO utiliza dois pontos principais: o ponto $\boldsymbol{p}$ indicando o local do corte na árvore $T_{d e}$, que será a raiz da sub-árvore a ser transferida para a árvore $T_{p a r a}$ e o ponto a que indica o local onde a sub-árvore será "enxertada" (conectada) na árvore $T_{\text {para. }}$

Para apresentar um exemplo de utilização do PAO serão utilizadas as árvores contidas na Figura 9: 


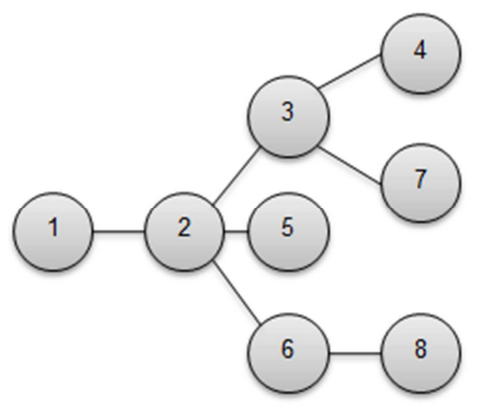

(a)

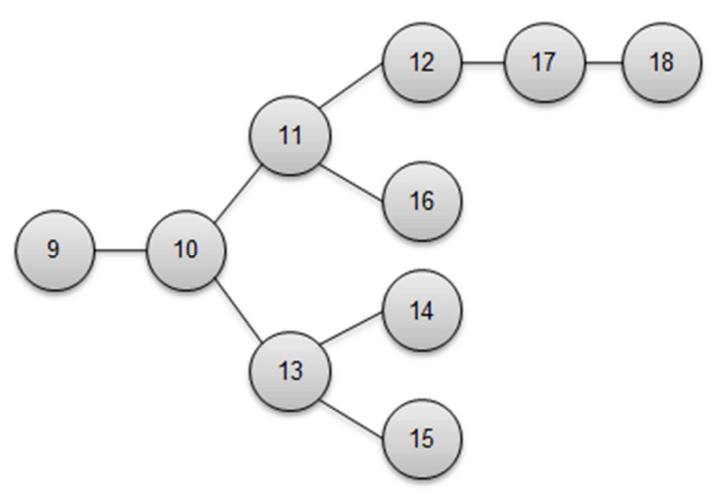

(b)

Figura 9. (a) Árvore $T_{\text {para }}$ (b) Árvore $T_{d e}$

As RNPs das árvores apresentadas na Figura 9 são as seguintes:

$$
\begin{gathered}
\left.\mathrm{T}_{\text {para }}=\begin{array}{c}
\text { nó } \\
\text { profundidade }
\end{array}\right]=\left[\begin{array}{cccccccc}
1 & 2 & 3 & 4 & 7 & 5 & 6 & 8 \\
0 & 1 & 2 & 3 & 3 & 2 & 2 & 3
\end{array}\right] \\
\mathrm{T}_{\mathrm{de}}=\left[\begin{array}{c}
\text { nó } \\
\text { profundidade }
\end{array}\right]=\left[\begin{array}{cccccccccc}
9 & 10 & 11 & 12 & 17 & 18 & 16 & 13 & 14 & 15 \\
0 & 1 & 2 & 3 & 4 & 5 & 3 & 2 & 3 & 3
\end{array}\right]
\end{gathered}
$$

Uma alternativa de sequencia lógica a ser utilizada na implementação do PAO pode ser realizada através dos seguintes passos:

1) Determinação dos pontos de corte $p$ (RNP $T_{d e}$ ) e de enxerto a (RNP $T_{p a r a}$ ), e verificação das suas localizações nas correspondentes RNPs (posições $i_{p} e$ $\left.i_{a}\right)$;

2) Verificação da posição na RNP $T_{d e}$ do último nó (nó $u$ ) na sub-árvore que contém o nó $p$ como raiz (posição $i_{u}$ ). $O$ conjunto de nós $x$ existentes entre as posições $i_{p}$ e $i_{u}$, da RNP $T_{\text {de }}$, serão enxertados na árvore $T_{\text {para }}$, de forma que $i_{x}>i_{p}$ e $p_{x}>p_{p}$ (retângulo tracejado na Figura 10 , onde $p_{x}$ e $p_{p}$ representam as profundidades de $x$ e $p$ respectivamente);

3) Transferência dos elementos da árvore $T_{d e}$ (contidos no retângulo da Figura 10) para a árvore $T_{\text {para }}$ (na posição especificada por a). Por se tratar de uma implementação através da técnica de listas encadeadas, os índices dos "próximos" nós em relação ao atual (campo "next" da variável representando o nó), são alterados redirecionando a lista conforme as alterações ocorridas nas 
árvores. Assim, o campo "next" do nó a será apontado para o nó p; o campo "next" do nó $u$ (posição $i_{u}$ ) para o nó posterior aa (posição $i_{a+1}$ ) e o campo "next" do nó anterior ao nó $p$ (posição $i_{p-1}$ ) será apontado para o nó posterior a $u$ (posição $\left.i_{u+1}\right)$ (Figuras 10 e 11);

4) Atualização das profundidades de cada nó $x$ contido no conjunto $\left(i_{p}-i_{u}\right)$ na RNP de $T_{d e}$, para serem alocados na RNP $T_{\text {para }}$, através da seguinte equação: $p_{x}=p_{x}-p_{p}+p_{a}+1$ (para que este passo possa ser realizado com sucesso, os valores de $p_{p}$ e $p_{a}$ deverão ser armazenados antes da realização do Passo 3);

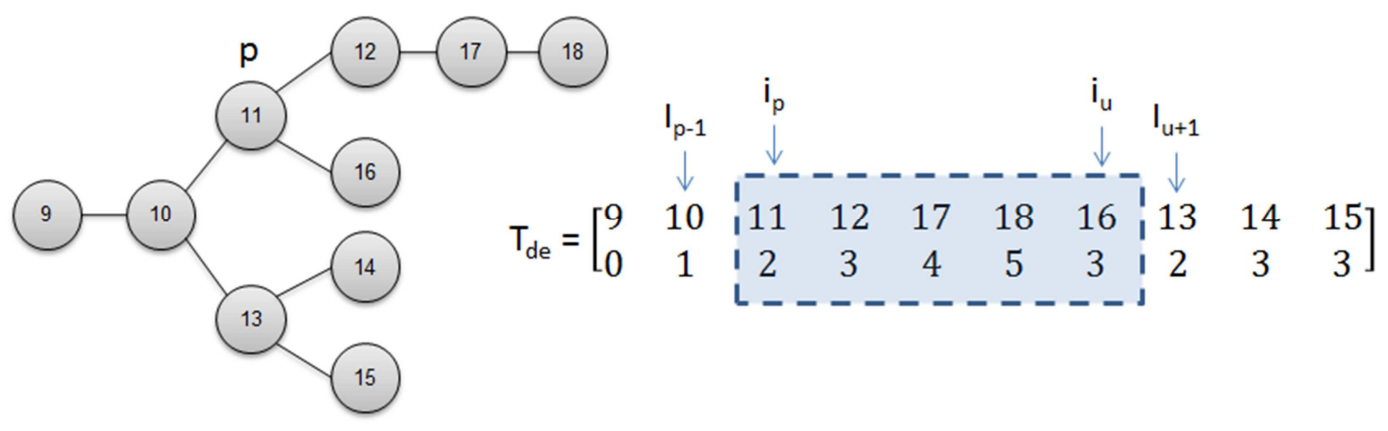

Figura 10. Local escolhido para o corte na RNP $T_{d e}$

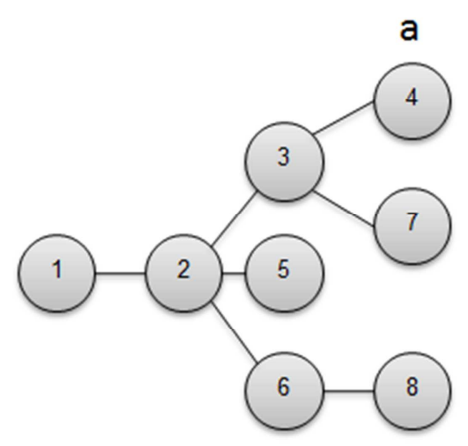

$$
\mathrm{T}_{\text {para }}=\left[\begin{array}{llllllll}
1 & 2 & 3 & 4 & 7 & 5 & 6 & 8 \\
0 & 1 & 2 & 3 & 3 & 2 & 2 & 3
\end{array}\right]
$$

Figura 11. Local escolhido para o enxerto na RNP $T_{\text {para }}$

As Figuras 12 e 13 apresentam as novas árvores com suas respectivas RNPs (o retângulo tracejado presente em $T_{\text {para }}$ apresenta os nós enxertados na respectiva árvore). 


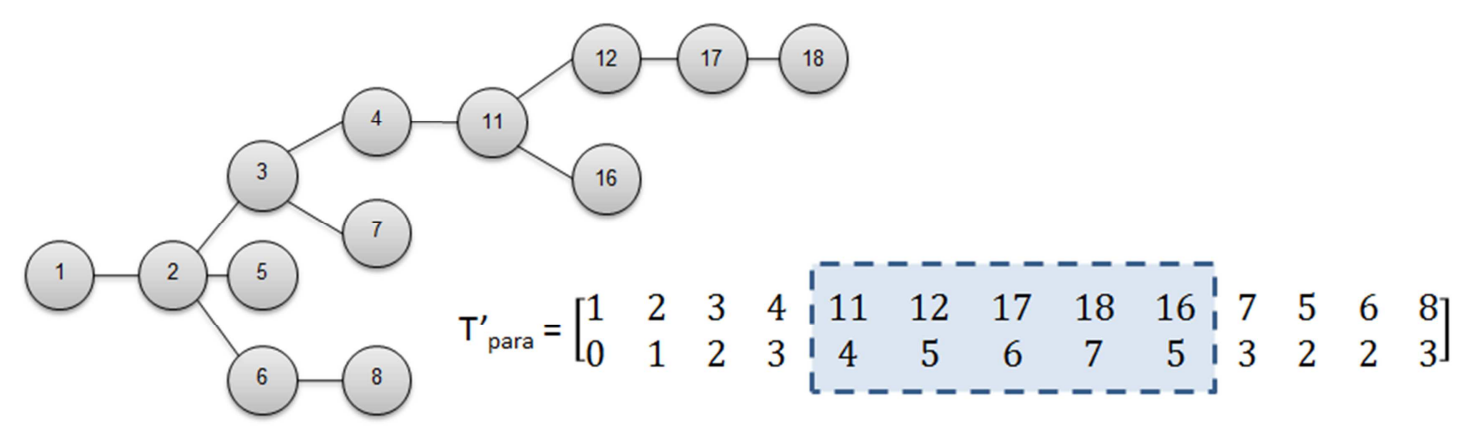

Figura 12. $T_{\text {para }}^{\text {, e sua RNP }}$

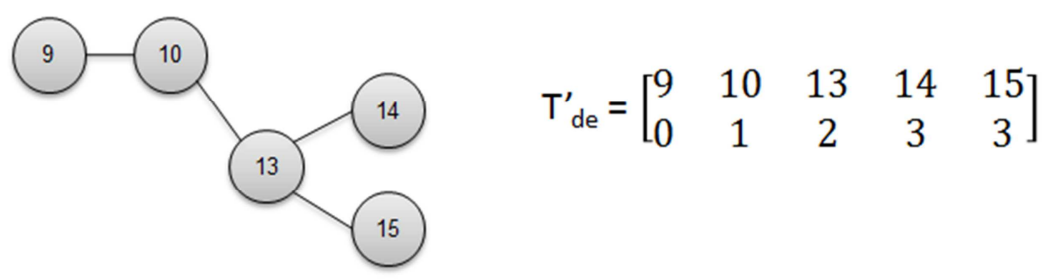

Figura 13. $T_{d e}^{\prime}$ e sua RNP

\subsubsection{Operador CAO}

Assim como o PAO, o CAO também necessita da definição dos nós $\boldsymbol{p}$ (ponto de corte na árvore $T_{d e}$ ) e a (ponto de enxerto na árvore $T_{\text {para) }}$. Porém, em incremento aos dois nós, o CAO necessita ainda da definição do novo nó raiz, chamado de $\boldsymbol{r}$, pertencente à árvore $T_{d e}$.

Para exemplificar a utilização do $\mathrm{CAO}$, serão utilizadas as mesmas árvores apresentadas na Figura 9. Nestas árvores, a escolha dos pontos a, percorreu conforme demonstrado nas Figuras 14 e 15.

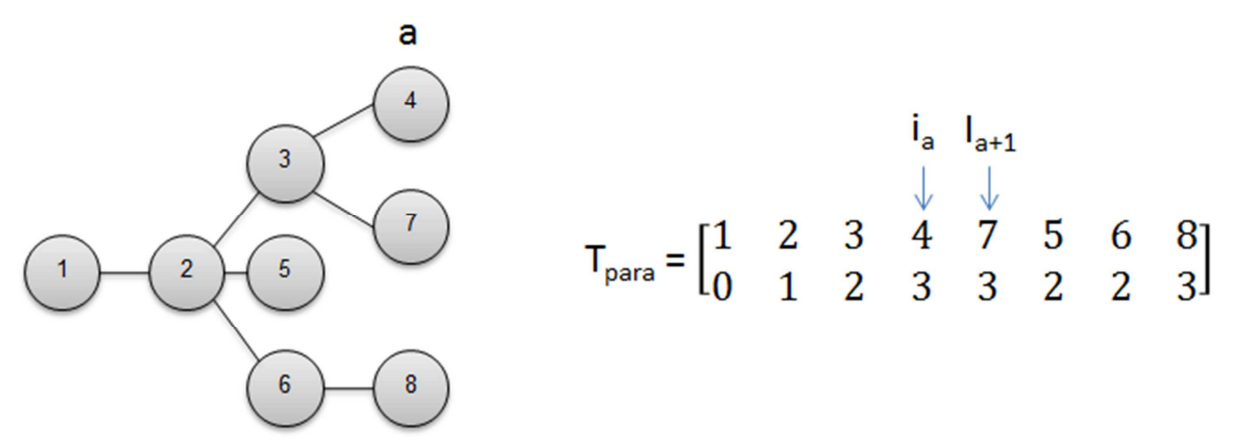

Figura 14. Local escolhido para o enxerto na RNP $T_{\text {para }}$ 


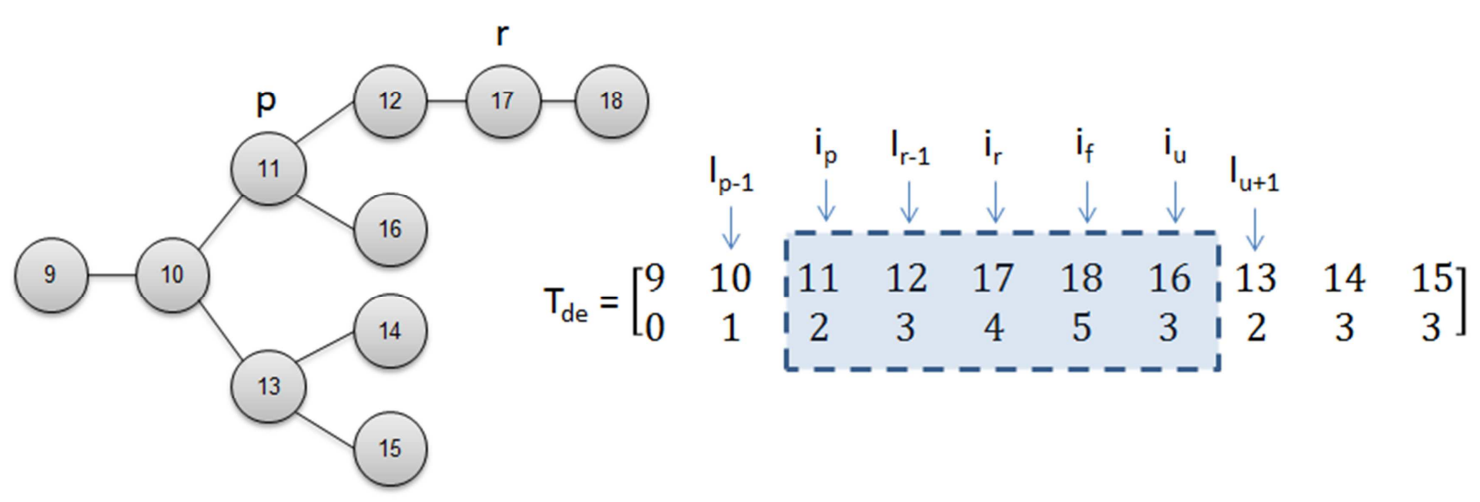

Figura 15. Local escolhido para o corte e novo nó raiz na RNP $T_{d e}$

Para o CAO, os passos 1 e 2 são os mesmos dos realizados no PAO. Já os passos seguintes possuem alterações. Observe que o passo 3 foi dividido em dois passos distintos conforme segue.

3.a) Transferência dos elementos da árvore $T_{d e}$ (contidos no retângulo da Figura 15) para a árvore $T_{\text {para }}$ (na posição especificada por a - Figura 14). A transferência dos elementos deverá obedecer à nova sequência estabelecida pela ligação através do ponto $r$. O primeiro corte a ser realizado na árvore $T_{d e}$ separa apenas os nós à jusante do nó $r$ (estes nós são identificados através da caminhada na RNP a partir de $r$, sentido extremidade, até a identificação de um nó cuja profundidade seja igual ou inferior à $\left.p_{r}\right)$. Este conjunto de nós $\left(i_{\Gamma}-i_{f}\right)$ é então enxertado na árvore $T_{\text {para }}$ através do apontamento do campo "next" de $i_{a}$ para o nó $i_{r}$. O apontamento do campo "next" de $i_{f}$ será realizado para o endereço de $i_{a+1}$. Para consolidar a retirada dos nós do conjunto $\left(i_{r}-i_{f}\right)$ da árvore $T_{d e}$, 0 campo "next" do nó de posição $i_{r-1}$ deve ser apontado para a posição $i_{u}$ (caso o nó de posição $i_{u}$ seja o mesmo do de posição $i_{u+1}$, esta operação é desnecessária).

3.a.1) $O$ passo de adequação das profundidades de cada nó $x$ contido no conjunto $\left(i_{r}-i_{f}\right)$ ocorre através do seguinte equacionamento: $p_{x}=p_{x}-p_{r}+p_{a}+1$. Lembrando que apenas os nós contidos no conjunto $\left(i_{r}-i_{f}\right)$ serão enxertados neste passo.

3.b) Antes do corte dos demais nós da sub-árvore (que ainda não foram enxertados em $T_{\text {para }}$, deve-se analisar a necessidade de readequação da 
sequência destes elementos, para isso o conjunto $\left(i_{p}-i_{u}\right)$ deve ser separado da árvore $T_{d e}$ e alocado em uma árvore temporária $\left(T_{\text {temp }}^{\prime}\right)$ - Figura 16. Esta separação ocorre através da alteração do campo "next" do elemento $i_{p-1}$ que passa a apontar para o nó do elemento $i_{u+1}$. A alteração na sequência dos elementos de $T_{\text {temp }}^{\prime}$ só ocorrerá caso o elemento $i_{r-1}$ seja diferente de $i_{p}$. Caso $i_{r} \neq i_{p}$ os elementos do conjunto $\left(i_{p}-i_{u}\right)$ serão reordenados adotando $i_{r-1}$ como novo nó raiz (conforme apresentado na Figura 16). Por fim, o enxerto dos referidos nós ocorre com o apontamento do campo "next" do nó de posição $i_{f}$ (da nova árvore $T_{\text {para) }}$ para a posição do elemento $i_{r-1}$ (que já está deslocado para a nova árvore $T_{\text {temp }}^{\prime}$ ) e com o apontamento do campo "nexf" do nó de posição $i_{t t}$ para a posição $i_{a+1}$.

4.b) Por fim, a atualização das profundidades dos demais nós $x$, contidos no conjunto $i_{p}-i_{u}$ depois da retirada dos elementos do conjunto $i_{\Gamma}-i_{\text {f }}$, ocorre através da seguinte equação: $p_{x}=p_{x}-p_{p}+p_{a}+2$.

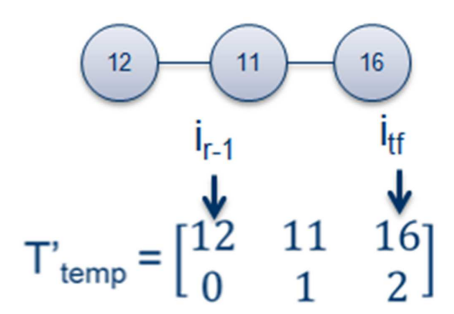

Figura 16. $T_{\text {temp }}^{\prime}$ e sua RNP

As Figuras 17 e 18 apresentam as novas árvores com suas respectivas RNPs (os retângulos tracejados presentes em $T_{\text {para }}$ apresentam os nós enxertados nessa árvore, destacando os conjuntos enxertados separadamente). 


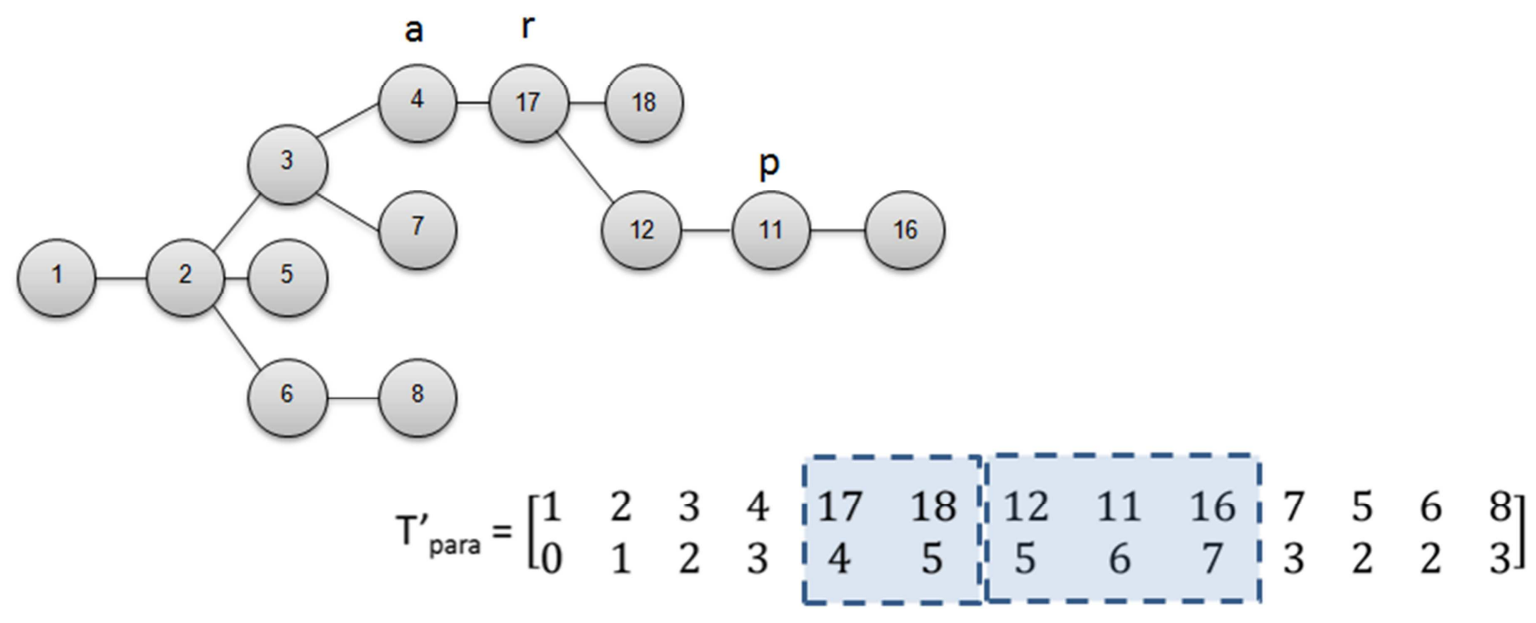

Figura 17. T' para e sua RNP

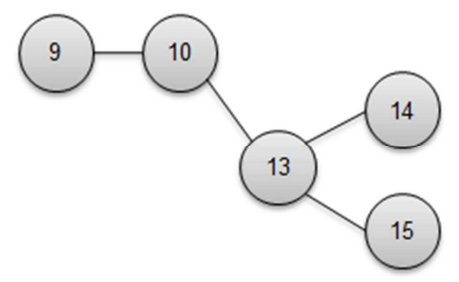

$$
\mathrm{T}_{\mathrm{de}}^{\prime}=\left[\begin{array}{ccccc}
9 & 10 & 13 & 14 & 15 \\
0 & 1 & 2 & 3 & 3
\end{array}\right]
$$

Figura 18. $T_{d e}^{\prime}$ e sua RNP 


\section{FUNDAMENTOS DE ALGORITMOS EVOLUTIVOS E DE OTIMIZAÇÃO MULTI- OBJETIVO}

Os AEs são métodos de otimização e busca inspirados nos princípios da Seleção Natural de Darwin. Estes algoritmos utilizam técnicas e conceitos da genética abordando uma gama de mecanismos da evolução biológica, tornando o processo dinâmico a cada iteração. Desta forma, cria-se uma população de indivíduos que vão reproduzir e competir pela sobrevivência. Os melhores sobrevivem e transferem suas características para novas gerações.

Essa área de pesquisa originou-se de várias frentes de estudo, dentre elas, os algoritmos genéticos (AGs) são os mais conhecidos [37].Os primeiros trabalhos envolvendo AEs são da década de 1930. Estes estudos foram intensificados a partir da década de 1960, quando um grupo de cientistas, em que o nome de Holland se destaca, realizaram diversos estudos teóricos e empíricos aplicando os conceitos dos AEs [38].

Conforme [38], foram desenvolvidas três abordagens de AEs: a programação evolutiva (PE), as estratégias evolutivas (EEs) e os algoritmos genéticos (AGs). O princípio básico de todas essas técnicas é, no entanto, o mesmo [39]: dada uma população de indivíduos, pressões do ambiente desencadeiam processos de seleção natural causando um incremento na adequação das soluções. Dessa forma, dada uma função a ser otimizada (seja maximizada ou minimizada), gera-se aleatoriamente um conjunto de soluções (indivíduos) e aplica-se a função para medir a qualidade das soluções candidatas, atribuindo-Ihes um valor que mede sua adequação, chamado fitness.

Com base no fitness, algumas das melhores soluções são selecionadas para darem origem a uma nova população pela aplicação de operadores de recombinação e/ou mutação. A recombinação é um operador aplicado a duas ou mais soluções candidatas (chamadas pais) e resulta em uma ou mais novas soluções (chamadas descendentes ou filhos). A mutação é aplicada em uma candidata a fim de gerar outra. Ao final desse processo, as novas candidatas (descendentes) competem com as candidatas da geração anterior, com base no fitness, para assumir um lugar na nova população. Esse processo é iterativo até que uma candidata apresente uma solução que seja suficientemente qualificada ou até que um número máximo de iterações, também chamadas gerações, seja obtido [40]. 
Vários componentes de um processo evolutivo são estocásticos: a seleção favorece indivíduos mais bem adaptados (ou seja, com melhor fitness), mas existe também a possibilidade de serem selecionados outros indivíduos [40].

Uma representação geral de um AE típico pode ser vista no pseudocódigo do Algoritmo 1.

Algoritmo 1: Pseudocódigo de um AE típico [39].

Entrada: Parâmetros típicos [38].

Saída: População final de soluções

1 INICIALIZA população com soluções candidatas aleatórias

2 AVALIA cada candidata

3 REPITA

4 SELECIONA pais

5 RECOMBINA pares de pais

$6 \quad$ MUTA os descendentes resultantes

$7 \quad$ AVALIA novas candidatas

8 SELECIONA indivíduos para a nova geração

9 ATÉ CONDIÇÃO DE PARADA satisfeita ;

Por se tratar de um conceito abordado em outros trabalhos, este capítulo terá como base principal os textos contidos em [40]. Sua organização procederá da seguinte forma:

$\rightarrow$ Seção 3.1: apresenta os aspectos básicos do processo evolutivo (que são fundamentas para o desenvolvimento de AEs);

$\rightarrow$ Seção 3.2: é apresentada a terminologia básica e o significado de cada um dos principais conceitos da área;

$\rightarrow$ Seção 3.3: são descritos os principais AEs e suas características.

Em seguida, o capítulo introduz os principais aspectos da otimização multi-objetivo (MOO, do inglês Multi-Objective Optimization) e algumas das principais técnicas de AEMOs. Estes tópicos terão como base principal os textos contidos em [48] e sua organização procederá da seguinte forma:

$\rightarrow$ Seção 3.4: são apresentados os principais conceitos teóricos de MOO e as principais diferenças entre otimização mono-objetivo e multi-objetivo; 
$\rightarrow$ Seção 3.5: são apresentados os conceitos de AEMOs que são base da metodologia AEMT-H.

\subsection{BASE BIOLÓGICA}

Os AEs podem ser vistos como técnicas de Computação Bioinspirada [41] ou Computação Natural [42], onde uma série de técnicas computacionais fundamentadas em conceitos biológicos são abordadas. Assim, visando um melhor entendimento da forma com que os AEs são aplicados nas diversas áreas da engenharia, os principais conceitos das técnicas evolutivas serão apresentados nesta seção.

\subsubsection{Processo Evolutivo}

Os AEs são fortemente inspirados em processos evolutivos que ocorrem na natureza. Segundo [38], os principais componentes dos sistemas evolutivos são:

$\checkmark$ Populações de indivíduos: uma ou mais populações concorrem por recursos limitados;

$\checkmark$ Aptidão (fitness), que reflete a habilidade do indivíduo para sobreviver e reproduzir-se;

$\checkmark$ A noção de mudanças dinâmicas nas populações devido ao nascimento e morte dos indivíduos;

$\checkmark$ Os conceitos de variabilidade e hereditariedade, ou seja, os novos indivíduos possuem muitas das características de seus pais, embora não sejam idênticos.

Tais conceitos foram inspirados na Teoria da Evolução de Darwin, onde os principais fatores evolutivos são a mutação, a recombinação (crossover) e a seleção natural. Estes conceitos são abordados nos tópicos seguintes.

\subsubsection{Mutação}

$\mathrm{Na}$ Biologia as mutações são caracterizadas pelas mudanças na sequência dos nucleotídeos do material genético de um organismo. Tais mudanças geram variações no conjunto de genes da população, criando novos valores de características que não existiam ou apareciam em pequena quantidade na 
população em análise.

Assim, o operador de mutação é necessário para introdução e manutenção da diversidade genética da população, assegurando que a probabilidade de se chegar a qualquer ponto do espaço de busca possivelmente não será zero.

A variável que determina a quantidade de mutação que ocorrerá em uma população é a taxa de mutação. Esta variável, que normalmente assume valores de pequena ordem, pode ser aplicada nos algoritmos computacionais da seguinte forma (dependendo do tipo de indivíduo presente no algoritmo).

- Taxa de Mutação em indivíduos binários: é o percentual de chance para alteração do cromossomo. Ao final do algoritmo, o percentual de cromossomos que sofreram mutação é probabilisticamente igual à taxa de mutação. A Figura 19 apresenta um exemplo de mutação com uma taxa de mutação de $10 \%$.

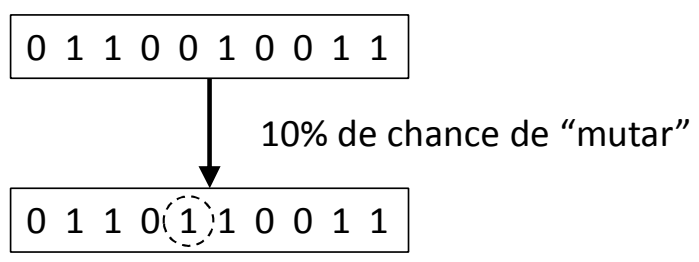

Figura 19. Exemplo de mutação em indivíduos binários

- Taxa de Mutação em indivíduos reais: é o percentual do valor do indivíduo a ser alterado. Para populações envolvendo indivíduos reais, parte-se do princípio de que todos os indivíduos serão alterados ("mutados"). Assim a taxa de mutação representa o valor percentual a ser alterado no indivíduo. Como exemplo, um indivíduo $x$ "mutado", a uma taxa de mutação de $1 \%$, poderá ter o seguinte novo valor: $x^{\prime}=x \pm(0,01 x)$.

\subsubsection{Recombinação}

Na Biologia, a recombinação é a troca aleatória de material genético, ocorrida durante a meiose (um tipo especial de divisão celular que ocorre durante a formação dos espermatozoides e óvulos e dá a eles o número correto de cromossomos). Assim, é através da recombinação que as características dos pais são "misturadas", dando origem a um indivíduo único com características tanto do 
pai, quanto da mãe.

É importante considerar que a seleção natural não atua aceitando ou rejeitando mudanças individuais, mas sim escolhendo as melhores combinações gênicas entre todas as variações presentes na população [40].

A taxa de recombinação (ou taxa de crossover), quando utilizada, representa o percentual de indivíduos da população que sofrerá recombinação.

\subsubsection{Seleção Natural}

Seleção natural é um processo da evolução proposto por Charles Darwin para explicar a adaptação e especialização dos seres vivos no decorrer das gerações. O conceito básico de seleção natural é que, em organismos que se reproduzem, as características favoráveis que são hereditárias tornam-se mais comuns em gerações sucessivas em relação às características desfavoráveis (que acabam se tornando menos comuns).

A seleção natural é consequência de dois fatores [40]:

$\checkmark$ os membros de uma espécie diferem entre si;

$\checkmark$ a espécie produz descendência em maior número de indivíduos em relação aos que de fato podem sobreviver.

Os indivíduos mais aptos a sobreviver são aqueles que, graças à variabilidade genética, herdaram a combinação gênica mais adaptada para determinadas condições naturais.

\subsection{TERMINOLOGIA BÁSICA}

Apresenta-se, a seguir, a terminologia necessária para o estudo de AEs [43].

\subsubsection{Genes, Cromossomo e Alelos}

Um cromossomo é uma longa sequência de DNA, que contém vários genes, e outras sequências de nucleotídeos com funções específicas nas células dos seres vivos. Os cromossomos associam-se de modo a formar um organismo e seu número varia de uma espécie para outra. O conjunto completo de cromossomos 
de um ser vivo é chamado genótipo e as características do organismo gerado com base no genótipo constituem o fenótipo. De forma similar, a representação de soluções de um problema podem ser codificadas em uma estrutura da dados chamada cromossomo.

O gene é um segmento de um cromossomo a que corresponde um código distinto, uma informação para produzir uma determinada proteína ou controlar uma característica, ou seja, os cromossomos são codificados em um conjunto de símbolos chamados genes. Os diferentes valores de um gene são chamados alelos.

\subsubsection{Fitness (aptidão)}

O fitness (ou a aptidão) é um conceito central na teoria da evolução que descreve a capacidade de um indivíduo. O valor deste fitness (seja um genótipo ou um cromossomo) é um número positivo que mede o quanto adequado é o indivíduo. Em alguns problemas de otimização o fitness pode ser o custo da solução. Nestes casos, as soluções de maior fitness são as de menor custo.

Este é um componente muito importante em qualquer algoritmo genético, pois é através da função de aptidão que se mede quão próximo um indivíduo está da solução desejada.

\subsubsection{Pais, Operadores de Reprodução e Descendentes}

Os AEs trabalham sobre os cromossomos de um indivíduo a fim de gerar novos descendentes, que representarão as novas soluções. Os operadores que trabalham sobre cromossomos, chamados operadores de reprodução, são a recombinação e a mutação. Esses operadores fazem analogia aos principais mecanismos da evolução natural, ou seja, a recombinação e a mutação gênica. Os indivíduos selecionados para o processo de recombinação são chamados pais e os indivíduos gerados a partir destes pais (seja pelo processo de mutação ou de recombinação) são chamados de descendentes.

\subsubsection{Geração}

A cada iteração, um novo conjunto de indivíduos é gerado a partir da 
população anterior. A este novo conjunto se dá o nome de "Geração". Através da criação de uma grande quantidade de gerações é possível se obter resultados positivos a partir dos AGs. Devido à criação de novos descendentes, o tamanho da população cresce; então um mecanismo de seleção controla esse tamanho.

A ideia básica da seleção é a seguinte: seja uma população de tamanho $M$ e seja $N_{d}$ O número de descendentes, então, para a próxima geração, são selecionados $M$ novos indivíduos ( $N_{d}$ pode ser maior que $M$ ). Cada $A E$ desenvolve, com base nesse princípio, uma estratégia de seleção [40].

\subsection{ALGORITMOS EVOLUTIVOS}

Alguns ramos distintos de pesquisa desenvolveram técnicas computacionais que construíram os chamados AEs. Os próximos tópicos abordarão alguns dos principais algoritmos e suas características.

\subsubsection{Programação Evolutiva}

A programação evolutiva foi proposta em [44] com o objetivo de utilizar os conceitos de evolução no desenvolvimento de Inteligência Artificial na qual cada indivíduo da população é representado por uma máquina de estados finitos (que processa uma sequência de símbolos). A função de aptidão é calculada através da comparação do valor da saída da máquina com a saída esperada para solução do problema. São características da programação evolutiva:

$\checkmark$ A reprodução é feita apenas por operadores de mutação, sendo que todos os indivíduos da população atual geram novos descendentes (reprodução assexuada);

$\checkmark$ A seleção de indivíduos para a próxima geração ocorre através da competição dos novos indivíduos com seus $\mu$ pais onde somente os indivíduos com maior fitness sobrevivem.

Este domínio total dos melhores indivíduos garante a sobrevivência dos $k$ melhores indivíduos, porém pode diminuir significativamente a diversidade de indivíduos, podendo estagnar em ótimos locais e/ou aumentar o tempo de convergência do algoritmo [38]. 


\subsubsection{Estratégias Evolutivas}

As estratégias evolutivas foram desenvolvidas com o objetivo de solucionar problemas de otimização de parâmetros. Nestes algoritmos um pai gera um único descendente (reprodução assexuada) e ambos competem pela sobrevivência. São características das estratégias evolutivas:

$\checkmark$ Cada gene no cromossomo representa uma dimensão do problema (com alelo representado em ponto flutuante);

$\checkmark$ Os cromossomos são compostos por dois vetores, um com valores para cada dimensão e outro com o desvio padrão desses valores;

$\checkmark$ A geração de um novo indivíduo é feita através da reprodução assexuada (operador de mutação), com distribuição de probabilidade Gaussiana, média zero e com desvio padrão do gene correspondente no pai;

$\checkmark$ Os indivíduos competem com os pais sobrevivendo apenas os melhores.

Segundo [38], o modelo original de Estratégia Evolutiva (EE) possui convergência lenta, sendo evoluído em outros modelos posteriores.

\subsubsection{Algoritmos Genéticos}

Os Algoritmos Genéticos (AGs) são uma das principais frentes de pesquisa em Algoritmos Evolutivos. Eles foram concebidos em 1960, por John Holland, com o objetivo inicial de estudar os fenômenos relacionados à adaptação das espécies e da seleção natural que ocorre na natureza, bem como desenvolver uma maneira de incorporar estes conceitos aos computadores.

A principal diferença dos AGs é a criação de descendente pelo operador de recombinação [38]. Além disso, a utilização de operadores de mutação e recombinação equilibra dois objetivos aparentemente conflitantes: o aproveitamento das melhores soluções e a exploração do espaço de busca.

A execução dos AGs pode ser resumida nos seguintes passos:

- Escolha da população inicial: normalmente formada por indivíduos criados aleatoriamente;

- Avaliação da população: através do cálculo do fitness;

- Obtenção da nova geração: aplicando-se sobre os indivíduos selecionados operações de recombinação e mutação; 
- Seleção dos sobreviventes: através da escolha dos indivíduos com melhor fitness;

- Condição de parada: repetição dos passos de obtenção da nova geração e seleção dos sobreviventes até que uma solução aceitável seja encontrada, ou até que o número predeterminado de passos seja atingido, ou, ainda, até que o algoritmo não consiga mais melhorar a solução já encontrada.

\subsubsection{Outros Algoritmos Evolutivos}

Mais recentemente, diversos aspectos complexos em problemas de otimização e aprendizado de máquina têm sido pesquisados na Computação Evolutiva (CE). Esses estudos têm buscado o desenvolvimento de AEs mais eficientes [40] e seus conteúdos serão apenas citados nos tópicos abaixo.

- Programação Genética: técnica de geração automática de programas de computador criada por John Koza [45] e inspirada na teoria de AG. Em Programação Genética (PG) é possível criar e manipular software geneticamente, aplicando conceitos herdados da Biologia para gerar programas de computador automaticamente;

- Micro-AG: variações de AGs desenvolvidas para evoluir eficientemente soluções utilizando populações com poucos indivíduos. O primeiro trabalho envolvendo micro-AGs foi proposto por [46] e atualmente possui importância especial em projetos onde a disponibilidade de recursos computacionais é limitada;

- Algoritmos de Estimação da Distribuição: técnicas de aprendizagem automatizada de correlações entre as variáveis codificadas na solução do problema, gerando um ajuste no modelo de probabilidade dos indivíduos e tornando desnecessária a especificação de determinados parâmetros dos AEs Canônicos (como a taxa de mutação e de recombinação). Uma fonte para pesquisa destes algoritmos é encontrada em [47].

\subsubsection{Técnicas de Seleção}

O objetivo da seleção é escolher um ou mais indivíduos para gerar um ou mais descendentes para a próxima população do processo evolutivo. Assim, devido 
à importância desta etapa na composição dos AEs, a escolha da estratégia adotada deve ser realizada com conhecimento das diferentes técnicas existentes. Assim, de uma maneira bastante sucinta, segue a descrição de algumas destas técnicas existentes na literatura:

- Seleção por torneio: um subconjunto da população com $k$ indivíduos é sorteado e os melhores indivíduos desse grupo são selecionados para decidir qual irá reproduzir;

- Seleção em rank: utiliza as posições dos indivíduos, quando ordenados de acordo com o fitness, para determinar a probabilidade de seleção. Podem ser usados mapeamentos lineares ou não lineares para determinar a probabilidade de seleção;

- Seleção Boltzmann: estabelece uma pressão de seleção diferente à cada iteração ou geração do algoritmo genético. Inicialmente, este operador promove a reprodução de indivíduos com fitness baixo, permitindo assim manter a diversidade da população e evitar convergências prematuras, e posteriormente aumenta a pressão para enfatizar os indivíduos com fitness alto.

\subsection{ALGORITMOS EVOLUTIVOS PARA OTIMIZAÇÃO MULTI-OBJETIVO}

\subsubsection{Problemas de otimização Multi-Objetivo}

Conforme [48], um problema de otimização multi-objetivo (MOOP, do inglês Multi-Objective Optimization Problem) possui um conjunto de funções objetivo a serem otimizadas (maximizar ou minimizar). Além disso, possui restrições que devem ser satisfeitas para que uma solução seja factível ao problema. $O$ enunciado geral de um MOOP é o seguinte [9]:

$$
\begin{array}{lll}
\text { Maximizar } / \text { minimizar } f_{m}(x), & m=1,2, \ldots, N_{\text {obj }} ; \\
\text { sujeito a: } & g_{j}(x) \leq 0, & j=1,2, \ldots, N R_{\text {des }} ; \\
& h_{k}(x)=0, & k=1,2, \ldots, N R_{\text {igu }} ; \\
& x_{i}^{(\text {inf })} \leq x_{i} \leq x_{i}^{(\text {sup })} & i=1,2, \ldots, N_{\text {var. }}
\end{array}
$$

Neste enunciado são encontradas as seguintes representações: 
$\checkmark \quad x$ é um vetor de $N_{\text {var }}$ variáveis de decisão, também denominado de solução;

$\checkmark$ os valores $x_{i}^{(i n f)}$ e $x_{i}^{\text {(sup) }}$ representam os limites inferior e superior da variável $x_{i}$ respectivamente. Esses limites definem o espaço de variáveis de decisão ou espaço de decisão $S_{\text {dec; }}$;

$\checkmark$ as $N$ Rdes desigualdades $(g j)$ e as $N R_{\text {igu }}$ igualdades ( $h k$ ) são chamadas de função de restrição. Uma solução $x$ factível satisfaz as $N R_{\text {igu }}+N R_{\text {des }}$ funções de restrição e os $2 N_{\text {var }}$ limites. Caso contrário, a solução não será factível;

$\checkmark$ O conjunto de todas as soluções factíveis formam a região factível ou espaço de busca $S_{\text {fact }}$.

Cada função $f_{m}(x)$ pode ser maximizada ou minimizada. Porém, para trabalhar com os algoritmos de otimização, é necessário converter todas as funções para serem apenas de maximização ou minimização. O vetor de funções objetivo $f(x)=\left[f 1(x), f 2(x), \ldots, f_{\text {Nobj }}(x)\right]$ compõe um espaço multidimensional chamado espaço de objetivos $S_{o b j}$. Para cada solução $x$ no espaço de decisão, existe um $f(x)$ em $S_{o b j}$. Esta é uma diferença fundamental em relação à otimização de objetivos simples, cujo espaço de objetivos é unidimensional. $O$ mapeamento ocorre então entre um vetor $x$ (de dimensão $N_{\text {var }}$ e um vetor $f(x)$ (de dimensão $N_{o b j}$ ). Por exemplo, se cada elemento de $x$ e $f(x)$ são números reais, então $f(x)$ estaria mapeada como $f(x): \Re^{N_{v a r} \rightarrow \Re^{N_{0 b j}}}$ [48].

\subsubsection{Solução Pareto-Ótimas}

Via de regra as funções objetivo empregadas nos MOOPs são conflitantes entre si. Estas funções são consideradas conflitantes quando não é possível melhorar o valor de $f_{1}$ sem piorar o valor da função $f_{2}$. Em [48] encontramos um exemplo prático de objetivos conflitantes: preço e desempenho na compra de computadores. Nesse exemplo se verifica que os equipamentos de maior custo apresentam, usualmente, um melhor desempenho e vice-versa. Assim, em uma compra devem ser considerados vários modelos de computadores com diversos valores nos objetivos de preço e desempenho. Se ambos os objetivos possuem a mesma importância (ou prioridade), não há como afirmar, por exemplo, que certa redução do preço compensa determinada perda do desempenho.

Em um MOOP, emprega-se o conceito de Dominância de Pareto para comparar duas soluções factíveis de um problema. Dadas duas soluções $x$ e $y$, diz- 
se que $x$ domina $y$ (denotado como $x \preceq y$ ) se as seguintes condições forem satisfeitas simultaneamente:

1. A solução $x$ é pelo menos igual a y em todas as funções objetivo;

2. A solução x é melhor que a y em pelo menos uma função objetivo.

Porém, existe um conjunto de soluções que não se enquadra neste conceito, ou seja, que possuem vantagens em desempenho, mas que não são melhores em custo e vice-versa. Resumindo, existe um conjunto de alternativas ótimas que são não dominadas entre si nos objetivos de custo e desempenho. Em um MOOP, o conjunto de soluções não dominadas é chamado de conjunto Pareto ótimo, que representa as soluções ótimas do problema. A fronteira de Pareto é o conjunto dos valores das funções objetivo das soluções do conjunto Pareto-ótimo.

A Figura 20 ilustra o exemplo supracitado. Nela os valores de desempenho são atribuídos em uma escala de 0 a 100 enquanto os de preço em uma escala de 0 a 10.000 (para as cinco alternativas do exemplo de compra de computadores). Por fim, ficam evidenciadas as relações de dominância entre as soluções, o conjunto Pareto-Ótimo e a fronteira de Pareto descritas abaixo:

$\checkmark$ Relação de dominância: $3 \preceq 2,5 \preceq 1,5 \preceq 2$;

$\checkmark$ Conjunto Pareto-ótimo: $\{3,4,5\}$;

$\checkmark$ Fronteira de Pareto: indicada na Figura 20.

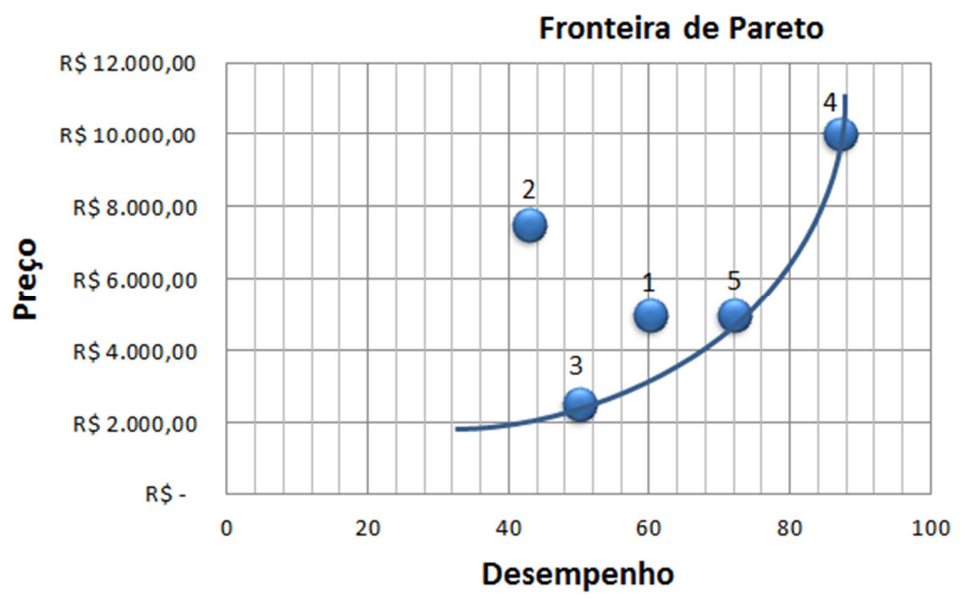

Figura 20. Exemplo de fronteira de Pareto 


\subsubsection{Dominância de Pareto: Definição e Propriedades}

Definição 1: Uma solução $x$ domina uma solução $y(x \preceq y)$ se as seguintes condições são satisfeitas:

1. A solução $x$ não é pior que $y$ em nenhum dos $N_{o b j}$, ou seja, $f_{m}(x) \leq f_{m}(y)$ para todo $m=1,2, \ldots, N_{o b j}$;

2. A solução $x$ é estritamente melhor que $y$ pelo menos em um objetivo, ou seja, $f_{m}(x)<f_{m}(y)$ pelo menos para um valor de $\mathrm{m}$.

Na Figura 20 temos que a solução 5 domina a solução $1(5 \preceq 1)$, e a solução 3 domina a solução 2 ( $3 \preceq 2)$.

A relação de dominância satisfaz as seguintes propriedades:

1. Não é reflexiva. Conforme a definição 1 , uma solução não pode ser dominada por si mesma;

2. Não é simétrica, ou seja, $x \preceq y$ não implica que $y \preceq x$;

3. É transitiva, isto é, se $x \preceq y$ e $y \prec z$ então $x \preceq z$.

Definição 2: Dado um conjunto de soluções $P$, o conjunto de soluções nãodominados $\mathrm{P}^{\prime}$ é formado por:

$$
P^{\prime}=\{x \in P \mid \nexists y \in P: y \prec x\}
$$

Quando um conjunto de soluções $P$ corresponde ao conjunto de soluções factíveis de um MOOP $\left(P=S_{\text {fact }}\right.$, o conjunto não-dominado $P^{\prime}$ é chamado de conjunto Pareto-ótimo.

Definição 3: Dado um conjunto de soluções $P$ e $\in$, um número positivo arbitrariamente pequeno, o conjunto Pareto-ótimo local $P$ " é formado por:

$$
P^{\prime \prime}=\left\{x \in P \mid \nexists y \in P: y \prec x \wedge\|y-x\|_{\infty} \leq \in\right\} .
$$


A Figura 21 ilustra dois conjuntos Pareto-ótimos que são não-dominados localmente, mostrando a sua vizinhança no seu espaço de objetivos e no espaço de variáveis.

Finalmente, a fronteira de Pareto de um MOOP pode ser definida:

Definição 4: Dado um MOOP com $f_{m}, m=1,2, \ldots, N_{o b j}$ funções objetivo, e cujo conjunto Pareto-ótimo é $P^{\prime}$, a fronteira de Pareto é formada por:

$$
\text { Fronteira de Pareto }(P F)=\left\{f(x) \mid \mathrm{x} \in \mathrm{P}^{\prime}\right\}
$$

em que $f(x)=\left[f_{1}(x), f_{2}(x), \ldots, f_{\text {Nobj }}(x)\right]$ é o vetor de funções objetivo para solução $x$.

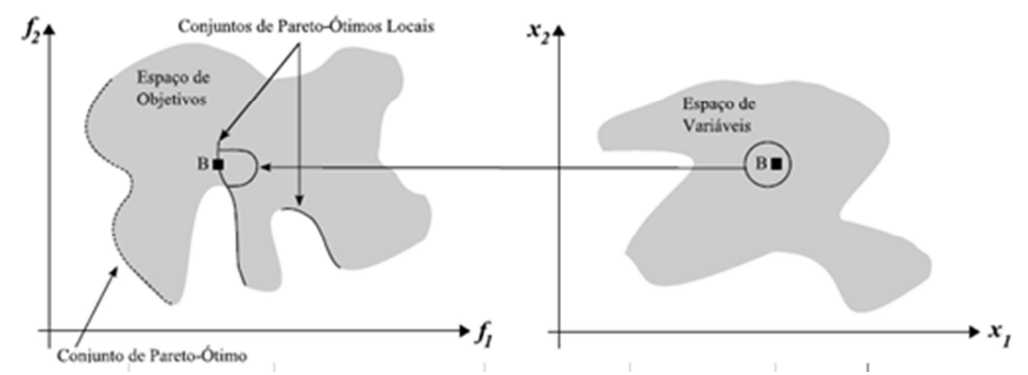

Figura 21. Soluções de Pareto-ótimas locais e globais (fonte: [48])

\subsubsection{Metas em otimização Multi-Objetivo}

Em [48] são destacadas três importantes metas em otimização multiobjetivo:

1. Encontrar um conjunto de soluções que esteja o mais próximo possível da fronteira de Pareto;

2. Encontrar um conjunto de soluções com a maior diversidade possível;

3. Realizar as duas metas anteriores com a maior eficiência computacional possível.

Encontrar um conjunto de soluções próximas da fronteira de Pareto é possível através da busca da maior diversidade dentro do conjunto de soluções (sendo esta a meta específica para otimização multi-objetivo). Assim, tornam-se indesejáveis as soluções distantes da fronteira de Pareto. 
A Figura 22.a ilustra uma distribuição quase uniforme das soluções na fronteira de Pareto, já a Figura 22.b apresenta a fronteira com apenas algumas soluções. É importante destacar que como em MOOP se trabalha com espaço de decisões e espaço de objetivos, é desejável que as soluções estejam adequadamente distribuídas em ambos os espaços e que, na medida do possível (considerando o esforço computacional necessário), haja uma maior cobertura da fronteira de Pareto.

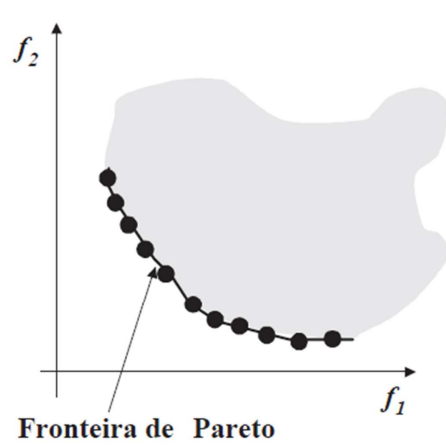

a

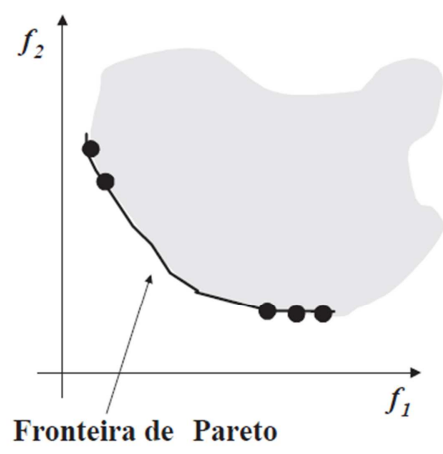

$b$

Figura 22. Diferentes distribuições de soluções na fronteira de Pareto (fonte: [48])

\subsubsection{Diferenças entre Otimização Multi-Objetivo e Mono-Objetivo}

Em [9] são identificados três importantes aspectos diferenciando a otimização multi-objetivo da mono-objetivo. São eles:

1. Em problemas de otimização mono-objetivo, a meta é encontrar uma solução ótima global. Se a função objetivo desses problemas for multimodal, poderia existir mais de um ótimo global. Neste caso, todos os ótimos são equivalentes. Por outro lado, em MOOP, determinar um conjunto de soluções da fronteira de Pareto é tão importante quanto preservar a diversidade neste conjunto. Um algoritmo eficiente para otimização multi-objetivo deve considerar ambos os aspectos;

2. Um MOOP trabalha com dois espaços, das variáveis e dos objetivos. Por outro lado, problemas de objetivo simples trabalham unicamente no espaço de variáveis, pois procuram apenas uma solução no espaço de objetivos. Manter a diversidade em ambos espaços complica mais o problema, dado que a proximidade de duas soluções no espaço de variáveis não implica proximidade no espaço de objetivos; 
3. As metodologias tradicionais de otimização multi-objetivo reduzem o conjunto de funções objetivo a uma função simples que pondera cada objetivo. Estas metodologias podem também tratar cada objetivo separadamente, utilizando os demais objetivos como restrições. Portanto, um MOOP pode ser convertido, por meio de algumas técnicas, em um problema de otimização simples.

\subsection{ALGORITMOS EVOLUTIVOS BASE DO AEMT-H}

Nesta seção são apresentados detalhadamente os AEMOs em Tabelas e NSGAII. Esta apresentação ocorre tendo em vista o AEMT-H utilizar AEMOs em sua base evolutiva.

\subsubsection{Algoritmo Evolutivo Multi-objetivo em Tabela}

O AEMO em Tabelas trabalha com várias subpopulações em paralelo armazenadas em tabela [19, 20], onde os melhores indivíduos para cada característica do problema são armazenados em sua respectiva subpopulação (cada subpopulação é representada por uma tabela). Conforme apresentado na seção 1.1, cada subpopulação armazena indivíduos de modo a otimizar (maximizar ou minimizar) as características selecionadas. Os novos indivíduos são gerados a partir de qualquer indivíduo de qualquer tabela através da aplicação dos operadores genéticos.

Para exemplificar, considere um problema com 3 objetivos (chamados de 01, 02 e 03) e com uma população total de 20 indivíduos (identificados de 11 a 120 respectivamente). Como parâmetro determinado, o AEMO em Tabelas deste exemplo irá armazenar 4 indivíduos por tabela. Ao analisar a aptidão (ou fitness) de cada um desses indivíduos para cada uma das funções objetivo, identifica-se que os 4 melhores indivíduos para o objetivo 01 são os indivíduos (11, 14, 19 e 120), que serão armazenados na tabela 01 . Neste mesmo contexto serão armazenados os indivíduos (15, 110, I14 e I20) na tabela O2 e (11, 14, 116 e I17) na tabela O3. Note que um mesmo indivíduo pode pertencer a mais de uma tabela. Seguem as tabelas citadas no exemplo e os respectivos indivíduos. 
Tabela 2. Tabelas e indivíduos de um exemplo de AEMT

\begin{tabular}{|c|c|c|}
\hline $\begin{array}{c}\text { Tabela do Objetivo } \\
\text { O1 }\end{array}$ & $\begin{array}{c}\text { Tabela do Objetivo } \\
\text { O2 }\end{array}$ & $\begin{array}{c}\text { Tabela do Objetivo } \\
\text { O3 }\end{array}$ \\
\hline 11 & 15 & 11 \\
\hline 14 & 110 & 14 \\
\hline 19 & 114 & 116 \\
\hline 120 & 120 & 117 \\
\hline
\end{tabular}

O indivíduo selecionado para a reprodução pode ser proveniente de qualquer subpopulação da tabela. Essa estratégia de seleção aumenta a diversidade entre os indivíduos que se reproduzem, pois, as características de um indivíduo de uma subpopulação podem migrar para as demais subpopulações. Em consequência, aumenta-se a possibilidade do algoritmo escapar de ótimos locais, aproximando-se de soluções com avaliações próximas de um ótimo global na fronteira de Pareto-ótima (ver Seção 5.1.1). Conforme [32], alguns parâmetros são importantes para o desempenho dos AEMTs:

1. O tamanho de uma subpopulação $S_{P i}$, que indica o número máximo de indivíduos que podem permanecer na subpopulação $P i$ de uma geração para outra;

2. O número máximo de gerações $\left(g_{\max }\right)$.

Conforme ilustrado no exemplo supracitado, as soluções geradas pelo AEMO em Tabelas podem ser armazenadas ou descartadas, dependendo do grau de adaptação do indivíduo a cada objetivo do problema (característica do problema em uma subpopulação $P I$ ). Assim, para ilustrar tal afirmação, o exemplo apresentado nesta seção terá, pelo processo de reprodução, uma nova geração criada contendo 10 novos indivíduos (denotados por 121 a 130). Para verificar se estes indivíduos serão armazenados em alguma das tabelas, calcular-se-á a aptidão de cada novo indivíduo para cada objetivo supracitado. Assim, no exemplo apresentado, os indivíduos 121 e 122 possuirão aptidão superior aos indivíduos 19 e 120 para 0 objetivo O1. A nova tabela O1será composta pelos indivíduos (11, 14, 121 e 122). Ainda neste exemplo, calcular-se-á a aptidão dos novos indivíduos para os objetivos O2 e 03 e se comparará estes valores com os valores dos indivíduos presentes nas tabelas 02 e 03 . A nova tabela $O 2$ ficará com os indivíduos $(15,110,120$ e 122) e a tabela 03 com os indivíduos (/1, 14, 116 e /17). 
Tabela 3. Tabelas e indivíduos de um exemplo de AEMT após reprodução

\begin{tabular}{|c|c|c|}
\hline $\begin{array}{c}\text { Tabela do Objetivo } \\
\text { O1 }\end{array}$ & $\begin{array}{c}\text { Tabela do Objetivo } \\
\text { O2 }\end{array}$ & $\begin{array}{c}\text { Tabela do Objetivo } \\
\text { O3 }\end{array}$ \\
\hline 11 & 15 & 11 \\
\hline 14 & 110 & 14 \\
\hline 121 & 120 & 116 \\
\hline 122 & 122 & 117 \\
\hline
\end{tabular}

Importante destacar que o mesmo indivíduo pode ser incluído em mais de uma tabela de acordo com esse critério de seleção. Como o tamanho da população é estacionário, os novos indivíduos substituem os piores. Nesse caso, a adequação do indivíduo é um vetor de seus valores relativos a cada objetivo.

\subsubsection{NSGAll: "Elitist Non-Dominanted Sorting Genetic Algorithm"}

Proposto em [57], o algoritmo "Elitist Non-Dominanted Sorting Genetic Algorithm" (NSGA-II) baseia-se na ordenação elitista por dominância chamada de "Pareto Ranking". Esse procedimento consiste em classificar as soluções de um conjunto $M$ em diversas fronteiras $\left(F_{1}, F_{2}, \ldots, F_{k}\right.$, onde $k$ é o número de fronteiras) conforme o grau de dominância de cada solução. Deste modo, a fronteira $F_{1}$ contém as soluções não dominadas de todo o conjunto de soluções $M, F_{2}$ contém as soluções não dominadas de $M-F_{1}, F_{3}$ contém as soluções não dominadas de $M-\left(F_{1} \cup F_{2}\right)$ e assim sucessivamente. O procedimento de ordenação por não dominância proposto em [57]é descrito no Algoritmo 3. Para cada solução $i$, contida em $P$, são calculados dois valores:

$\checkmark$ ndi, o número de soluções que dominam a solução i;

$\checkmark$ Ui, o conjunto de soluções que são dominadas pela solução $i$.

As linhas 1-15 do Algoritmo 3 calculam tais valores para as soluções em $M$. Além disso, as soluções com $n d_{i}=0$ estão contidas na fronteira $F_{1}$. Em seguida, as linhas 17-29 percorrem o conjunto de soluções dominadas $U_{i}$, para cada solução $i$ em $F_{1}$. O contador $n d_{j}$, de cada solução $j$ em $U_{i}$, é decrementado em 1 . Se $n d_{j}=0$, então a solução $j$ pertence à próxima fronteira, neste caso, $F_{2}$. A iteração das linhas 17-29 é repetida até que todas as soluções estejam classificadas em uma fronteira. A Figura 23 ilustra este procedimento aplicado às soluções que minimizam $f_{1}$ e $f_{2}$. 


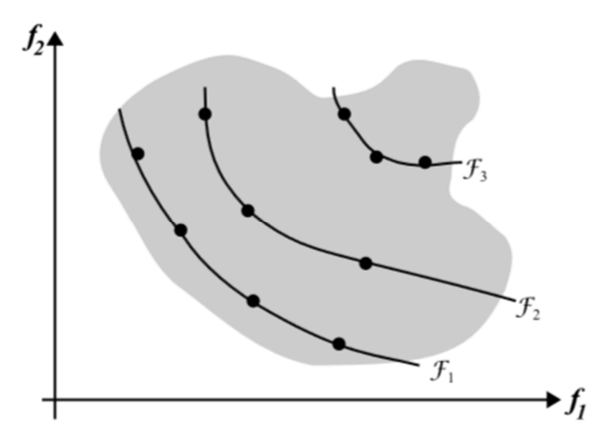

Figura 23. Ordenação por não-dominância (fonte: [57])

O algoritmo NSGA-II trabalha com duas populações, denotadas por $P$ e $Q$, ambas de tamanho $N_{\text {ind }}$. As populações $P$ e $Q$ em cada iteração $t=1,2, \ldots, N_{\text {iter }}$ são denotadas por $P_{t}$ e $Q_{t}$, respectivamente. Na primeira geração, os indivíduos iniciais da população $P_{1}$ geram as soluções em $Q_{1}$, através da aplicação dos operadores genéticos. Em seguida, estabelece-se um processo competitivo para preencher $N_{\text {ind }}$ vagas para a solução $P_{t+1}$, entre $2 N_{\text {ind }}$ indivíduos contido em $R_{t}=P_{t} \cup$ $Q_{t}$. Esta operação é realizada utilizando a ordenação por não dominância em $R_{t}$, encaminhando as soluções não dominadas contidas nas fronteiras diretamente para a próxima geração (elitismo).

Para garantir a diversidade na fronteira, o NSGA-II emprega uma estimativa de densidade das soluções que rodeiam cada indivíduo da população. Assim, calcula-se a média da distância das duas soluções adjacentes a cada indivíduo para todos os objetivos. Esse valor é denominado distância de multidão. $\mathrm{O}$ Algoritmo 4 descreve os passos para calcular tal valor, onde crowdist $_{n}$ é o valor da distância de multidão do $n$-ésimo indivíduo do conjunto $M$ (denotado como $M_{n}$ ) e $f_{m}$ $\left(M_{n}\right)$ é o valor da $m$-ésima função objetivo para o $n$-ésimo indivíduo.

O fitness de cada solução $i$ é determinado pelos seguintes valores:

1. rank $_{i}=k$, o valor de ranking $i$ é igual ao número da fronteira $F_{k}$ à qual $i$ pertence;

2. crowdist $i$, o valor de distância de multidão de $i$.

O NSGA-II emprega um processo de seleção por torneio, que é guiado por um novo operador denominado "crowded-comparison operator" $\left(<_{c}\right)$. Em tal abordagem, duas soluções são comparadas para escolher qual delas vai gerar descendentes na nova população. Uma solução $i$ é escolhida sobre uma solução $j$ se:

1. i possui um ranking menor que j, ou seja, ranki<rank $k_{j}$ 
2. ambas as soluções possuem o mesmo ranking e $i$ possui um maior valor de distância de multidão, ou seja, rank $k_{i}=r a n k_{j}$ e corwdist crowdist $_{j}$.

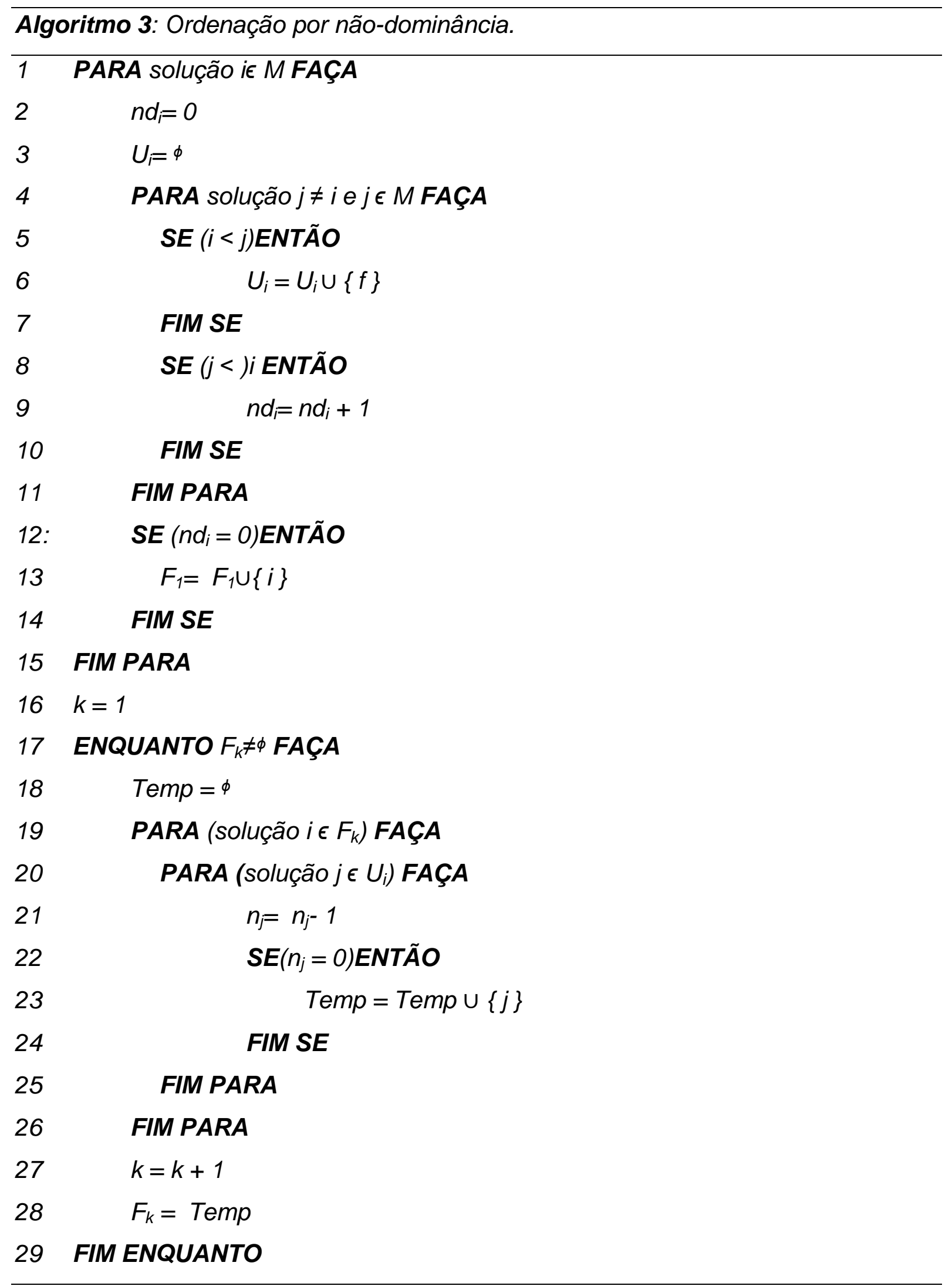




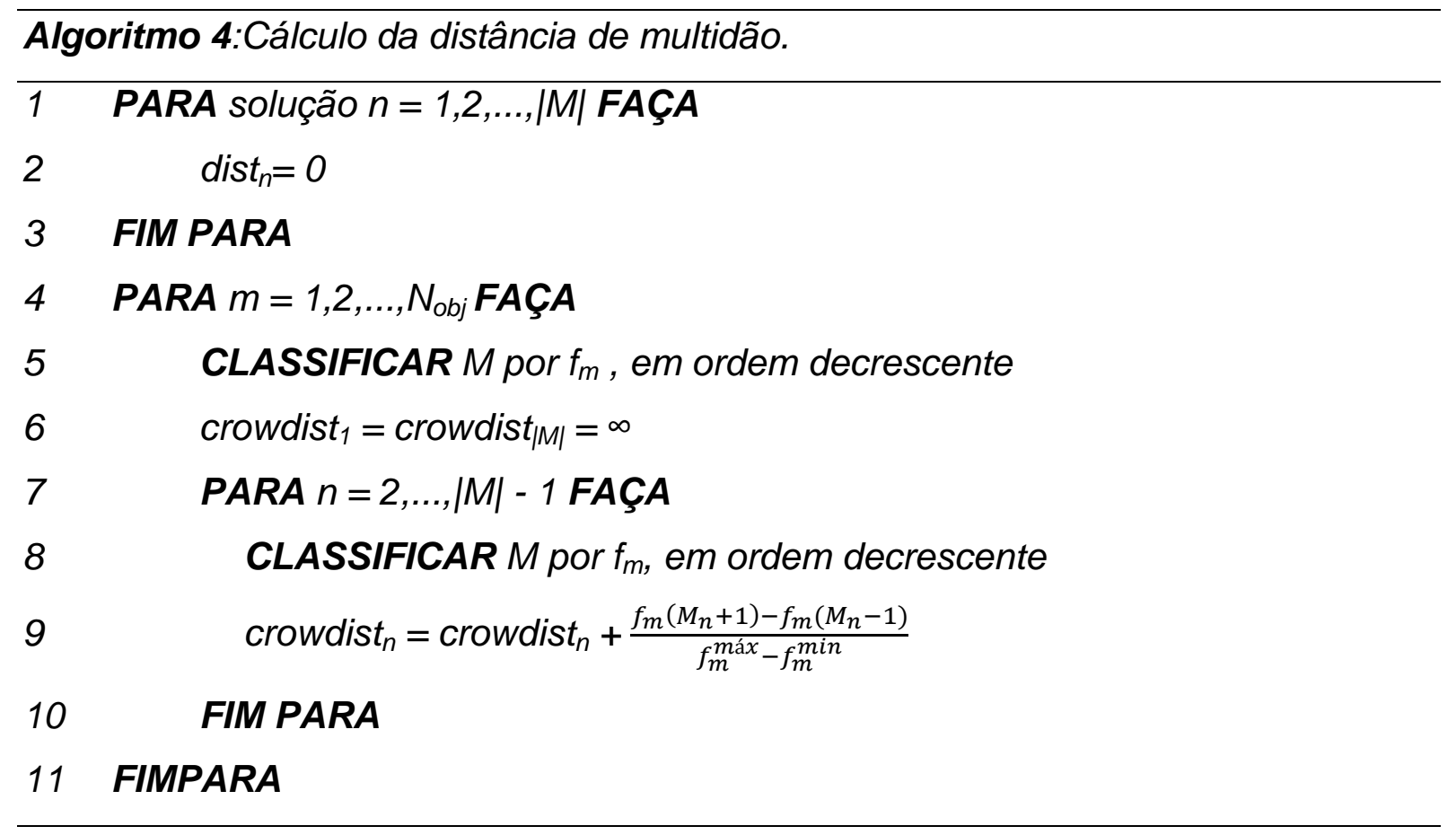

O cálculo da distância de multidão permite que as soluções melhores espalhadas passem a ocupar as últimas vagas disponíveis de $P_{t+1}$, garantindo a diversidade das soluções. A população $Q_{t+1}$ é gerada utilizando os operadores de seleção por torneio, recombinação e mutação em $P_{t+1}$. O NSGA-II continua por $N_{\text {iter }}$ iterações e as soluções finais se encontram em $P_{\text {Niter }} \cup Q_{\text {Niter }}$. A sequência de passos do NSGA-Il é descrita no Algoritmo 5. A Figura 24 ilustra o esquema para uma iteração do NSGA-II.

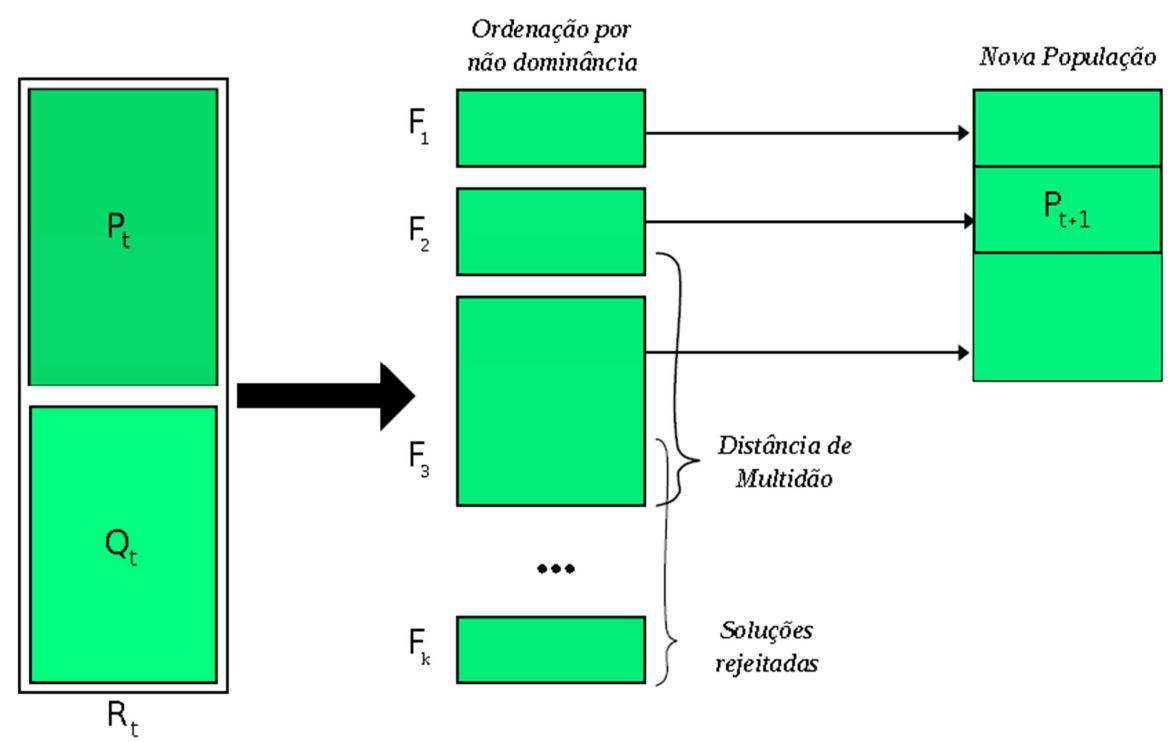

Figura 24. Esquema para uma iteração do NSGA-II (fonte: [57]) 


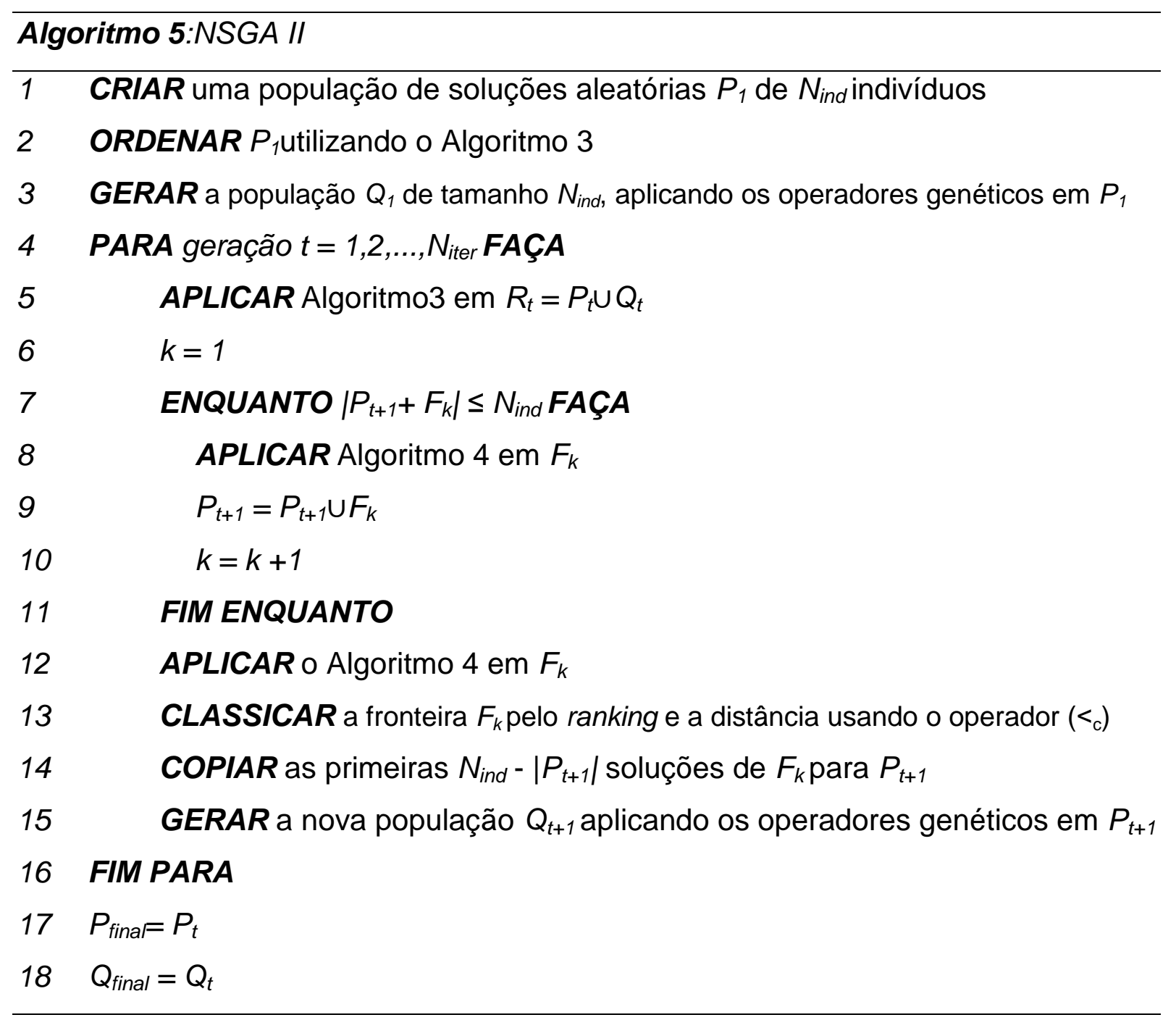




\section{METODOLOGIA PARA RESTABELECIMENTO DE ENERGIA EM SISTEMAS DE DISTRIBUIÇÃO BASEADA NA RNP E EM AEMO}

Conforme apresentado no capítulo 1 , a validação da metodologia proposta em [72] ocorrerá através da aplicação do aplicativo computacional do AEMT-H no sistema de distribuição da COPEL na cidade de Londrina. Lembrando que a metodologia em questão possibilita a obtenção de PREs de forma eficiente computacionalmente, mesmo para sistemas de grande porte (com milhares de barras, linhas e chaves), sem simplificações e considerando todos os seus alimentadores e subestações.

Ainda conforme apresentado no capítulo 1 , a eficiência computacional da metodologia proposta em [72] resulta principalmente da aplicação da estrutura de dados RNP e de seus operadores genéticos (PAO e CAO), apresentados no capítulo 2 (ver seção 1.1). Para tratar o problema multi-objetivo de forma mais adequada, essa metodologia trabalha em paralelo com várias subpopulações armazenadas em tabelas (ver seção 3.5.1). Dessa forma, os indivíduos (configurações do sistema) são avaliados para cada característica do problema (número de manobras, perdas resistivas, queda de tensão, carregamento da rede, carregamento da subestação), sendo os melhores em cada característica armazenados em suas respectivas subpopulações. Assim, para compreender a forma com que a avaliação dos indivíduos ocorre, ou seja, a forma com que o AEMT-H realiza o cálculo do número de manobras e das perdas, queda de tensão e carregamentos, as seções 4.1 e 4.2 apresentarão as rotinas computacionais responsáveis pelo cálculo do número de manobras e também do fluxo de carga no algoritmo. Segue a disposição das seções deste capítulo.

$\rightarrow$ Seção 4.1: apresentação de métodos de fluxo de carga utilizando a RNP;

$\rightarrow$ Seção 4.2: apresentação do processo para cálculo eficiente do número de manobras com alta performance computacional;

$\rightarrow$ Seção 4.3: detalhamento das tabelas e parâmetros utilizados no AEMT-H.

\subsection{FLUXO DE CARGA}

Conforme [67], entende-se por estudo de fluxo de carga a resolução do circuito elétrico que representa a rede, para o qual se dispõe da topologia, com as 
constantes elétricas de seus elementos (resistência, reatância, etc), das demandas das cargas e das tensões dos geradores que o excitam. Assim, a finalidade principal do estudo do fluxo de carga, com foco na simulação da operação da rede, pode ser descrita nos seguintes tópicos:

$\checkmark$ Cálculo das tensões nas diversas barras do sistema, certificando-se de que estes níveis de tensão se encontrem dentro dos limites tolerados pela reguladora;

$\checkmark$ Cálculo da corrente e potência fluindo pelos diversos trechos da rede, certificando-se de que estes parâmetros não excedam os limites de carregamento dos condutores de energia e demais elementos do sistema.

São encontradas ainda outras finalidades no estudo do fluxo de carga, finalidades estas cuja representatividade tem aumentado à medida que seus estudos vão evoluindo e que a tecnologia presente nos sistemas elétricos aumenta. Entre estas finalidades complementares, pode-se citar:

$\checkmark$ Cálculo das perdas, em termos de potência e energia, que podem ser minimizadas a partir da reconfiguração do sistema elétrico alcançando uma condição operativa de melhor desempenho técnico e econômico;

$\checkmark$ Determinação dos desequilíbrios de tensão e corrente em redes assimétricas, permitindo uma redistribuição das cargas no sistema melhorando os níveis técnicos do mesmo.

Métodos convencionais de fluxo de potência para sistemas de transmissão como Newton-Raphson, Newton-Raphson Desacoplado Rápido e seus derivados, em geral não são adequados para resolução de fluxo de carga em sistemas de distribuição [68]. Esta afirmação é baseada na necessidade de fatoração das matrizes do sistema de distribuição que em geral são mal condicionadas e de grande dimensão. Segue o resumo do significado destas características das matrizes dos sistemas de distribuição de energia.

- Mal condicionadas: devido à alta relação entre a resistência e a reatância $(\mathrm{R} / \mathrm{X})$, alto número de cargas distribuídas e a partes de redes com alta impedância associadas a trechos de baixa impedância;

- Grande dimensão: devido à grande quantidade de barras, sendo necessária utilização de matrizes com milhares de linhas e colunas. 
Nas ultimas décadas, com a automatização dos sistemas de distribuição, muitas aplicações têm requerido métodos de fluxo de potência eficientes e robustos. Surgiram então, métodos específicos para sistemas de distribuição que exploram sua natureza radial. Estes métodos têm apresentado desempenho melhor que os métodos convencionais (em termos de tempo de processamento, esforço computacional, convergência, etc.). Devido à robustez e simplicidade na implementação, métodos de varredura "direta e inversa" [68] têm obtido a preferência de muitos pesquisadores. Esses métodos exploram uma característica especial dos SDRs: a existência de um único caminho entre qualquer barra da rede e a barra raiz, na subestação.

Assim, a rede é representada por uma árvore orientada, onde a raiz corresponde à subestação, o tronco ao ramal principal e os ramos estão associados aos ramais secundários que partem do tronco. A varredura reversa consiste em, partindo-se dos nós extremos e usando uma estimativa inicial das tensões nodais, calcular as correntes ou fluxos nas linhas até o nó raiz. A partir do resultado da injeção de corrente ou potência do nó raiz, e do valor conhecido da tensão nessa barra, procede-se a varredura direta a qual consiste em recalcular os valores de tensão das barras da rede até os nós extremos. Esse processo é repetido até que os valores de tensão não variem mais que um valor de tolerância pré-estabelecido no decorrer de duas iterações. Existem muitas variações dos métodos de varredura direta e inversa, são elas: método da soma de potência [69], método da soma de corrente [70], método da soma de impedância, entre outros.

A seguir será apresentado o método de soma de potências, sendo detalhado o método utilizado neste projeto nos tópicos subsequentes.

\subsubsection{Método da Soma de Potência}

Nos métodos de varredura direta e inversa existem dois estágios fundamentais:

- Estágio 1 - Varredura Inversa: estágio inicia pelas últimas barras da árvore e termina na barra raiz. No método da Soma de Potência, a potência ativa da iteração $k, P^{(k)}$, e a potência reativa da iteração $k, Q^{(k)}$, são calculadas para todas as barras da rede; 
- Estágio 2 - Varredura Direta: estágio inicia pela barra raiz e termina na barra terminal. Neste passo, a tensão $V^{(k)}$ deve ser atualizada para todas as barras da rede.

Assim, o problema de fluxo de carga de um SDR pode ser resolvido iterativamente a partir do conjunto de duas equações recursivas. Inicialmente, a amplitude e o ângulo da tensão da barra raiz são atribuídos a todas as barras da rede. Em seguida, na varredura inversa, as seguintes equações são utilizadas:

$$
\begin{gathered}
P_{i-1}=P_{i}+r_{i} \frac{P_{i}^{\prime 2}+Q_{i}^{\prime 2}}{V_{i}^{2}}+P_{L i} \\
Q_{i-1}=Q_{i}+x_{i} \frac{P_{i}^{\prime 2}+Q_{i}^{\prime 2}}{V_{i}^{2}}+Q_{L i},
\end{gathered}
$$

em que:

$P_{i}$ é o fluxo de potência ativa no ramo $i$;

$Q_{i}$ e o fluxo de potência reativa no ramo $i$;

$P_{L i}$ é a potência ativa de carga na barra $i$, ou seja, o somatório das potências ativas das barras diretamente conectadas após a barrai;

$Q_{L i}$ é a potência reativa de carga na barra $i$;

$P_{i}^{\prime}=P_{i}+P_{L i} ;$

$Q_{i}^{\prime}=Q_{i}+Q_{L i}$

A Figura 25 detalha as linhas e barras contidas nas equações (3) e (4).

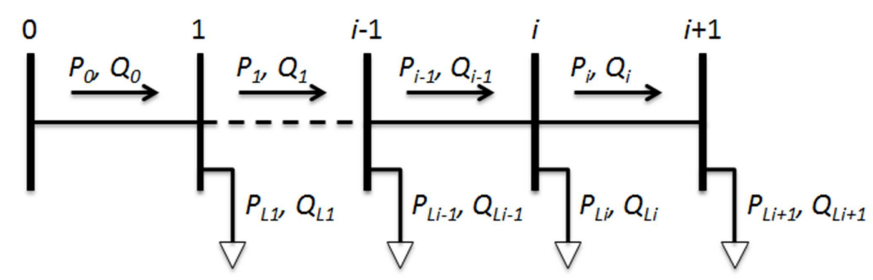

Figura 25. Diagrama unifilar de um circuito alimentador

Na varredura direta, as seguintes equações são utilizadas:

$$
\begin{gathered}
V_{i+1}^{2}=V_{i}^{2}-2\left(r_{i} P_{i}+x_{i} Q_{i}\right)+\left(r_{i}^{2}+x_{i}^{2}\right) \frac{P_{i}^{2}+Q_{i}^{2}}{V_{i}^{2}} \\
\delta_{i+1}=-\tan ^{-1}\left({ }^{k} / k_{2}\right)
\end{gathered}
$$




$$
\begin{gathered}
k_{1}=\frac{\left(P_{i} x_{i}-Q_{i} r_{i}\right)}{V_{i}} \\
k_{2}=V_{i}-\frac{\left(P_{i} r_{i}-Q_{i} x_{i}\right)}{V_{i}} .
\end{gathered}
$$

Se o ângulo da tensão na barra i é $\delta_{i}$ (ao invés de zero), $\delta_{i+1}$ torna-se:

$$
\delta_{i+1}=\delta_{i}-\tan ^{-1}\left(k_{1} / k_{2}\right)
$$

em que:

$V_{i}$ é a amplitude da tensão na barra $i$;

$\delta_{i}$ é o ângulo de tensão na barra $i$;

$r_{i}$ é a resistência série do ramo $i$;

$x_{i}$ é a reatância série do ramo $i$.

Computacionalmente o problema de fluxo de carga pelo método de Soma de Potência pode ser dividido em 04 (quatro) passos [32]:

1. Considerações Iniciais: Leia os dados do sistema. Construa árvores armazenando as barras de rede na estrutura de dados ordenados com uma relação MPF. Assuma a tensão inicial para todas as barras sendo a mesma da barra raiz (barra da subestação);

2. Somatório de Potência: Pelo estágio inverso, calcule o fluxo de potência ativo e reativo em cada ramo da árvore pelas equações (3) e (4), respectivamente;

3. Cálculo da Tensão: Pelo estágio direto, calcule a tensão complexa na barra final de cada ramo usando as equações (5), (6) ou (9);

4. Verificação da Tolerância: Encontre as diferenças de tensão entre a iteração atual e a ultima iteração para todas as barras (amplitude e ângulo separadamente). Se todas as diferenças são menores que uma tolerância especificada, pare o processo. Caso contrário, vá para o passo 2.

\subsubsection{Fluxo de Carga a partir da RNP}

Conforme já apresentado anteriormente, "setores" são conjuntos de barras e linhas não separadas por chaves. Vale destacar que em muitos trabalhos, as barras de carga de um setor são modeladas como se estivessem concentradas em um único ponto. Tal procedimento reduz o grau de assertividade das 
informações calculadas, podendo comprometer a confiabilidade das soluções obtidas.

Assim, de maneira equivalente à abordada em [32], o presente trabalho não realiza simplificações no SDR. Assim, para que a o aplicativo possua uma eficiência computacional serão utilizados dois tipos diferentes de RNPs: a RNP do alimentador e a RNP do setor. Para apresentação destes dois tipos de RNPs, será utilizado o sistema ilustrado na Figura 26. As barras em preto pertencem ao Alimentador $1 \mathrm{e}$ as barras em vermelho pertencem ao Alimentador 2. As linhas cheias representam as chaves NF, as linhas tracejadas são chaves NA e os círculos são setores.

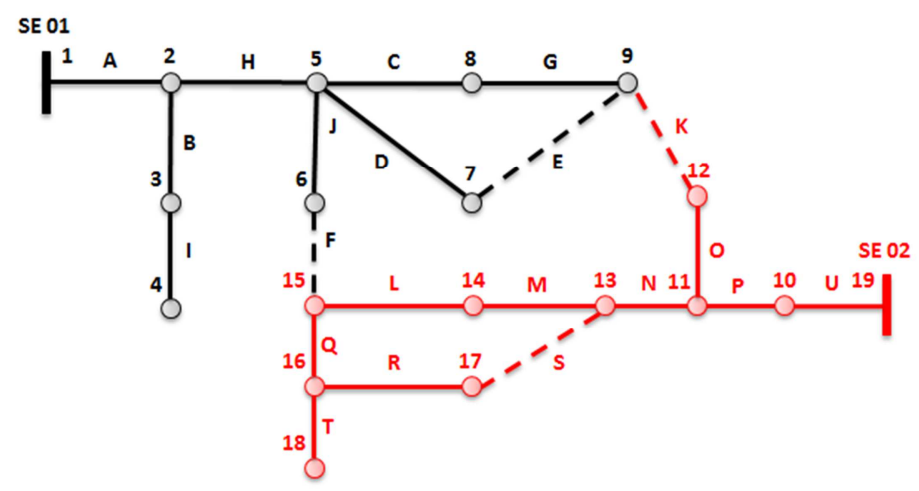

Figura 26. Exemplo de SRD com 02 (dois) alimentadores

Assim, temos uma estrutura $T_{1}$ que armazena o endereço de memória da RNP do "Alimentador 1" e a estrutura $T_{2}$ que armazena o endereço de memória da RNP do "Alimentador 2", conforme apresentado a seguir. Estas RNPs são denominadas de RNPs do Alimentador.

$$
\begin{gathered}
\mathrm{T}_{1}=\left[\begin{array}{c}
\text { nó } \\
\text { profundidade }
\end{array}\right]=\left[\begin{array}{lllllllll}
1 & 2 & 3 & 4 & 5 & 6 & 7 & 8 & 9 \\
0 & 1 & 2 & 3 & 2 & 3 & 3 & 3 & 4
\end{array}\right] \\
\mathrm{T}_{2}=\left[\begin{array}{c}
\text { nó } \\
\text { profundidade }
\end{array}\right]=\left[\begin{array}{cccccccccc}
19 & 10 & 11 & 12 & 13 & 14 & 15 & 16 & 17 & 18 \\
0 & 1 & 2 & 3 & 3 & 4 & 5 & 6 & 7 & 7
\end{array}\right] .
\end{gathered}
$$

A partir da Figura 27 é possível detalhar os elementos presentes no setor em análise (no caso da referida figura, o setor 7). Estes elementos serão detalhados no capítulo 5 , porém, para compreensão da figura cabe destacar que os quadrados preenchidos em vermelho simbolizam as chaves NF, os em verde as chaves NA, os pontos representam as barras e o triângulo o posto transformador. Pela figura é 
possível também observar todas as barras conectadas ao setor 7 que, dependendo da configuração em operação, podem estar fornecendo energia para esse setor. Por exemplo, para o caso da configuração apresentada na Figura 26, a energia está fluindo do setor 5 para o setor 7 (neste caso a barra fonte de energia para o setor 7 será a barra 5.6).

Assim, a RNP do setor pode ser representada computacionalmente de forma semelhante à RNP do alimentador, onde as árvores foram armazenadas em estruturas denotadas por $T_{i}$. Para RNP do setor, denotar-se-á por $B_{S R}$, onde $S$ representa o setor em análise e $R$ se refere ao setor pelo qual a energia chega ao setor $s$, ou seja, o setor pai. Para um mesmo setor pode haver mais de uma RNP, conforme pode ser observado nas representações de $B_{75}$ e $B_{79}$ referentes ao setor 7 .

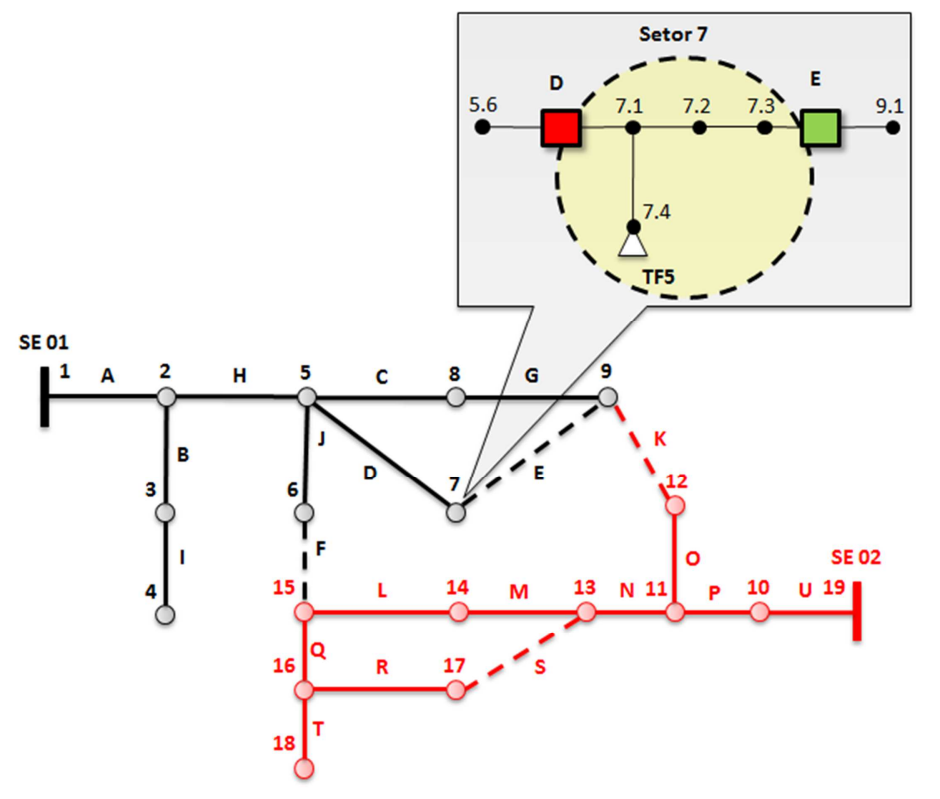

Figura 27. SRD exemplo com destaque para o "Setor 07"

Pela Figura 26 pode-se notar que o caminho de alimentação para o "Setor 07" é através do "Setor 05" e que, portanto, a representação na configuração atual está contida em B75. As estruturas que armazenam as RNPs possíveis para 0 "Setor 07" são as seguintes:

$$
\begin{aligned}
& B_{75}=\left[\begin{array}{c}
\text { nó } \\
\text { profundidade }
\end{array}\right]=\left[\begin{array}{ccccc}
5.6 & 7.1 & 7.4 & 7.2 & 7.3 \\
0 & 1 & 2 & 2 & 3
\end{array}\right] \\
& B_{79}=\left[\begin{array}{c}
\text { nó } \\
\text { profundidade }
\end{array}\right]=\left[\begin{array}{ccccc}
9.1 & 7.3 & 7.2 & 7.1 & 7.4 \\
0 & 1 & 2 & 3 & 4
\end{array}\right] .
\end{aligned}
$$




\subsubsection{Varredura direta e inversa com RNP}

Devido às características específicas dos SDRs utilizadas neste projeto (rede puramente radial e com as barras armazenadas na RNP segundo o MPF) e à necessidade de encontrar configurações adequadas em curto tempo de processamento, para o cálculo do fluxo de carga o aplicativo computacional avaliado faz uso método de soma de correntes (utilizando a varredura direta e inversa) representando as cargas através do modelo de corrente constante (método apresentado em [67]). No aplicativo computacional avaliado a convergência do método de soma de correntes ocorre após a primeira iteração. Esta simplificação é apresentada em [1] e resultou da análise de diversas simulações onde a variação do resultado foi consideravelmente pequena quando se comparada a resposta do fluxo para apenas 1 iteração com a resposta do mesmo para o caso da convergência "tradicional" (onde se parametriza um valor de erro a ser considerada entre as iterações).

No modelo de corrente constante, as linhas são representadas através de uma impedância $Z_{m n}$, para cada linha entre as barras $m$ e $n$. $O$ cálculo das tensões nas barras é realizado através da diferença de tensão da barra anterior e a queda de tensão no trecho entre a barra anterior e a barra atual $(V(m)-\Delta V)$.

O algoritmo para cálculo de fluxo de carga finaliza seu ciclo após a realização de duas sub-rotinas: uma obtém as correntes à jusante por meio de inversa, para todas as barras de um alimentador (CORRENTES, ver Algoritmo 6) e a outra utiliza as correntes à jusante para obter as tensões nas barras do mesmo alimentador, utilizando a varredura direta (TENSÕES, ver Algoritmo 7) [32].

Conforme descrito anteriormente, a sub-rotina "CORRENTES" utiliza a varredura inversa, ou seja, realiza seu caminho partindo das barras terminais do sistema até a barra raiz da subestação. Vale destacar ainda que a RNP já impõe esta ordem de maneira natural aos seus elementos (ver seção 1.1). A carga de uma barra $m$ é denominada $I_{m}$ e a corrente à jusante dessa barra $m$ é denominada $J_{m}$. 


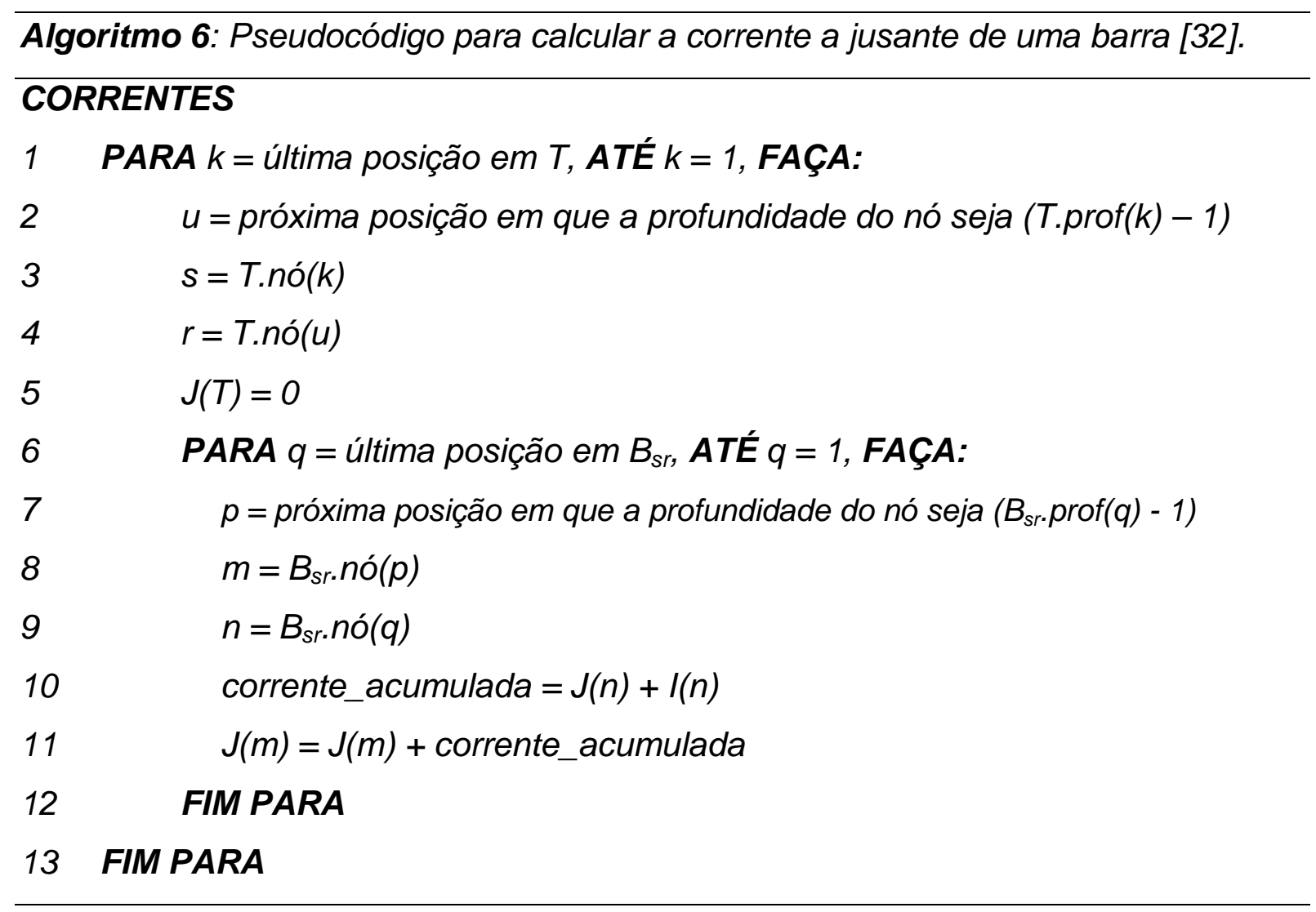

Note que a linha 5 da sub-rotina CORRENTES atribui zero à variável $J(T)$, com isso a corrente a jusante em todas as barras em $T$ recebem zero.

A rotina TENSÕES é apresentada no Algoritmo 7. Novamente a ordem em que os nós serão visitados está pré-determinada nas RNPs do alimentador e do setor. As tensões serão obtidas partindo da barra raiz em direção às barras terminais. $O$ algoritmo TENSÕES necessita que as correntes à jusante de cada barra tenham sido obtidas previamente pela rotina CORRENTES. Assim, para se obter as tensões em cada barra é necessária a corrente na barra $I_{n}$, a tensão à montante da barra $n\left(V_{m}\right)$ e a impedância $Z_{m n}$ entre as barras $m$ e $n$.

Na rotina TENSÕES, a variável $V_{\text {sub }}$ representa a tensão na barra da subestação e a variável $\Delta V$ a queda de tensão na rede entre as barras $m$ e $n$. 


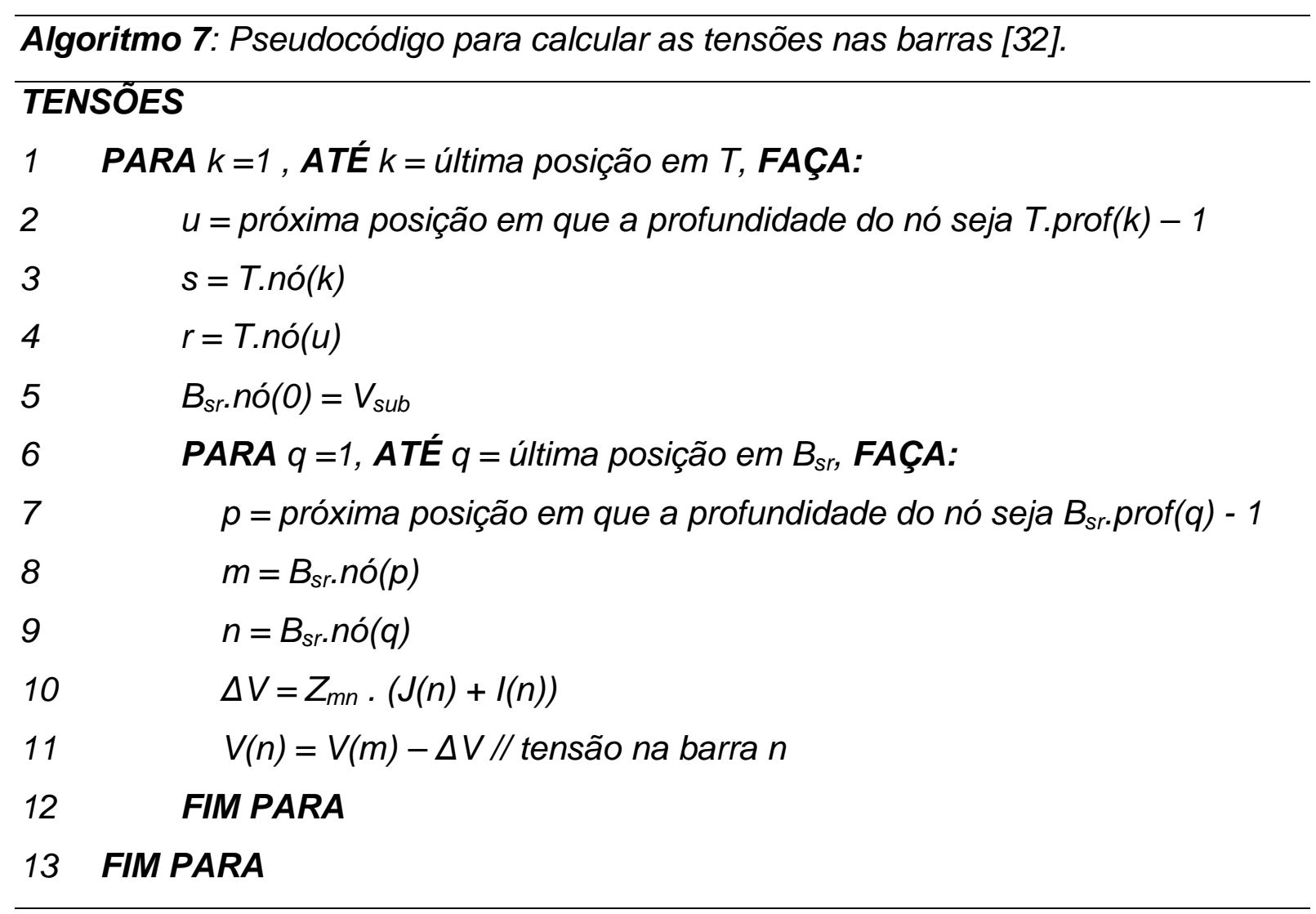

Por fim, o Algoritmo 8 apresenta a rotina principal do fluxo de carga utilizando a RNP. Como os operadores PAO e CAO modificam pares de árvores de uma floresta, para cada nova floresta, apenas 2 alimentadores serão alterados. Assim, as sub-rotinas TENSÕES e CORRENTES são aplicadas somente a esses alimentadores, pois o fluxo de carga para os outros alimentadores não se altera [32]. As sub-rotinas TENSÕES e CORRENTES são executadas para cada estrutura $T_{i}$ (indicada por um ponteiro) de $F$.

Algoritmo 8: Pseudocódigo para determinar o fluxo de carga em SDRs [41].

\section{ALGORITMO PRINCIPAL}

1 PARA $i=0, \boldsymbol{A T E} i=$ número de ponteiros em F, FAÇA:

2 CORRENTES $\left(F \rightarrow T_{i}\right)$

3 TENSÕES $\left(F \rightarrow T_{i}\right)$

4 FIM PARA 


\subsection{CÁLCULO DO NÚMERO DE MANOBRAS}

Conforme apresentado na seção 1.2.2, o número de manobras em chaves (necessárias para implementar uma nova configuração do sistema), é uma informação de suma importância para avaliar as configurações geradas para o tratamento do problema de restabelecimento de energia elétrica. Portanto, é parte da solução desse problema a minimização desse número de manobras, possibilitando a obtenção de configurações de mais fácil implantação prática.

Em geral, este número de manobras é determinado a partir da comparação dos vetores que guardam o estado das chaves (de forma binária) de cada configuração (atual e proposta). Dessa forma, para obter o número de manobras necessárias para implantar uma dada configuração, comparam-se o vetor com o estado de todas as chaves dessa configuração com o vetor que armazena o estado das chaves da configuração inicial. Porém, o processo envolve um custo computacional relativamente alto, pois para cada nova configuração gerada é necessário criar um vetor com o estado atual das chaves e realizar a comparação com o vetor da configuração inicial. Como esses vetores têm o comprimento igual ao número de chaves $(m)$ no sistema, o tempo para percorrê-lo uma vez é bem maior que o tempo de realizar uma modificação no sistema pelos Operadores PAO ou $\mathrm{CAO}$, que requerem tempo de computação da ordem do tamanho dos alimentadores envolvidos, em geral, bem menor que $m$ [32].

Assim, desenvolveu-se em [32] um algoritmo que visa melhorar o desempenho computacional, determinando o número de manobras de forma mais eficiente exigindo menor esforço computacional. Na formulação desse algoritmo é necessário apenas um vetor com o estado das chaves na configuração inicial e outro vetor de tamanho $g_{\max }$ (número máximo de gerações) que guarda a quantidade de chaves alteradas em relação à configuração inicial.

Para ilustrar o problema e a solução apontada, a Figura 26 foi reproduzida na Figura 28, onde o "Setor 05" sofreu uma falta. Por se tratar de um setor cuja proteção se encontra no Disjuntor da Subestação, a presença de uma falta permanente provocará a abertura (ou desligamento) de todo o Alimentador 01. Assim, o processo de restabelecimento terá início com a manobra de abertura da chave $\mathrm{He}$ posterior religamento do circuito alimentador. Neste primeiro passo, notase a realização de 01 manobra de chave que impactou na alteração da configuração 
da rede.

Em seguida, para isolar o setor em falta, considere que tenha sido realizado a manobra de abertura das chaves $C, D$ e $J$ (mais 3 manobras de chaves). Porém, na configuração escolhida, os setores 08, 09, 07 e 06 ficam desconectados do sistema (consequentemente permanecem desligados mesmo após 0 restabelecimento do circuito alimentador). Assim, uma opção para os conectar de volta ao SDR, é através do fechamento das chaves $K, E$ e $F$ (mais 3 manobras de chaves), sendo que a alimentação para estes setores passa a ser realizada pelo Alimentador 02. Resumindo, através da alternativa selecionada para 0 restabelecimento, a alteração de topologia da rede foi realizada através de 7 manobras de chaves. Note que nesta primeira etapa (que pode ser chamada de isolação do problema e restabelecimento imediato da energia nas áreas sãs), as manobras não ocorreram em pares.

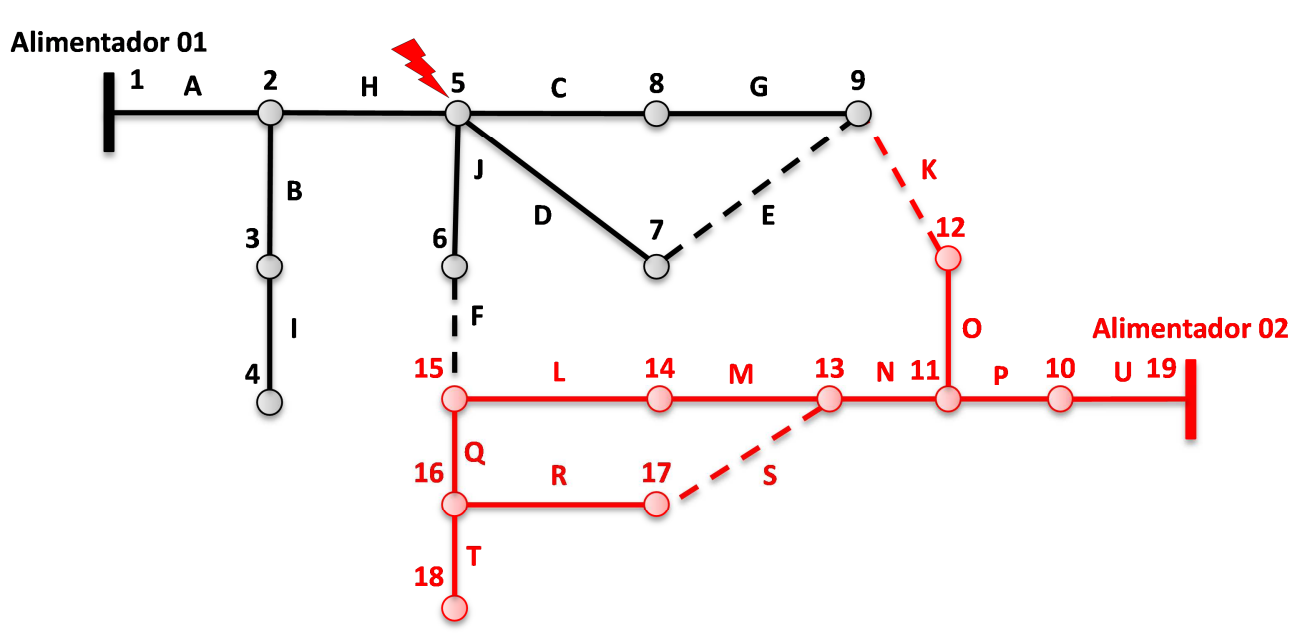

Figura 28. Operações necessárias para isolar o setor em falta

A Figura 29 apresenta o SRD exemplo já com a configuração alterada permitindo o isolamento do setor em falta e restabelecimento dos demais setores do SDR. Note que a configuração proposta provocará uma elevação no carregamento de diversas linhas do alimentador 02 e uma alteração nos valores de tensão no respectivo alimentador. Estas alterações deverão ser analisadas através do cálculo de fluxo de carga. 


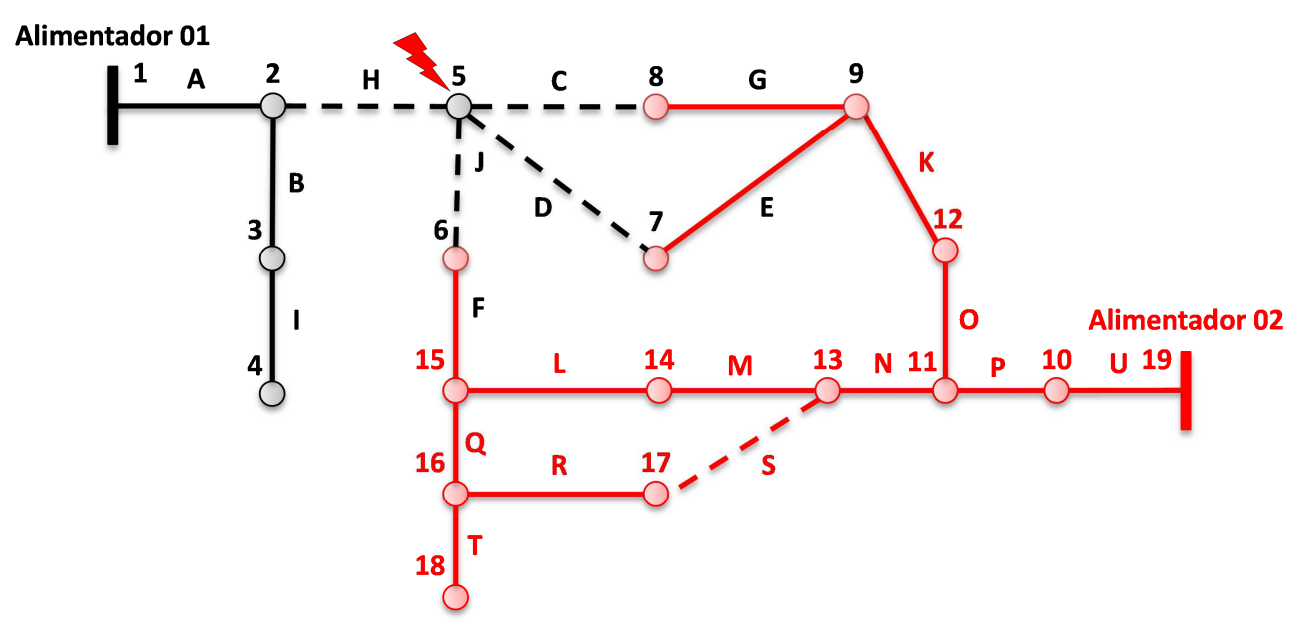

Figura 29. Configuração proposta para isolação e restabelecimento

Após o procedimento descrito anteriormente, as alterações nas chaves que resultarão em mudanças na configuração sempre ocorrerão aos pares, ou seja, quando uma chave é aberta, outra será fechada. Para determinar o número de manobras para originar uma dada configuração, considere o estado das chaves em 3 configurações específicas: configuração inicial (o), configuração alterada durante a etapa para isolamento do trecho defeituoso e recomposição dos demais $(x)$ e configuração final $(y)$. Dessa forma, considerando que uma configuração $y$ originouse de alterações na configuração $x$, temos 3 possibilidades para computar o número de chaves alteradas da configuração $y$ [32]:

1. Os estados das duas chaves alteradas em $y$, em relação $a x$, são diferentes dos estados dessas chaves em $o$. Portanto, o número de chaves alteradas de $y$ será o número de chaves alteradas de $x$ mais 2 . Considere que as chaves 1 e 4 da Tabela 4 foram alteradas em $x$ para originar $y$. Como $y_{1} \neq o_{1}$ e $y_{4} \neq o_{4}$, duas manobras de chaves a mais que as manobras para implantar $x$ são necessárias. Como de $o$ para $x, 2$ alterações foram realizadas, de $o$ para $y$ são necessárias 4; 
Tabela 4. Manobras de chaves: Caso 1

\begin{tabular}{|c|c|c|c|c|}
\hline & \multicolumn{3}{|c|}{ Configurações } \\
\hline & & $0 \ldots$ & X ... & $y$ \\
\hline \multirow{5}{*}{ 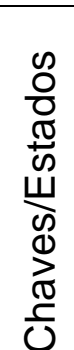 } & 1 & 1 & 1 & 0 \\
\hline & 2 & 1 & 0 & 0 \\
\hline & 3 & 0 & 1 & 1 \\
\hline & 4 & 0 & 0 & 1 \\
\hline & 5 & 1 & 1 & 1 \\
\hline
\end{tabular}

2. Os estados das duas chaves alteradas em $y$, em relação a $x$, são iguais aos estados dessas chaves em 0 . Portanto, o número de chaves alteradas de $y$ será o número de chaves alteradas de $x$ menos 2 . Considere alterações realizadas nas chaves 2 e 3 da Tabela 5. Como $y_{2}=o_{2}$ e $y_{3}=o_{3}$, os estados dessas duas chaves em y retornaram aos seus estados em o. Portanto, para implantar y serão necessárias 2 manobras a menos que o número de manobras para implantar $x$;

3. O estado de uma das chaves alteradas em $y$, em relação ax, é igual ao estado dessa chave em o e, o estado da outra chave alterada é diferente. Portanto, o número de chaves alteradas de y será igual ao número de chaves alteradas de $x$.

Tabela 5. Manobras de chaves: Caso 2

\begin{tabular}{|c|c|c|c|c|}
\hline & \multicolumn{3}{|c|}{ Configurações } \\
\hline & & $0 \ldots$ & $\mathbf{x} \ldots$ & $\mathbf{y}$ \\
\hline \multirow{5}{*}{ 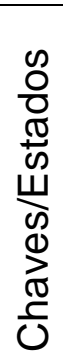 } & 1 & 1 & 1 & 1 \\
\hline & 2 & 1 & 0 & 1 \\
\hline & 3 & 0 & 1 & 0 \\
\hline & 4 & 0 & 0 & 0 \\
\hline & 5 & 1 & 1 & 1 \\
\hline
\end{tabular}


Tabela 6. Manobras de chaves: Caso 3

\begin{tabular}{|c|c|c|c|c|}
\hline & \multicolumn{3}{|c|}{ Configurações } \\
\hline & & $0 \ldots$ & $\mathbf{x} \ldots$ & $\mathbf{y}$ \\
\hline \multirow{5}{*}{ 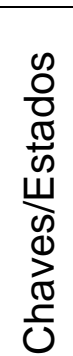 } & 1 & 1 & 1 & 1 \\
\hline & 2 & 1 & 0 & 1 \\
\hline & 3 & 0 & 1 & 1 \\
\hline & 4 & 0 & 0 & 0 \\
\hline & 5 & 1 & 1 & 0 \\
\hline
\end{tabular}

$\mathrm{Na}$ Tabela 6, nota-se que $y_{2}=\mathrm{O}_{2}$ e $y_{5} \neq 0_{5}$. Portanto, para originar a configuração $y$ assim como para originar $x$, são necessárias 2 manobras de chaves.

\subsubsection{Exemplo ilustrativo de cálculo do número de manobras}

O Algoritmo 9 mostra os passos necessários para determinar o número de manobras realizadas para obter uma configuração $y$ a partir de uma configuração $x$. Neste algoritmo, para cada configuração $y$ gerada a partir de uma configuração $x$, comparam-se os estados das 2 chaves alteradas com os estados delas na configuração original. Note que a comparação realizada na linha 3 se refere ao Caso 1 (onde o número de manobras da configuração x mais 2 é atribuído à configuração y), já a comparação da linha 5 se refere ao Caso 2 (onde o número de manobras da configuração x menos 2 é atribuído à configuração y). Por fim, a comparação da linha 7 se refere ao Caso 3 (onde o número de manobras da configuração x é atribuído à configuração y). 


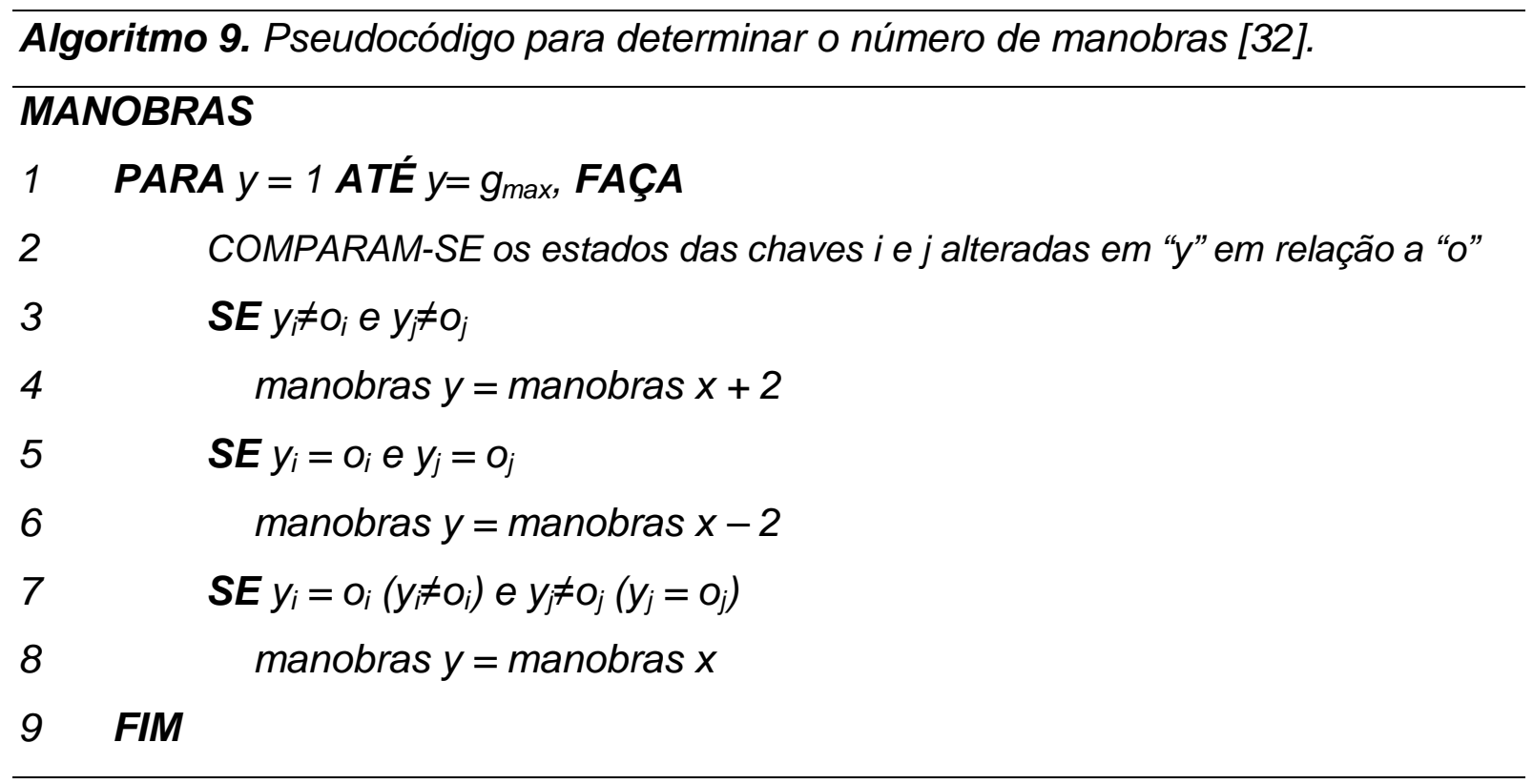

Para ilustrar o Algoritmo 9, considere o SDR representado na Figura 30 (idem à Figura 26) como sendo a configuração inicial (o). O vetor com o estado das chaves para configuração o é representado a seguir:

$\begin{aligned} & \text { Chaves } \\ & \text { Est. Ini. }\end{aligned}=\left[\begin{array}{ccccccccccccccccccccc}\mathrm{A} & \mathrm{B} & \mathrm{C} & \mathrm{D} & \mathrm{E} & \mathrm{F} & \mathrm{G} & \mathrm{H} & \mathrm{I} & \mathrm{J} & \mathrm{K} & \mathrm{L} & \mathrm{M} & \mathrm{N} & \mathrm{O} & \mathrm{P} & \mathrm{Q} & \mathrm{R} & \mathrm{S} & \mathrm{T} & \mathrm{U} \\ 1 & 1 & 1 & 1 & 0 & 0 & 1 & 1 & 1 & 1 & 0 & 1 & 1 & 1 & 1 & 1 & 1 & 1 & 0 & 1 & 1\end{array}\right]$

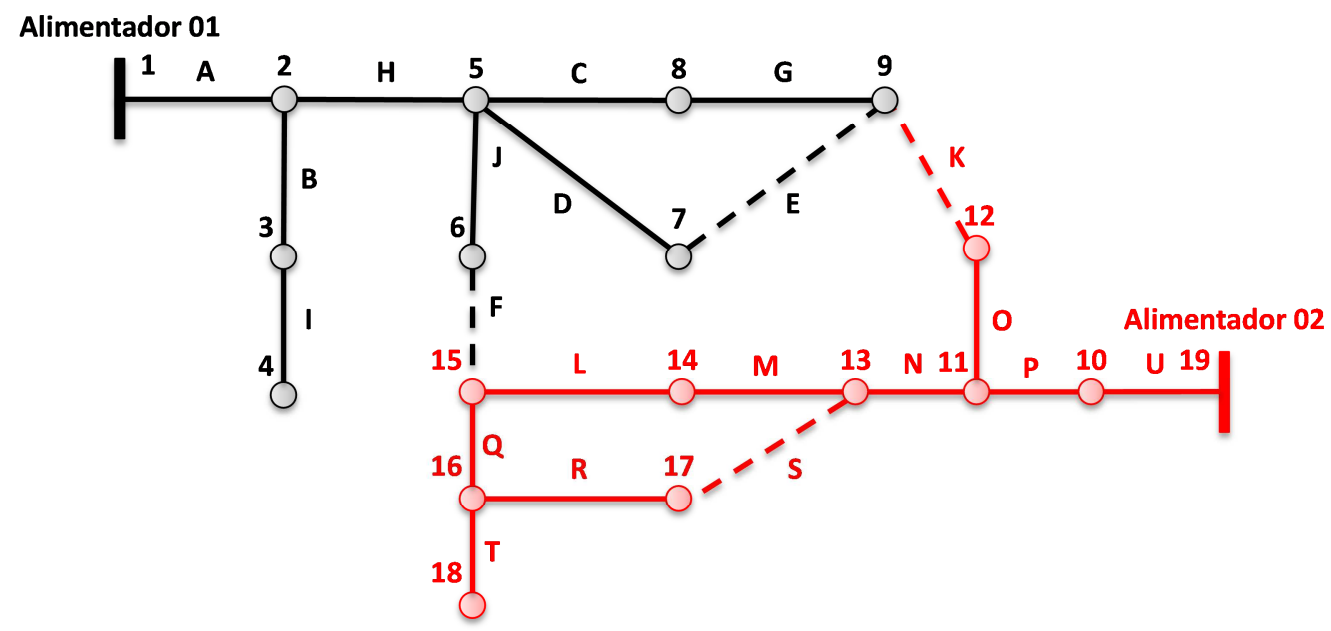

Figura 30. Cálculo das manobras: configuração inicial

Como tarefa inicial, o algoritmo cria um vetor para armazenar as manobras necessárias para gerar cada configuração. Neste vetor são armazenados o número da configuração e a quantidade de manobras necessárias para se chegar a esta configuração (conforme vetor abaixo). 


$$
\left[\begin{array}{c}
\text { Configuração } \\
\text { Manobras }
\end{array}\right]=\left[\begin{array}{lllllll}
0 & 1 & 2 & 3 & 4 & \ldots & g_{m a ́ x} \\
0 & & & & & \ldots &
\end{array}\right] .
$$

Para gerar a configuração 1 a partir da configuração inicial 0 , conforme exemplo ilustrado na Figura 31, as chaves $H, C, D$ e $J$ são abertas e a chaves $K, E$ e $F$ fechadas. Comparando-se, então, os estados dessas chaves com os estados das mesmas na configuração o, verifica-se que são necessárias 07 (sete) manobras para implantar a configuração 1 (y). A Figura 31 apresenta a configuração $y$.

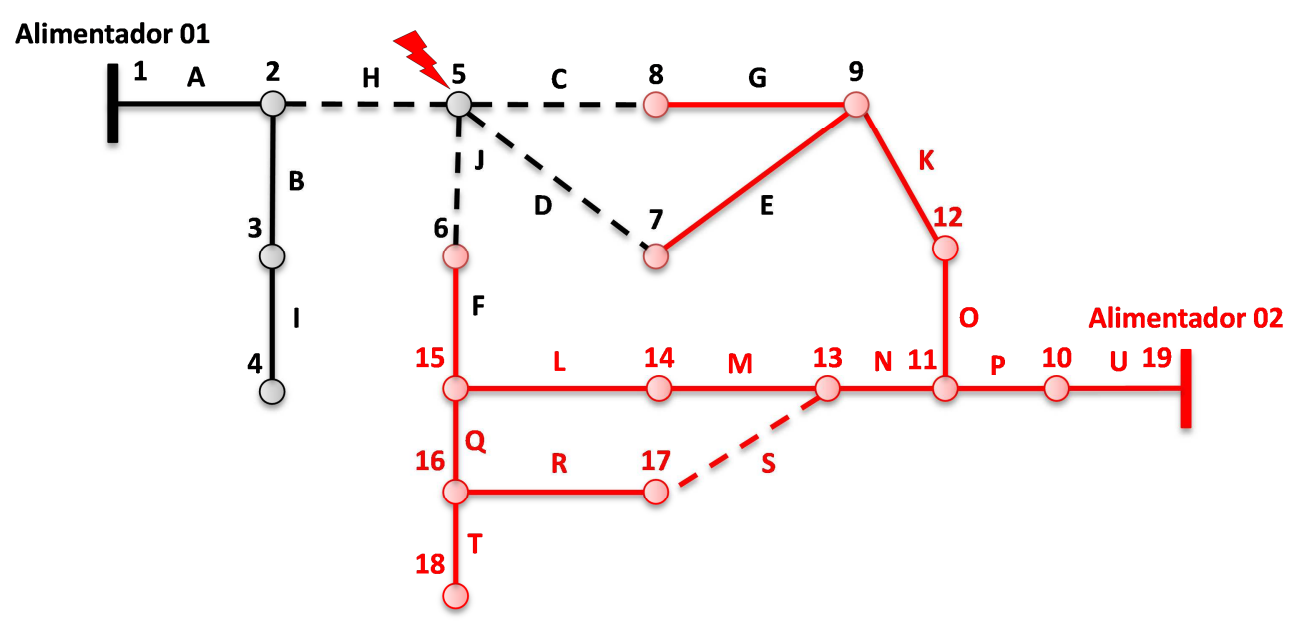

Figura 31. Configuração após alterações iniciais $(y)$

Assim, o vetor de armazenamento da quantidade de manobras é atualizado para:

$$
\left[\begin{array}{c}
\text { Configuração } \\
\text { Manobras }
\end{array}\right]=\left[\begin{array}{lllllll}
0 & 1 & 2 & 3 & 4 & \ldots & g_{\text {máx }} \\
0 & 7 & & & & \ldots &
\end{array}\right] .
$$

Para originar a configuração 2 (y) a partir da configuração 1 (x), suponha que a chave $M$ é aberta e a chave $S$ fechada. A Figura 32 mostra a nova topologia do SDR. Ao comparar o estado destas chaves com seus estados na configuração $o$, verifica-se que os estados são todos diferentes. Esta alteração é apresentada no Caso 1 , onde o número de manobras da configuração x mais 2 é atribuído à configuração y. Assim, o vetor de armazenamento da quantidade de manobras é atualizado da seguinte maneira:

$$
\left[\begin{array}{c}
\text { Configuração } \\
\text { Manobras }
\end{array}\right]=\left[\begin{array}{lllllll}
0 & 1 & 2 & 3 & 4 & \ldots & g_{m a ́ x} \\
0 & 7 & 9 & & & \ldots &
\end{array}\right]
$$




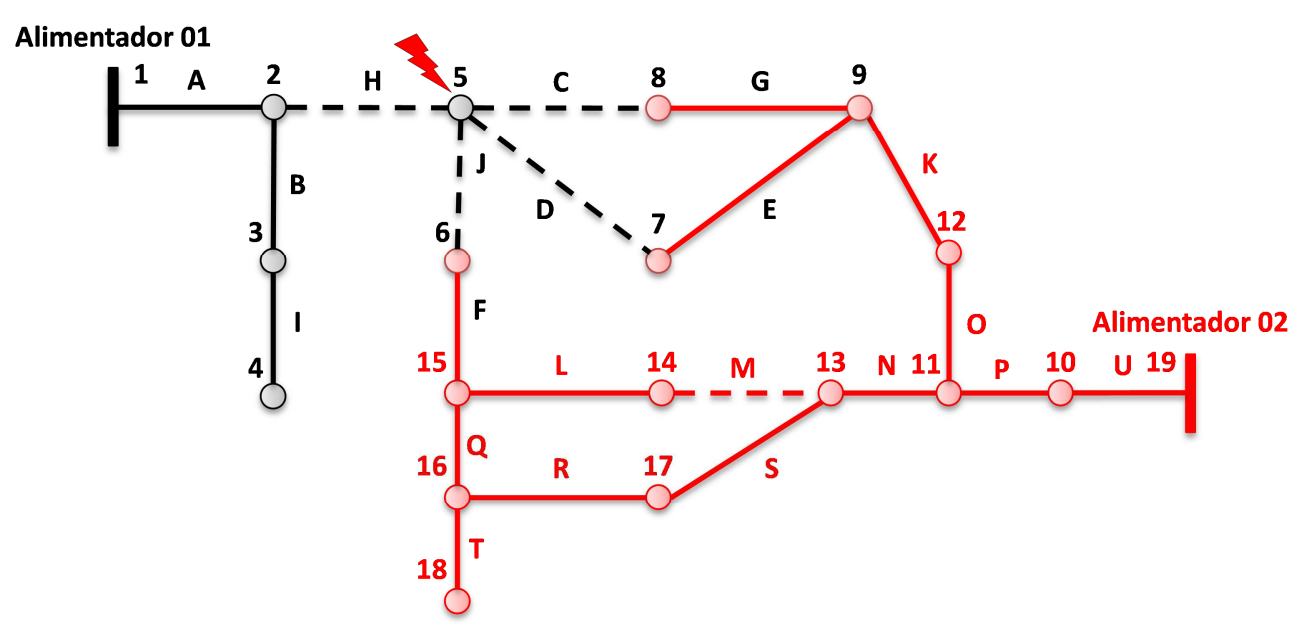

Figura 32. Cálculo das manobras: configuração 2

Suponha agora, que a configuração 2 foi escolhida para ser alterada $(x) \mathrm{e}$ originar a configuração $3(y)$. A chave $L$ é aberta e a chave $M$ é fechada, alterando seus estados para 0 e 1 respectivamente. Ao comparar o estado da chave $M$ (agora fechada) com seu estado na configuração $o$, verifica-se os estados iguais. Porém, 0 estado da chave $L$ (aberta) é diferente de seu estado na configuração 0 . Portanto, o número de manobras realizadas para obter a configuração $3(y)$ continua sendo 9 , ou seja, o número de manobras da configuração $x$ é atribuído à configuração y (Caso 3). A Figura 33 apresenta a configuração 3 do SDR cujo vetor de armazenamento da quantidade de manobras é o seguinte:

$$
\left[\begin{array}{c}
\text { Configuração } \\
\text { Manobras }
\end{array}\right]=\left[\begin{array}{lllllll}
0 & 1 & 2 & 3 & 4 & \ldots & g_{\text {máx }} \\
0 & 7 & 9 & 9 & & \ldots &
\end{array}\right] .
$$

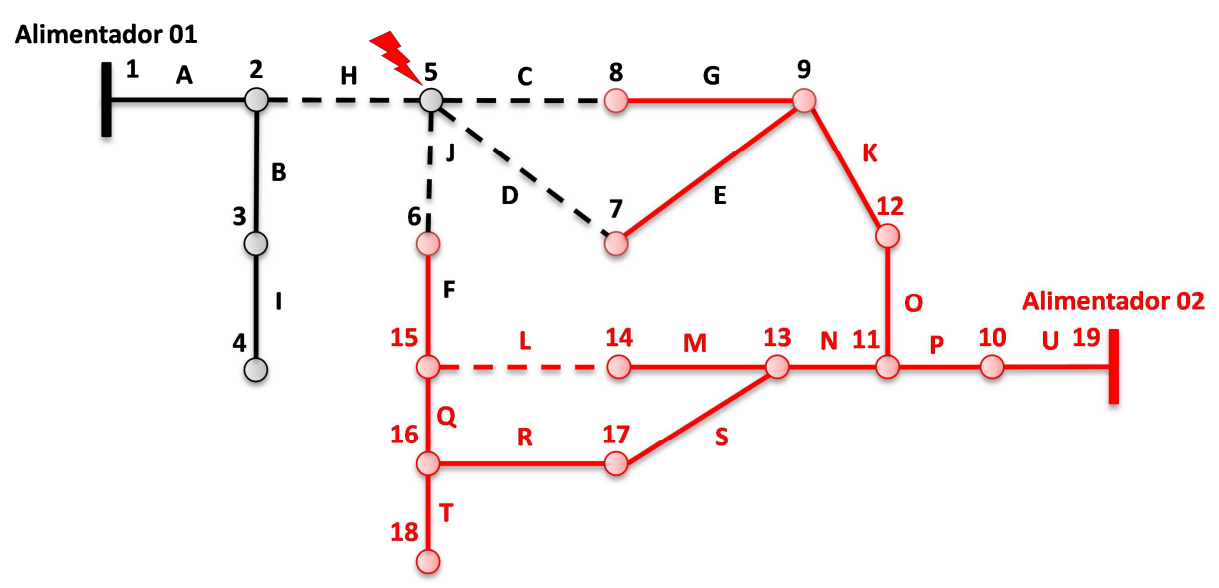

Figura 33. Cálculo das manobras: configuração 3 
Uma terceira possibilidade ocorre quando os estados das duas chaves alteradas se tornam iguais aos seus estados na configuração inicial. Considere as seguintes alterações realizadas na configuração $3(x)$ para gerar a configuração 4 $(y)$ : A chave $S$ é aberta e a chave $L$ é fechada. Nesse caso subtraem 2 manobras do vetor de manobras da configuração $3(x)$, obtendo 7 manobras. $O$ vetor atualizado com o número de manobras é:

$$
\left[\begin{array}{c}
\text { Configuração } \\
\text { Manobras }
\end{array}\right]=\left[\begin{array}{lllllll}
0 & 1 & 2 & 3 & 4 & \ldots & g_{\text {máx }} \\
0 & 7 & 9 & 9 & 7 & \ldots &
\end{array}\right] .
$$

O algoritmo proposto em [32] não exige que as novas configurações sejam geradas a partir da configuração imediatamente anterior à mesma. Por exemplo, nada impede que seja gerada uma configuração 5 a partir da configuração 2. Neste caso, porém, o valor da quantidade de manobras da configuração 5 , a ser atualizado no correspondente vetor, deve ser em relação à quantidade de manobras da configuração 2 e não da configuração 4 (conforme ocorreram em todos os exemplos supracitados).

\subsection{ALGORITMO EVOLUTIVO EM TABELAS COM HEURÍSTICA (AEMT-H)}

Conforme mencionado nas seções anteriores, o algoritmo avaliado na presente dissertação é o AEMT-H. Este algoritmo, proposto em [72], utiliza os conceitos do AEMO em Tabelas "alocando" os indivíduos das novas gerações em tabelas conforme sua "qualificação" em relação aos demais indivíduos ali presentes. O AEMT-H utiliza ainda os conceitos do NSGAll nos quais são povoadas 03 (três) tabelas utilizando o conceito de subpopulações "não-dominadas" $\left(F_{1}\right.$ a $\left.F_{3}\right)$. Assim, o AEMT-H utiliza um total de 14 tabelas "povoadas" conforme os critérios descritos a seguir. No aplicativo avaliado, as tabelas de 1 a 11 foram parametrizadas com uma quantidade de 05 (cinco) indivíduos por tabela. A tabela 12 possui uma população de 20 indivíduos e as tabelas 13 e 14, 40 indivíduos cada. Estes valores foram atribuídos após testes de desempenho realizados [1] e [72]. 
1. Indivíduos com menor valor na função agregação;

2. Indivíduos com menores perdas ôhmicas;

3. Indivíduos com menores quedas de tensão;

4. Indivíduos com menores carregamentos da rede;

5. Indivíduos com menores carregamentos das subestações;

6. Indivíduos com 1 par de manobras além da recomposição inicial ${ }^{4}$;

7. Indivíduos com 2 pares de manobras além da recomposição inicial;

8. Indivíduos com 3 pares de manobras além da recomposição inicial;

9. Indivíduos com 4 pares de manobras além da recomposição inicial;

10. Indivíduos com 5 pares de manobras além da recomposição inicial;

11. Indivíduos com 6 pares de manobras além da recomposição inicial;

12. Indivíduos da subpopulação com soluções "não-dominadas" $F_{1}$;

13. Indivíduos da subpopulação com soluções "não-dominadas" $F_{2}$;

14. Indivíduos da subpopulação com soluções "não-dominadas" $F_{3}$.

As tabelas de 1 a 5 realizam uma comparação direta entre os valores "objetivo" das mesmas. Por exemplo, no caso da tabela 2, a definição de qual o indivíduo que permanecerá para a geração seguinte ocorre através da comparação direta do valor do total de perdas ôhmicas de cada indivíduo. O com menor valor permanece na tabela, enquanto que o de maior não permanece. Para exemplificar o disposto, a Tabela 7 apresenta uma relação de 5 supostos indivíduos $\left(I N D_{a}\right.$ a $\left.I N D_{e}\right)$ que em uma determinada geração $i$ povoam a tabela de Indivíduos com menores perdas ôhmicas. Após a reprodução ocorrida na geração $i+1$, um novo indivíduo é gerado $\left(I N D_{f}\right)$ e compete para povoar a tabela em questão. Neste exemplo, como o indivíduo possui um valor de perdas ôhmicas menor que alguns indivíduos da tabela, ele passar a povoá-la, enquanto o $I N D_{e}$ (com maior valor de perdas ôhmicas deixa de povoar a tabela). A Tabela 8 apresenta os indivíduos que passarão a povoar a tabela de Indivíduos com menores perdas ôhmicas após a geração $i+1$.

\footnotetext{
${ }^{4}$ O número de manobras para recomposição inicial é calculado no início do algoritmo e é composto pelas operações de abertura das chaves "NF" para isolamento do setor em falta e ainda as operações de fechamento das chaves "NA" para restabelecimento dos setores "sãos" à jusante do setor em falta.
} 
Tabela 7. Exemplo de seleção dos indivíduos da tabela 2 do AEMT-H (geração i)

\begin{tabular}{|c|c|c|c|c|}
\hline \multirow{2}{*}{\multicolumn{2}{|c|}{ (2) }} & \multicolumn{3}{|c|}{ Parâmetros } \\
\hline & & Num. Pares de Manob. & Perdas ôhmicas (kW) & \% Queda de Tensão \\
\hline \multirow{5}{*}{ 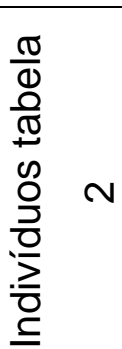 } & $I N D_{a}$ & 13 & 1000 & 5,1 \\
\hline & $I N D_{b}$ & 7 & 1100 & 6,0 \\
\hline & $I N D_{c}$ & 11 & 1200 & 4,5 \\
\hline & $I N D_{d}$ & 4 & 1300 & 5,1 \\
\hline & $I N D_{e}$ & 1 & 1400 & 6,5 \\
\hline & $I N D_{f}$ & 10 & 1150 & 5,9 \\
\hline
\end{tabular}

Tabela 8. Exemplo de seleção dos indivíduos da tabela 2 do AEMT-H (geração i)

\begin{tabular}{|c|c|c|c|c|}
\hline & \multicolumn{3}{|c|}{ Parâmetros } \\
\hline & & $\begin{array}{c}\text { Num. Pares de } \\
\text { Manobras }\end{array}$ & Perdas ôhmicas (kW) & \% Queda de Tensão \\
\hline \multirow{5}{*}{ 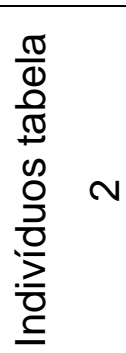 } & $I N D_{a}$ & 13 & 1000 & 5,1 \\
\hline & $I N D_{b}$ & 7 & 1100 & 6,0 \\
\hline & $I N D_{f}$ & 10 & 1150 & 5,9 \\
\hline & $I N D_{c}$ & 11 & 1200 & 4,5 \\
\hline & $I N D_{d}$ & 4 & 1300 & 5,1 \\
\hline & $I N D_{e}$ & 1 & 1400 & 6,5 \\
\hline
\end{tabular}

Para as tabelas de 6 a 11, a definição do indivíduo que as povoará ocorre através da constatação de que seu número de manobras é igual ao solicitado na tabela. Já a disputa com os demais indivíduos ocorrerá através da comparação do valor da soma do percentual de carregamento da rede com o percentual da queda de tensão (os indivíduos com o menor valor desta soma permanecem na tabela). Por fim, os indivíduos que povoarão as tabelas de 12 a 14 obedecem aos critérios de dominância de Pareto (conforme seção 3.4.1.2). As funções objetivo utilizadas para determinar a dominância são a quantidade de operações de manobra e ainda a função agregação. Os indivíduos presentes na tabela de Indivíduos da subpopulação com soluções "não-dominadas" $F_{1}$ são aqueles não dominados por nenhum outro indivíduo presente na população avaliada. Já os da tabela de 
Indivíduos da subpopulação com soluções "não-dominadas" $F_{2}$ são aqueles dominados apenas pelos indivíduos de $F_{1}$. Por fim, os da tabela de Indivíduos da subpopulação com soluções "não-dominadas" $F_{2}$ são aqueles dominados apenas pelos indivíduos de $F_{1} \cup F_{2}$.

A função agregação supracitada é composta pelos valores de perdas ôhmicas, número de operações de manobras e restrições operacionais do sistema (perfil de tensão, carregamento da rede e carregamento da subestação). No caso dos valores calculados para a as restrições operacionais, por se tratar de valores do sistema, seus resultados representam os "piores" valores considerando todos os elementos presentes. Por exemplo, no caso do valor de carregamento de rede, em todos os alimentadores são analisados os valores do carregamento em todas as linhas existentes. O maior valor de percentual de carregamento encontrado é atribuído ao alimentador. Para se verificar o valor do sistema, verifica-se então o maior valor entre todos os alimentadores existentes. A equação da função agregação é descrita abaixo:

$$
f(x)=x_{1}+x_{2}+\delta_{1} x_{3}+\delta_{2} x_{4}+\delta_{3} x_{5}
$$

em que:

$x_{1}$ é o somatório das perdas ôhmicas em kW;

$x_{2}$ é a quantidade de chaveamentos realizada para o completo restabelecimento;

$x_{3}$ é o máximo carregamento da rede em p.u.;

$x_{4}$ é o máximo carregamento da subestação em p.u.;

$x_{5}$ é a máxima queda de tensão em p.u;

$\delta_{i}$ é a penalização de cada objetivo $x_{i}$ sendo: $\left(\delta_{i}=100\right.$, se uma restrição foi violada para pelo menos uma barra e $\delta_{i}=0$, caso nenhuma restrição tenha sido violada).

No AEMT-H, os operadores genéticos da RNP são selecionados para a reprodução de maneira aleatória com uma probabilidade que se ajusta dinamicamente. O algoritmo inicia sua busca utilizando a mesma taxa de probabilidade para os dois operadores da RNP (CAO e PAO). Suponha que um operador tenha sido escolhido para gerar um novo indivíduo. Se o indivíduo gerado tiver sucesso, ou seja, for acrescentado a uma ou mais subpopulações, aumenta-se a taxa de probabilidade do operador escolhido, como consequência, diminui-se a taxa de probabilidade de aplicação do outro operador, e assim por diante. Esse ajuste dinâmico do processo de escolha dos Operadores melhora o desempenho do 
algoritmo consideravelmente, conforme mostrado em testes apresentados em [32].

A heurística aplicada ao AEMT-H visa a restrição dos circuitos alimentadores que participarão da etapa de escolha aleatória do alimentador para aplicação dos operadores da RNP. A ideia é a de restringir o espaço de busca e, consequentemente, obter soluções com menor número de manobras e que não violem os limites operacionais do sistema.

De acordo com a heurística proposta, cria-se uma lista ordenada de alimentadores para aplicação dos operadores RNP. O alimentador que possuir a maior queda de tensão será o primeiro da lista, e assim por diante. Em caso de empate, o valor percentual do carregamento da rede é então verificado. Mantendose o empate a definição ocorre de maneira aleatória. Ao final, um percentual estipulado de alimentadores é eliminado da lista de opções, restando assim somente os "piores" com possibilidade de alteração em sua configuração. 


\section{PREPARAÇÃO DOS DADOS COPEL PARA APLICAÇÃO NO AEMT-H}

\subsection{INTRODUÇÃO}

Conforme apresentado no capítulo 4, para possibilitar a validação proposta nesta dissertação, a metodologia apresentada em [72] foi estudada em detalhes. Houve ainda o estudo completo do algoritmo computacional utilizado pelos pesquisadores da USP, sendo necessária uma compreensão das funções computacionais utilizadas. A partir desses estudos, observou-se a necessidade de conversão dos dados do sistema COPEL para o utilizado na USP, sendo esta uma etapa onerosa e bastante longa. Por fim, foi necessário o estudo da forma de exposição dos resultados e da conversão das configurações finais para modelos gráficos objetivando a posterior análise e comparação com a realidade esperada em um Centro de Operação da Distribuição da concessionária. Assim, inicialmente, foi necessário compreender a forma de armazenamento da base de dados da concessionária.

\subsection{BASE DE DADOS DA COPEL - MODELO COPEL}

Os dados da COPEL são separados em dois "macro-sistemas", um para a rede "Primária" (13,8kV e 34,5kV) e outro para a rede "Secundária" (220/127V). No banco de dados da rede Primária encontram-se as tabelas com as informações dos elementos da Média Tensão do SDR (Circuito Alimentador, Subestações, Banco de Capacitor, Regulador de Tensão, Postos Transformadores, Cabos Condutores de Energia - Trechos Primários, Postes, etc). Já no banco da rede Secundária estão as tabelas com informações da Baixa Tensão do SDR e dos consumidores presentes no sistema de BT e MT.

Para cada poste é atribuído um número de identificação através do qual é possível verificar, consultando as demais tabelas da base de dados, todos os elementos presentes na estrutura (chaves de manobra, bancos capacitores, trecho primário, etc). Na tabela de chaves de manobra, é possível verificar, além do poste onde a mesma está instalada, em qual bloco elétrico (setor) está a fonte da energia e qual é o bloco elétrico à jusante da referida chave (chamado de bloco "ligado"). Já na tabela de Trechos Primários são verificados os números dos postes de início e 
fim do condutor elétrico. Na Figura 34, cada ponto representa um poste cujos números de identificação ("1010" a "1013") aparecem em azul e são alinhados na vertical (foram representados apenas os números de alguns postes a fim de facilitar a análise da figura), as linhas representam os Trechos Primários (TPs) cujos números de identificação ("1" a "26") aparecem em preto (alinhados na horizontal), as letras representam as identificações das chaves conforme simbologia apresentada na Figura (" $B$ " e " $D$ " representam chaves fusíveis, " $A$ " e " $C$ " chaves do tipo seccionadora unipolar e " $G$ " representa a chave à óleo), os triângulos representam os postos transformadores identificados através dos termos " $T F^{*}$ " ("TF1" e "TF2") e o por fim, o banco de capacitor ("BC1"), conforme simbologia em legenda, é representado pelo termo " $B C$ *'. Para facilitar a identificação futura, este modelo será denominado de modelo COPEL.

A comprovação da conectividade elétrica entre dois TPs ocorre quando as duas condições abaixo são atendidas simultaneamente:

$\checkmark$ o número de identificação do poste do fim de um TP é o mesmo número de identificação do início de um outro TP;

$\checkmark$ o bloco elétrico (setor) é igual para ambos os elementos.

Já a conectividade entre um TP e uma Chave de Manobra ocorre quando as seguintes condições são atendidas simultaneamente:

$\checkmark$ o número de identificação do poste do início ou do fim do TP é coincidente com o número de identificação do poste da chave;

$\checkmark$ o bloco elétrico (setor) do TP é igual ao bloco elétrico (setor) fonte ou ligado da chave.

Através da Figura 34 é possível exemplificar a maneira com que uma conectividade elétrica é verificada. Assim, como exemplo, nota-se que há conectividade entre os TPs 16 e 17, pois o número de identificação do poste do fim TP 16 (poste 1012) é o mesmo do poste do início do TP 17. Além disso, os referidos TPs fazem parte do mesmo bloco elétrico (Setor 4).

Outro exemplo aponta para a existência de conectividade entre a chave $\mathbf{C}$ e o TP 16, pois o número de identificação do poste do início do TP 16 é o mesmo do poste da chave $\mathbf{C}$. Verifica-se ainda que o bloco elétrico (setor) do TP 16 é o mesmo do bloco ligado à chave $\mathbf{C}$ (Setor 4 ). 


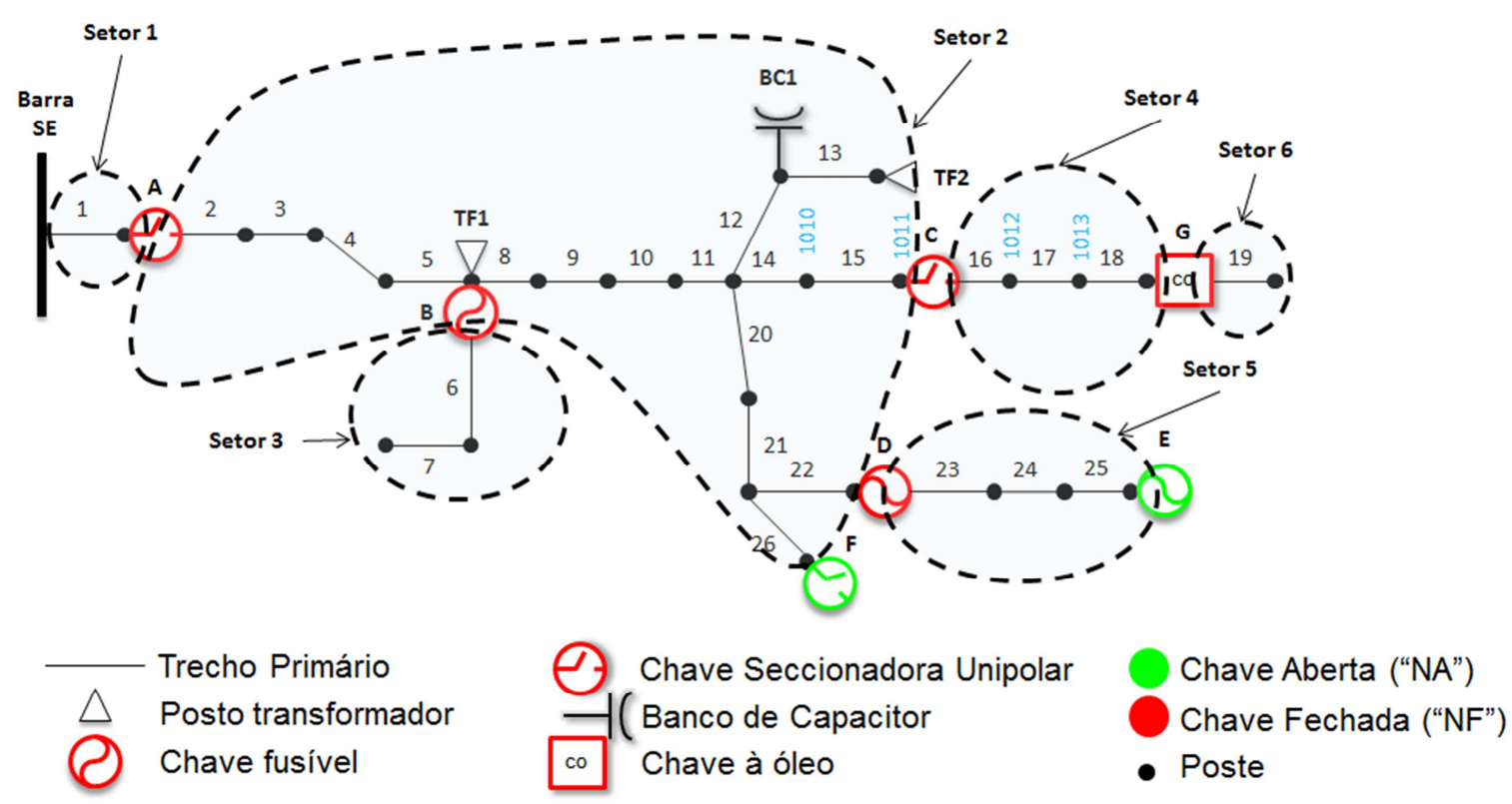

Figura 34. Exemplo de SDR a ser modelado (modelo COPEL)

\subsection{MODELO INTERMEDIÁRIO}

No modelo barra-linha temos que as barras são os nós da rede e as linhas/chaves são os elos entre esses nós. As barras são condutores com resistência desprezível quando comparadas com as impedâncias de linhas e transformadores. Por isso cada barra é representada através de um nó elétrico no qual a tensão é uma só em todas as partes do condutor.

Com base no modelo barra-linha, os componentes de um sistema de energia elétrica podem ser classificados em dois grupos: os que estão ligados diretamente ao nó (entre fases e fase-terra), como é o caso das cargas e banco de capacitores, e os que estão ligados entre dois nós quaisquer da rede, como é o caso dos TPs, dos reguladores de tensão e das chaves de manobra. As cargas são consideradas como a parte externa do sistema, e são modelados através de injeções de potência nos nós da rede [71].

Para representar a topologia elétrica do SDR da COPEL, realiza-se uma busca em profundidade, "partindo" sempre de barras da subestação sentido cargas, "percorrendo" os elementos do sistema conforme a conectividade elétrica existente entre os mesmos. Por definição deste trabalho, cada poste do sistema foi denotado por um número diferente, assim, cada poste representa uma barra.

Deve-se lembrar que a obtenção da representação inicial do SDR se realizará através de um processamento fora do tempo real ("off-line"), contornando 
assim os problemas que poderiam surgir pelo grande esforço computacional necessário.

Em seguida, faz-se necessário converter os dados indicando quais são os elementos adjacentes ao atual, compondo assim a matriz de adjacência. Por fim, os dados são então representados através da RNP descrita no capítulo 2.

Após a obtenção da representação do SDR através da matriz de adjacência e da RNP, será atribuído um número para cada "bloco elétrico", ou "setor", do SDR. O "bloco" ou "setor" consiste de um agrupamento de "trechos primários", eletricamente conectados e sem a presença de chaves entre eles. São ainda incluídos, nos "blocos elétricos" ou "setores", os postos de transformação e capacitores eletricamente conectados aos "trechos primários" a eles pertencentes. Assim, os "blocos elétricos" podem estar dispostos entre chaves, entre uma chave e um "fim de linha" ou ainda entre a saída de um alimentador na subestação e uma chave. A fim de simplificarmos os textos seguintes, chamaremos os "blocos elétricos" ou "setores" apenas de "setores".

No exemplo da Figura 34 serão formados 06 (seis) setores numerados de 01 a 06 com os seguintes elementos:

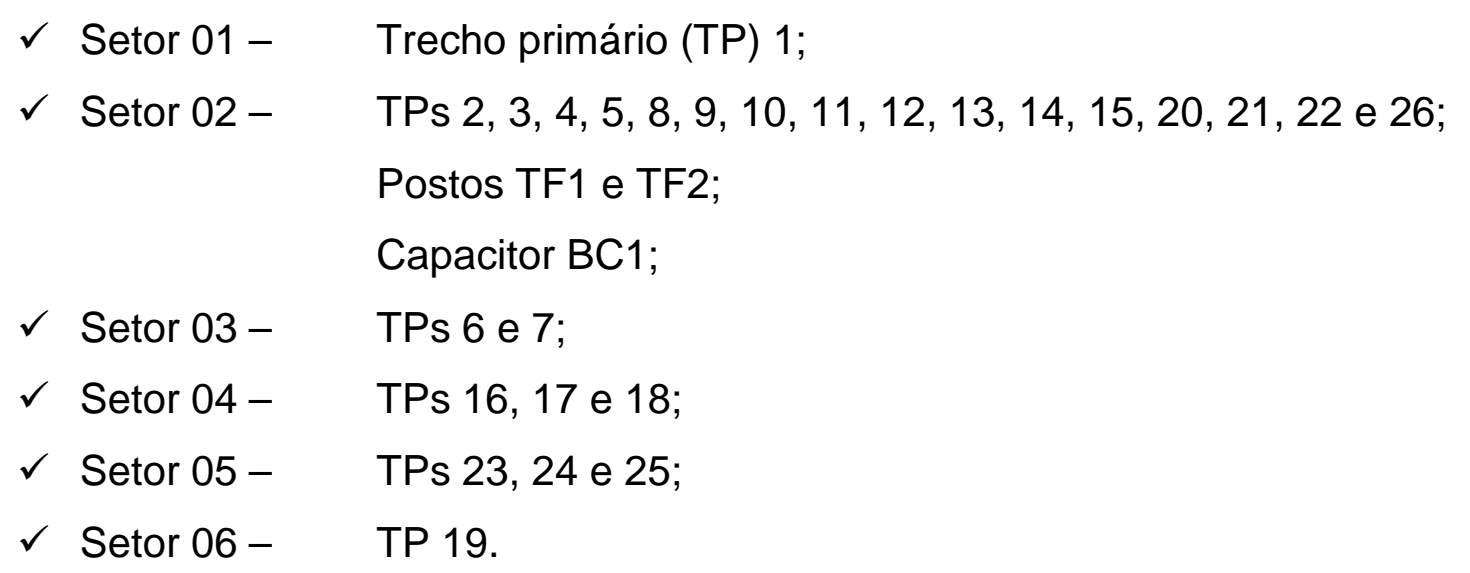

Para melhor detalhar a forma de conversão dos dados do modelo COPEL para o modelo USP, define-se um modelo Intermediário, conforme apresentado na Figura 35. Neste modelo, as chaves serão representadas como um quadrado, não havendo distinção para o tipo da chave, a diferenciação ocorrerá apenas em função da posição de operação (quadrado pintado de vermelho para chaves "NF" e pintado de verde para chaves "NA"). Neste modelo os elementos presentes nos setores (TPs, postos transformadores, etc) serão "ocultados" restando apenas a representação do "caminho elétrico" existente (representado pelas linhas contínuas). Este modelo Intermediário foi o escolhido para apresentar aos 
Operadores do COD da concessionária as configurações finais do AEMT-H.

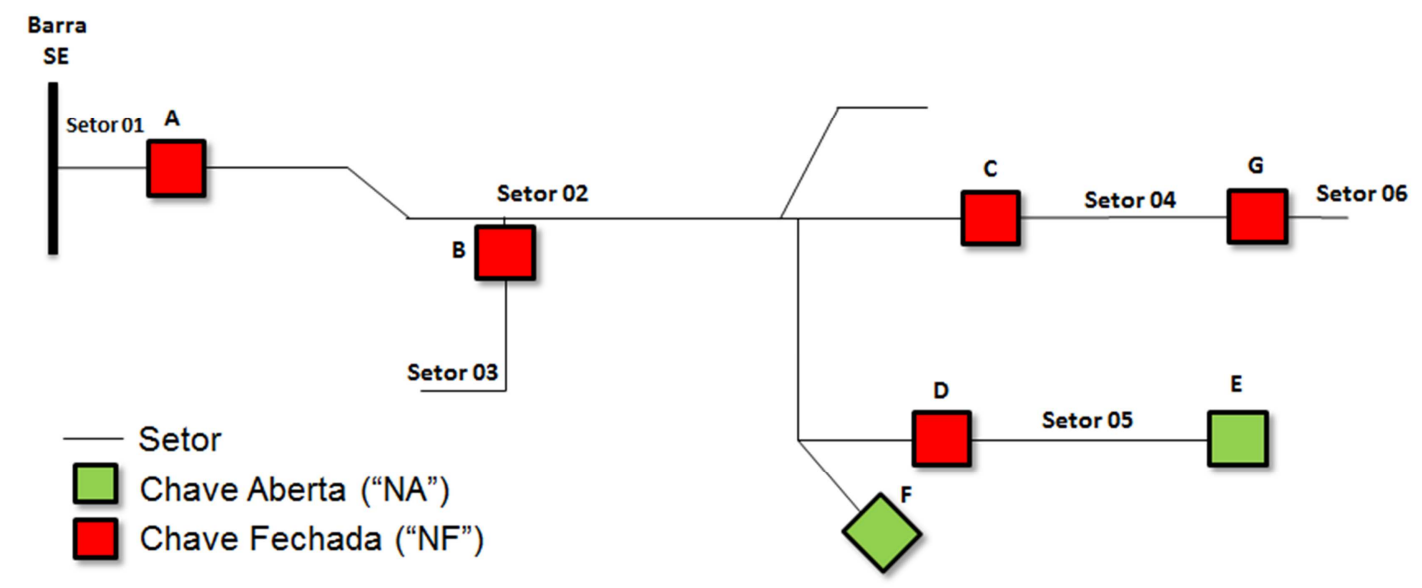

Figura 35. Exemplo dos setores de um SDR qualquer (modelo Intermediário)

\subsection{MODELO USP}

A modelagem do sistema em estudo utilizada pelos pesquisadores da USP ocorrerá alterando, no modelo Intermediário, a forma de representação dos setores e das chaves. No modelo intermediário os setores eram representados pelas linhas contínuas e passarão a serem representados pelas circunferências. As chaves, que por sua vez eram representadas pelos quadrados "vermelhos" e "verdes" na modelagem intermediária, são representados por linhas contínuas (chaves "NF") e tracejadas (chaves "NA") no modelo utilizado pelos pesquisadores da USP. A Figura 36 ilustra a representação do sistema da Figura 34 no modelo utilizado pelos pesquisadores da USP. Este modelo será denotado de "modelo USP".

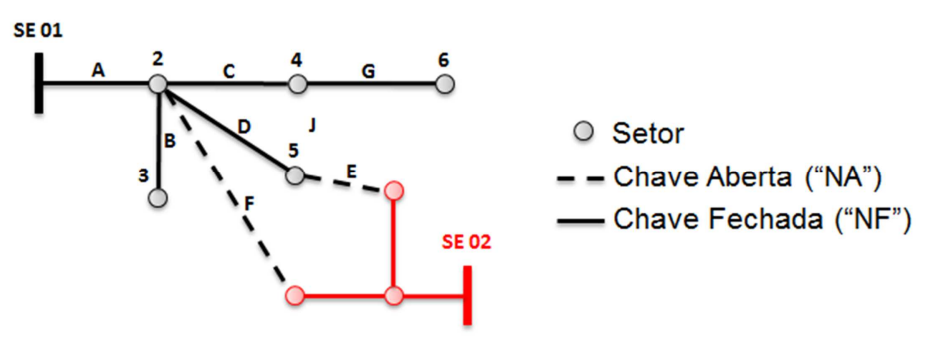

Figura 36. Representação Proposta para o SDR da Figura 34 (modelo USP) 


\section{RESULTADOS EXPERIMENTAIS}

Este capítulo apresentará os resultados das simulações computacionais realizadas, conforme metodologia descrita nos capítulos anteriores. As simulações foram realizadas no SDR real da cidade de Londrina em operação no ano de 2013. O sistema em questão possui 30.156 barras, 2.660 chaves "NF", 250 chaves "NA" e atende um universo de mais de 231.000 consumidores ligados diretamente ao sistema de 13,8kV ou, após os transformadores de distribuição, nas tensões de $220 \mathrm{~V}$ e 127V. Neste sistema estão presentes 6 subestações $138 \mathrm{kV} / 13,8 \mathrm{kV}$ e 64 circuitos alimentadores, totalizando uma capacidade de transformação de energia de 541,7MVA.

A Figura 37 ilustra a configuração inicial do sistema de Londrina antes da ocorrência da falta.

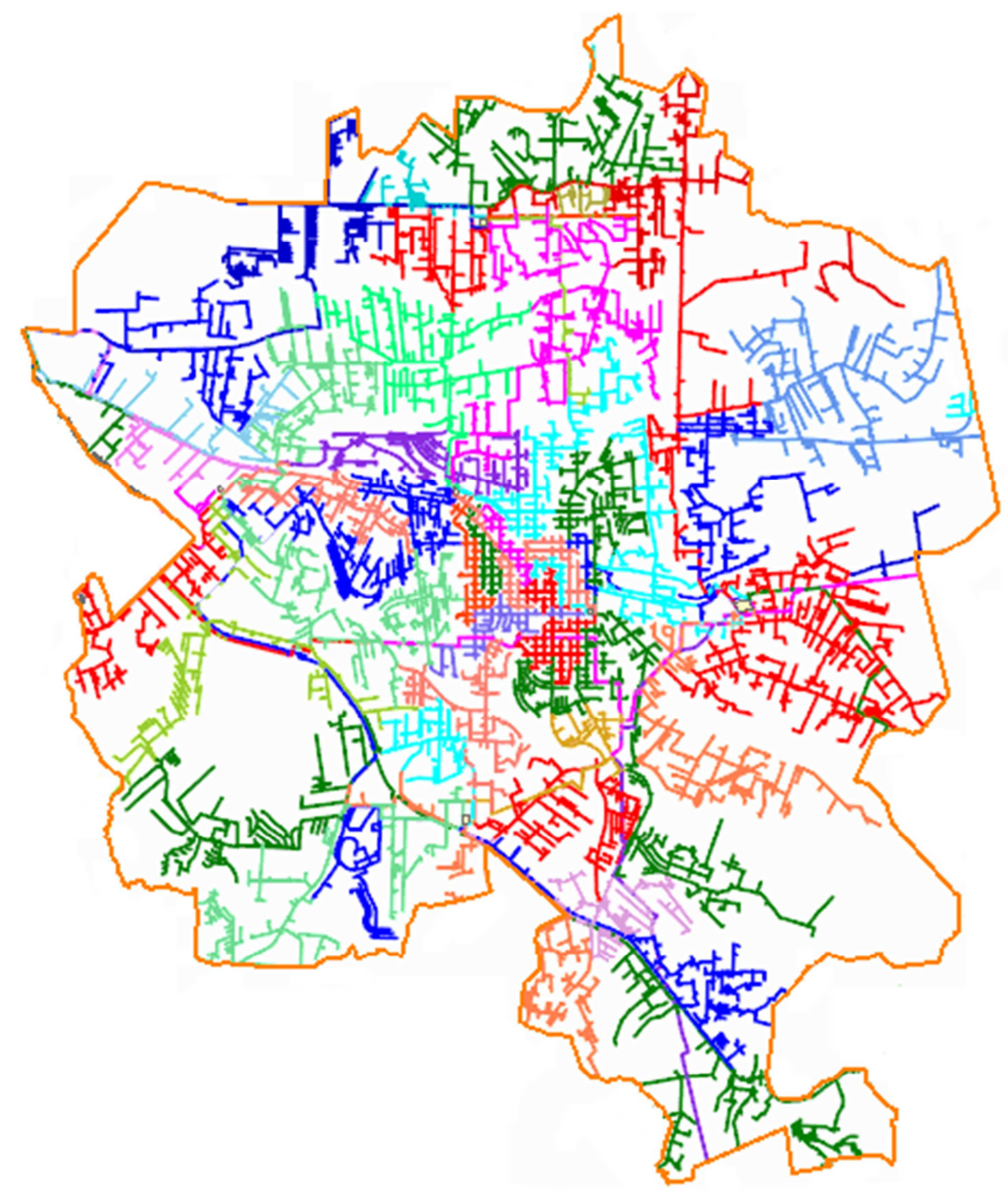

Figura 37. SDR de Londrina antes da ocorrência da falta 
O AEMT-H foi implementado utilizando um computador com processador Intel Core i7-3770, 12GB de RAM. Sistema Operacional Linux, distribuição Ubuntu 12.4 e GCC 4.4 com compilador de linguagem $C$.

Os parâmetros utilizados para execução do AEMT-H foram os seguintes:

- Número máximo de indivíduos gerados: $G_{M A ́ X}=70.000$;

- Queda máxima de tensão admissível: 10\% em relação à tensão nominal da SE (13.800V);

- Máximo Carregamento admissível: $100 \%$ da capacidade do condutor e da subestação;

- Critério de Parada do Algoritmo: ter atingido o número máximo de indivíduos avaliados $\left(G_{M A ́ x}\right)$.

As simulações que serão apresentadas buscaram solucionar um problema de falta simples no setor 2364 , do alimentador 59 . Conforme descrito anteriormente os resultados das simulações serão analisados em duas frentes, uma estatística e outra subjetiva. Assim o capítulo 6 é dividido da seguinte maneira:

$\rightarrow$ Seção 6.1: apresentação dos resultados das simulações para falta simples no SDR de Londrina;

$\rightarrow$ Seção 6.2: apresentação gráfica dos resultados e análise subjetiva das informações através de profissionais do COD da concessionária com proposição de melhorias e sugestões para trabalhos futuros;

$\rightarrow$ Seção 6.3: apresentação dos resultados das simulações de outros setores do sistema a fim de validar as sugestões de trabalhos futuros;

\subsection{SIMULAÇÕES CONSIDERANDO FALTA ÚNICA}

O primeiro passo na execução do algoritmo trata das manobras de isolamento do setor em falta e recomposição dos setores "sãos" à jusante deste. Nesta primeira etapa, conforme pode ser observado na Figura 38, a isolação do setor em falta ocorreu através da abertura das chaves 3186, 905 e 3593. Já para a recomposição dos setores "sãos" à jusante da falta, existe uma variedade de alternativas possíveis. No total são 15 alternativas possíveis combinando as 05 chaves "NA" à jusante da chave 905 (434, 234, 2759, 236 e 437) e 03 chaves "NA" à jusante da chave 3593 (743, 1532 e 748). No ensaio de número 1, a opção escolhida aleatoriamente foi o fechamento das chaves 1532 e 234 (conforme Figura 
39). A Figura 39 mostra ainda as demais chaves "NA" que poderiam ter sido selecionadas para o restabelecimento dos trechos "sãos" à jusante da falta.

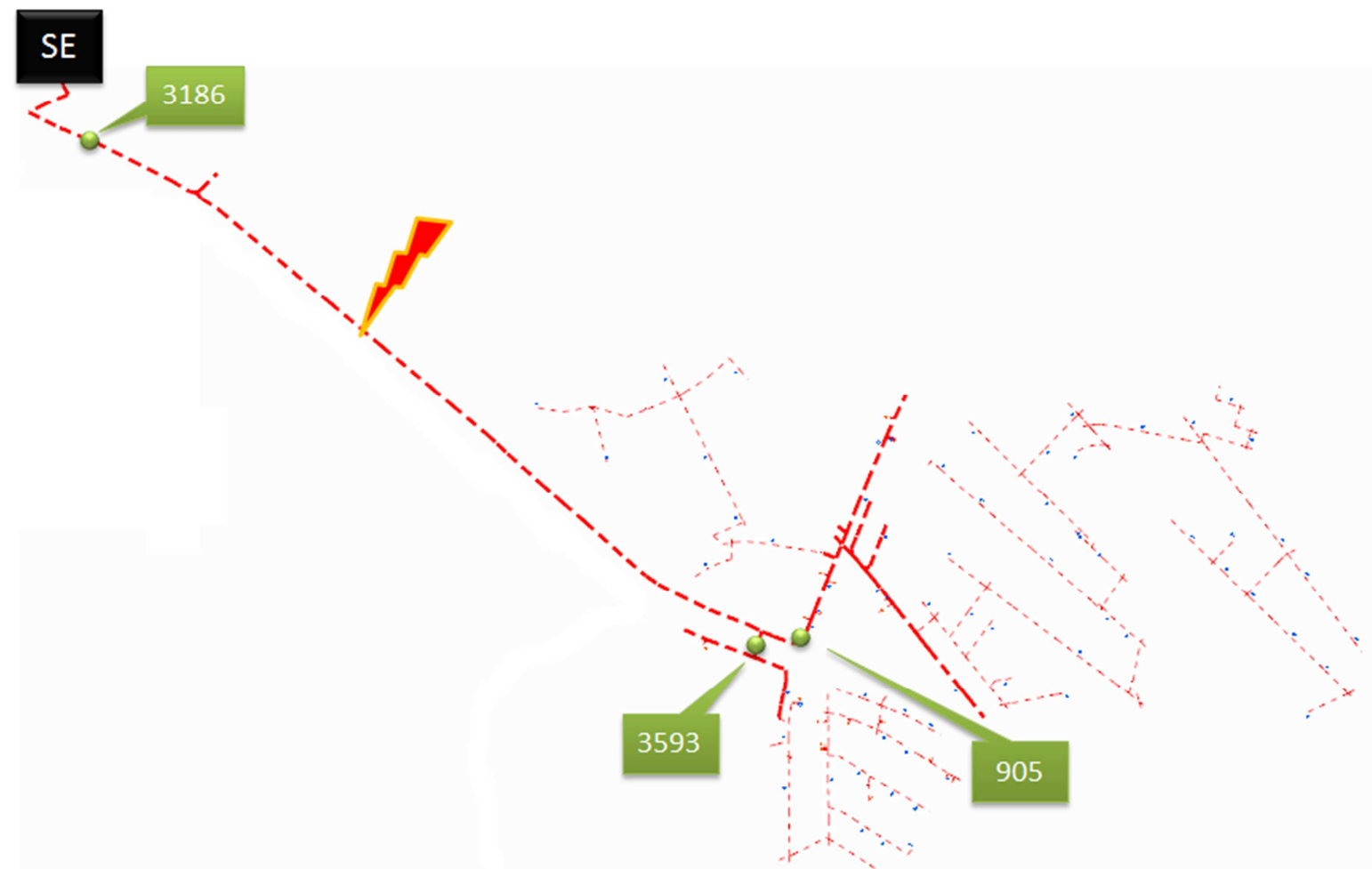

Figura 38. Alimentador $59 \mathrm{em}$ falta - Chaves para isolamento do defeito

Conforme Figura 39, foram necessárias 05 manobras para o isolamento do trecho sob falta e recomposição dos setores "sãos" (03 manobras de abertura de chaves e mais 02 de fechamento). As características elétricas do indivíduo, ou configuração, obtida após essas manobras são apresentadas na Tabela 9. Conformo pode ser observado esse indivíduo é uma solução factível do problema, isto é, é uma configuração factível (radial, restabelece energia para todos os setores não atingidos pela falta) que respeita todas as restrições do problema de restabelecimento. 
Tabela 9. Características do indivíduo da 1a geração para o sistema em estudo

\begin{tabular}{|l|c|}
\hline & Sistema em Estudo \\
\hline Perdas Ôhmicas (kW) & 1061,15 \\
\hline Queda de Tensão (\%) & 3,26 \\
\hline Carregamento da Rede (\%) & 79,54 \\
\hline Carregamento da Subestação (\%) & 53,77 \\
\hline Quantidade de Manobras & 5 \\
\hline
\end{tabular}

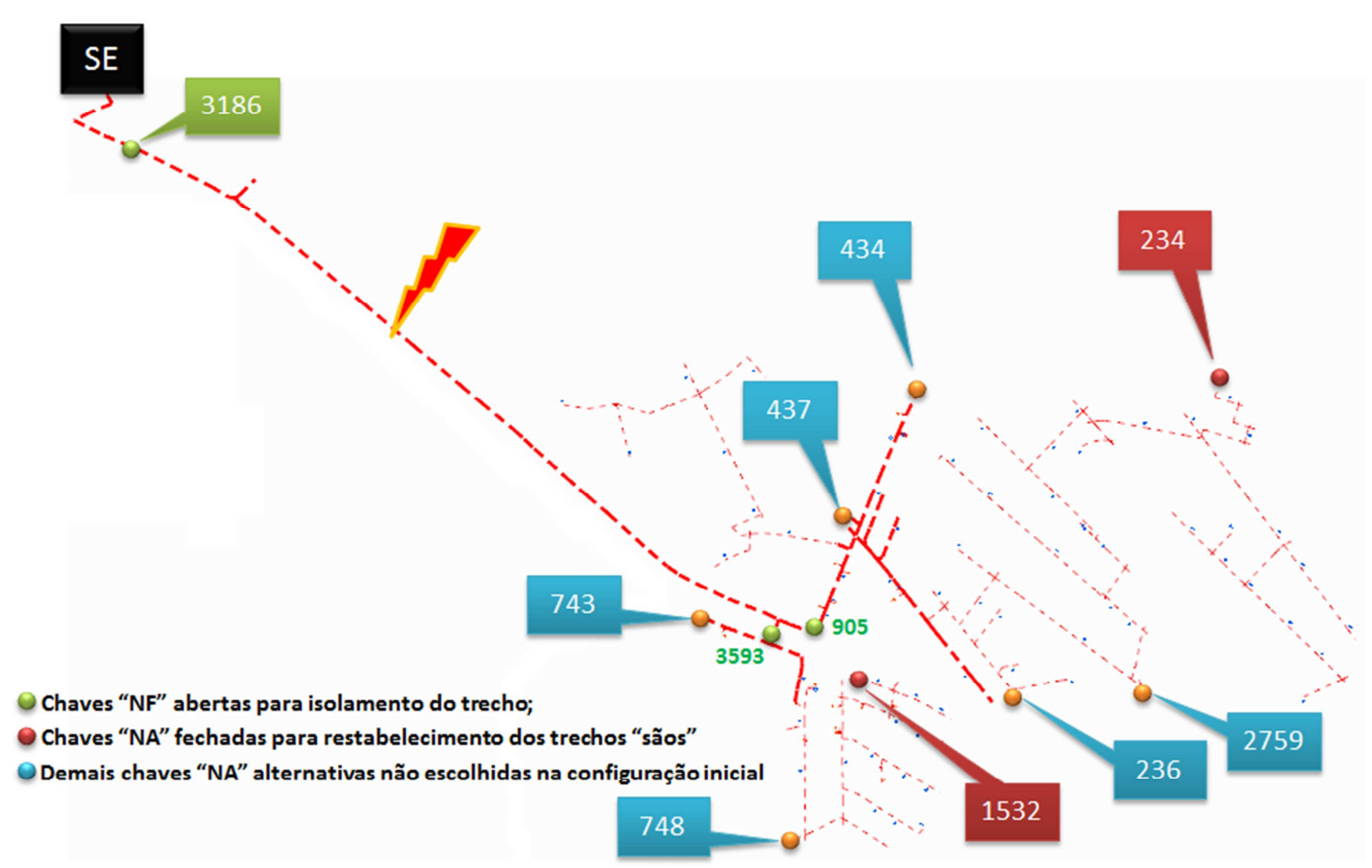

Figura 39. Alimentador 59 em falta - Chaves para restabelecimento e opções

A Tabela 10 apresenta o resumo dos resultados obtidos através da aplicação do AEMT-H no sistema de Londrina. Os resultados apresentados referemse aos valores da quantidade de manobras (valor mínimo, máximo, médio e desvio padrão). Estes valores foram obtidos com base nos resultados de 50 simulações. Importa destacar que estes valores foram obtidos através da tabela de soluções "não-dominadas" $F_{1}$. 
Tabela 10. Número de manobras obtidos no SDR de Londrina

\begin{tabular}{|l|c|}
\hline & $\begin{array}{c}\text { Número de } \\
\text { Manobras }\end{array}$ \\
\hline Mínimo & 5 \\
\hline Média & 12 \\
\hline Máximo & 29 \\
\hline Desvio Padrão & 3,98 \\
\hline
\end{tabular}

A Tabela 11 sintetiza os resultados de perdas ôhmicas e das restrições operacionais obtidos pelo AEMT-H considerando os indivíduos de todas as 50 simulações e presentes nas tabelas de 0 a 6 pares de manobras e de soluções "nãodominadas" $F_{1}$. Foram incluídos ainda os valores do tempo de processamento.

Tabela 11. Síntese dos resultados das 50 simulações

\begin{tabular}{|l|c|c|c|c|c|}
\hline & $\begin{array}{c}\text { Perdas } \\
\text { Ôhmicas } \\
(\mathbf{k W})\end{array}$ & $\begin{array}{c}\text { Queda de } \\
\text { Tensão (\%) }\end{array}$ & $\begin{array}{c}\text { Carrega- } \\
\text { mento da } \\
\text { Rede (\%) }\end{array}$ & $\begin{array}{c}\text { Carrega- } \\
\text { mento da } \\
\text { Subestação } \\
(\%)\end{array}$ & $\begin{array}{c}\text { Tempo de } \\
\text { Processa- } \\
\text { mento (s) }\end{array}$ \\
\hline Mínimo & 956,69 & 1,91 & 79,54 & 52,23 & 10,08 \\
\hline Média & $\mathbf{1 0 0 2 , 2 8}$ & $\mathbf{2 , 1 8}$ & $\mathbf{7 9 , 5 4}$ & $\mathbf{5 3 , 7 4}$ & $\mathbf{1 3 , 1 2}$ \\
\hline Máximo & 1078,66 & 3,26 & 79,54 & 56,97 & 17,60 \\
\hline Desvio Padrão & 23,33 & 0,17 & 0,00 & 0,23 & 2,20 \\
\hline
\end{tabular}

Ao analisar os resultados presentes na Tabela 11, comprovou-se a eficiência computacional do AEMT-H. Destaca-se que o tempo médio de pouco mais de 13 segundos caracteriza a aplicação como funcional para o tempo real, principalmente ao comparar este tempo com o limite considerado pela ANEEL para caracterizar interrupções de energia como sendo "Falhas Momentâneas" (que atualmente é de até 180 segundos).

$\mathrm{Na}$ sequência, a Figura 40 ilustra as Fronteiras de Pareto obtidas pelo AEMT-H aplicada ao problema de restabelecimento de energia para o SDR de Londrina. Foram escolhidas aleatoriamente 04 gerações cujos indivíduos da tabela de soluções "não-dominadas" $F_{1}$ foram utilizados para compor as referidas Fronteiras de Pareto. 


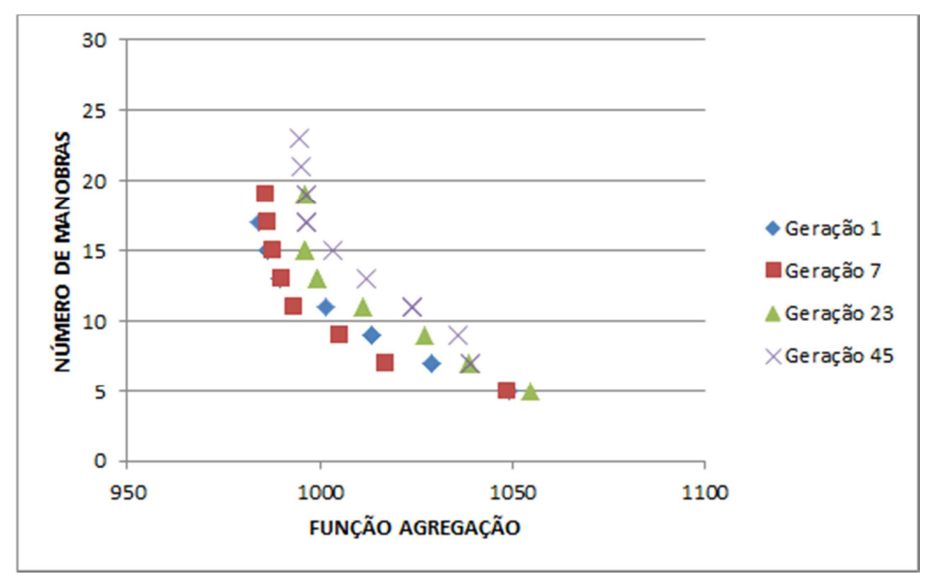

Figura 40. Fronteiras de Pareto obtidas para o SDR de Londrina

\subsection{ANÁLISE SUBJETIVA DOS RESULTADOS}

O passo seguinte, após a obtenção e apresentação dos valores estatísticos dos resultados obtidos para as 50 simulações da aplicação do AEMT-H no SDR de Londrina, foi o de representar graficamente alguns dos indivíduos gerados como soluções do problema de restabelecimento de energia. Esta representação gráfica busca apresentar de maneira clara, aos Operadores e demais profissionais do COD da concessionária, as alterações propostas pela metodologia avaliada.

O objetivo desta seção é o de analisar de maneira subjetiva as soluções propostas pelo AEMT-H. A Figura 41 apresenta o indivíduo da geração inicial, após o restabelecimento de todos os setores "sãos" do SDR (considerando uma simulação selecionada aleatoriamente dentre as 50 realizadas). As 05 manobras realizadas foram apresentadas anteriormente quando da explanação da Figura 39.

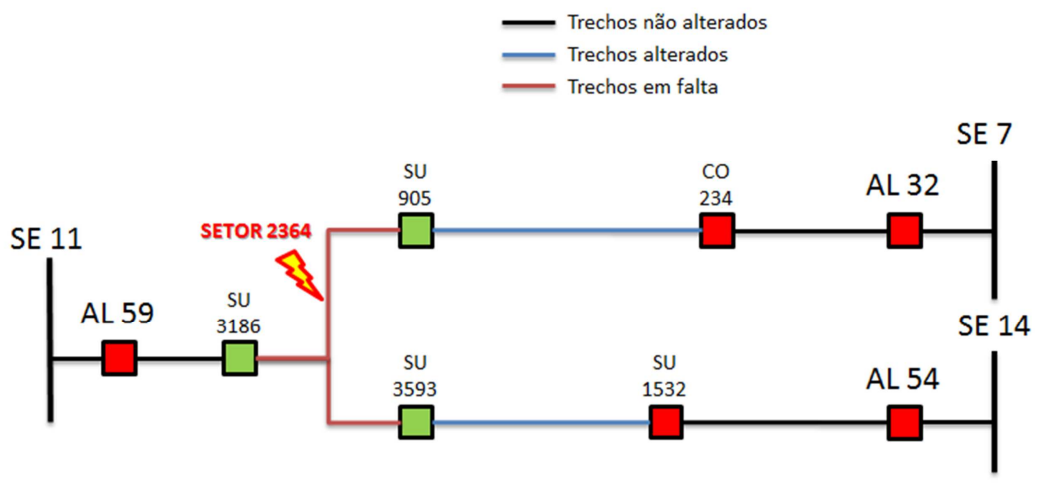

Figura 41. Representação Gráfica do indivíduo da geração inicial 
Ao debater sobre a solução inicial apontada pelo AEMT-H, notou-se que as manobras sugeridas para realizar a recomposição dos trechos "sãos" respeitam os critérios de carregamento e nível de tensão para os alimentadores ali envolvidos (alimentadores 59, 32 e 54), porém foi observado que a recomposição do trecho à jusante da SU 3593 foi realizada através do fechamento da SU 1532, que não é uma chave operável com carga (conforme apresentado no capítulo 2.2.1).

Para realizar esta manobra no sistema real, seria necessário o desligamento do alimentador 54 para fechamento da SU 1532 sem a presença de tensão na chave, isto porque a carga que será suprida pela referida chave supera os limites estabelecidos pela concessionária para operação com carga. Esta necessidade de abertura momentânea do alimentador 54 afetaria consumidores que não tem relação direta com o defeito no setor 2364 , o que prejudica sua satisfação e, portanto, só seria utilizada caso não houvesse alternativas. Vale destacar ainda que o trecho à jusante da chave 3593 possui opção de alimentação pelo setor 1976, que pertence ao alimentador 53, cuja chave existente para realização desta manobra é do tipo CO (chave à óleo), que é operável com carga. Assim, caso o indivíduo selecionado pelo AEMT-H sugerisse esta manobra, o desligamento ou "pique" do alimentador 54 não seria necessário. A Figura 42 apresenta todas as possibilidades de alimentação dos trechos "sãos" no indivíduo inicial do SDR.

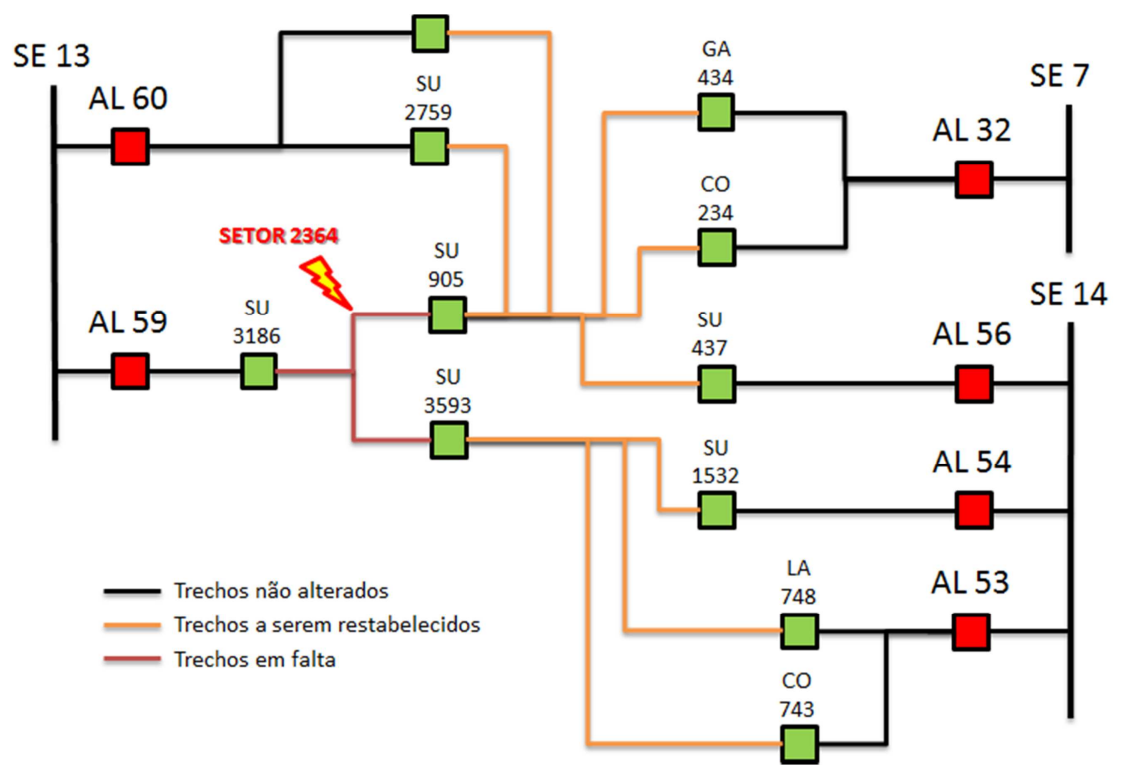

Figura 42. Representação Gráfica das alternativas para gerar o indivíduo inicial

Importa destacar que os critérios de planejamento das concessionárias de energia buscam investimentos em circuitos alimentadores de tal maneira que estes 
possuam configurações alternativas que possibilitem seu restabelecimento em casos de faltas simples $(\mathrm{n}-1)$. Normalmente os trechos planejados para tais manobras são dotados de chaves operáveis com carga. Desta maneira uma sugestão inicial para trabalhos futuros (identificada como "Sugestão 1") é a de se avaliar todas as combinações possíveis para a primeira recomposição (configuração inicial), gerando um indivíduo para cada configuração eletricamente factível. Acredita-se que esse procedimento aumenta a probabilidade de obtenção de uma solução do problema com um número mínimo de manobras. Veja que para o exemplo em questão seriam apenas 15 indivíduos gerados inicialmente.

Para exemplificar o disposto no parágrafo acima, temos que dos 64 alimentadores em estudo, 34 possuem um valor de corrente, no horário de carga pesada, menor que $50 \%$ do limite máximo de carregamento utilizado na concessionária (considerando as limitações de cabo, conexões, etc.). Se considerarmos o patamar de $70 \%$ do limite máximo, este valor chega a 56 alimentadores $(87,5 \%$ do total em estudo).

$\mathrm{Na}$ simulação analisada, os 70.000 indivíduos gerados em uma das simulações (01 indivíduo em cada geração), foram verificados e se constatou que, por exemplo, nos setores à jusante da chave 3593, os indivíduos das gerações de número 3.064 e 4.006 são indivíduos com 05 manobras (portanto indivíduos que representam configurações iniciais), e cujas configurações representam as alternativas de alimentação do trecho à jusante da chave 3593 pelas chaves CO 743 e LA 748, respectivamente. Já para os setores à jusante da chave 905 foi observado, por exemplo, que os indivíduos das gerações 13.622 e 55.283 são indivíduos com 05 manobras e cujas configurações representam alternativas de alimentação pelas chaves SU 2759 e GA 234.

Ao analisar as características do indivíduo da geração 3.064, indivíduo que realiza as manobras utilizando apenas chaves operáveis com carga para restabelecer os setores "sãos" (CO 234 e CO 743), nota-se que as restrições operacionais são respeitadas (queda de tensão de 3,26\%, carregamento da rede de $79,54 \%$ e carregamento da subestação de 53,77\%), sendo esta, portanto, a configuração ideal (do ponto de vista dos Operadores do COD).

Assim a sugestão para trabalhos futuros (identificada como "Sugestão 2"), é a da utilização do tipo do equipamento para direcionamento e/ou priorização quando da escolha da chave a ser manobrada para o restabelecimento dos setores, 
utilizando, portanto, as características operacionais das chaves, como, por exemplo, a possibilidade de manobra com carga e a presença de comando remoto (sendo este ultimo um critério bastante importante para possibilitar um rápido restabelecimento da energia). A configuração priorizada é aquela que respeita as restrições operacionais e utiliza, prioritariamente, chaves com comando e controle remotos e operáveis com carga.

Uma segunda análise realizada buscou verificar um indivíduo com baixo valor de queda de tensão. $O$ objetivo é avaliar quais manobras foram realizadas e qual o grau de importância destas manobras no contexto do problema de restabelecimento de energia. O indivíduo escolhido foi o da geração 54.452, cujos resultados de perdas ôhmicas, número de manobras e demais restrições operacionais são apresentados na Tabela 12.

Tabela 12. Resultados do indivíduo da geração54.452

\begin{tabular}{|l|c|c|c|c|c|}
\hline & $\begin{array}{c}\text { Perdas } \\
\text { Ôhmicas } \\
(\mathbf{k W})\end{array}$ & $\begin{array}{c}\text { Queda de } \\
\text { Tensão (\%) }\end{array}$ & $\begin{array}{c}\text { Carrega- } \\
\text { mento da } \\
\text { Rede (\%) }\end{array}$ & $\begin{array}{c}\text { Carrega- } \\
\text { mento da } \\
\text { Subestação } \\
(\%)\end{array}$ & $\begin{array}{c}\text { Número de } \\
\text { Manobras }\end{array}$ \\
\hline Indivíduo 54.452 & 976,67 & 2,26 & 79,54 & 53,77 & 11 \\
\hline
\end{tabular}

A Figura 43 apresenta o indivíduo da geração 54.452, considerando somente as alterações realizadas no sistema inicial.

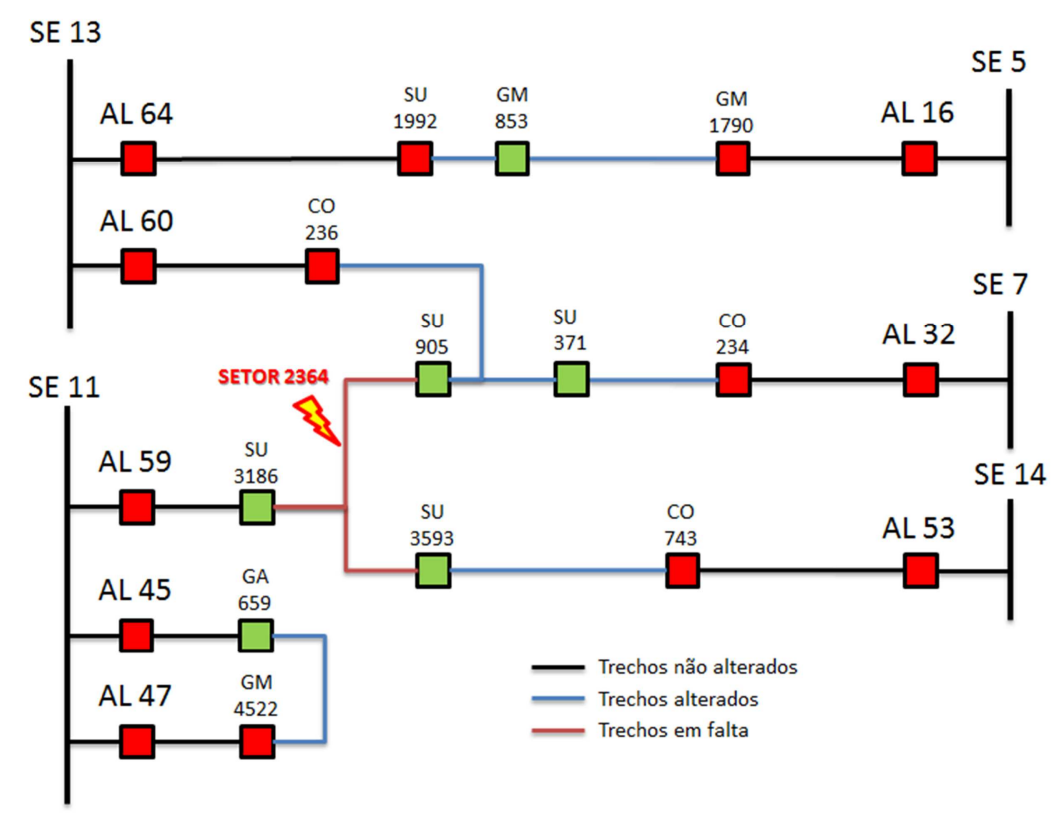

Figura 43. Representação Gráfica do indivíduo da geração 54.452 
$\mathrm{Na}$ análise inicial do sistema da Figura 43, houve uma dúvida sobre qual a necessidade da manobra envolvendo as chaves 5438 e 5431 (entre alimentadores 42 e 52). Lembrando que o problema em questão é o de restabelecimento de energia e, portanto, de uma maneira associativa, as manobras deveriam estar concentradas no alimentador 59 e nos demais que assumiram parte da sua carga (neste caso os alimentadores 32 e 53).

Da mesma forma, do ponto de vista de restabelecimento de energia, a manobra envolvendo as chaves 3532 e 4522 deixa dúvidas quanto à sua real necessidade (entre os alimentadores 45 e 47).

Analisando o caso um pouco mais a fundo, observou-se que as variáveis que apresentam o valor de queda de tensão e carregamentos (da rede e subestação) são globais, ou seja, variáveis que registram o pior valor encontrado no sistema como um todo. No caso em estudo, analisando o momento anterior à falta, o alimentador com maior queda de tensão é o alimentador 45 (com queda de 2,48\%). Assim, a menos que a configuração inicial (configuração resultante do restabelecimento do setor em falta) resulte em uma queda superior ao valor apresentado de 2,48\%, o valor informado como de "Queda de Tensão" será sempre o de $2,48 \%$.

Analisando a sequência das gerações que deram origem ao indivíduo da geração 54.452, encontram-se os parâmetros apresentados na Tabela 13:

Tabela 13. Resultados desde a geração inicial até a do indivíduo 54.452

\begin{tabular}{|l|c|c|c|c|c|}
\hline & $\begin{array}{c}\text { Perdas } \\
\text { Ôhmicas } \\
(\mathbf{k W})\end{array}$ & $\begin{array}{c}\text { Queda de } \\
\text { Tensão (\%) }\end{array}$ & $\begin{array}{c}\text { Carrega- } \\
\text { mento da } \\
\text { Rede (\%) }\end{array}$ & $\begin{array}{c}\text { Carrega- } \\
\text { mento da } \\
\text { Subestação } \\
(\%)\end{array}$ & $\begin{array}{c}\text { Número de } \\
\text { Manobras }\end{array}$ \\
\hline Geração Inicial & 1061,15 & 3,26 & 79,54 & 53,77 & 5 \\
\hline Geração 3.768 & 1022,13 & 2,48 & 79,54 & 53,77 & 7 \\
\hline Geração 9.689 & 1004,13 & 2,48 & 79,54 & 53,77 & 9 \\
\hline Geração 12.493 & 971,45 & 2,28 & 79,54 & 53,77 & 11 \\
\hline Geração 54.452 & 976,67 & 2,26 & 79,54 & 53,77 & 11 \\
\hline
\end{tabular}

Observa-se que a geração inicial apresenta uma queda de tensão superior ao valor do pior alimentador antes da falta. Com isso o valor de queda de tensão para a referida geração é de 3,26\% (este valor é registrado no alimentador 
32). Através da Figura 44, pode-se observar que a geração 3.768 realiza uma manobra de alívio de carga do alimentador 32, transferindo parte do trecho para o alimentador 60 (manobras envolvendo as chaves 371 e 236).

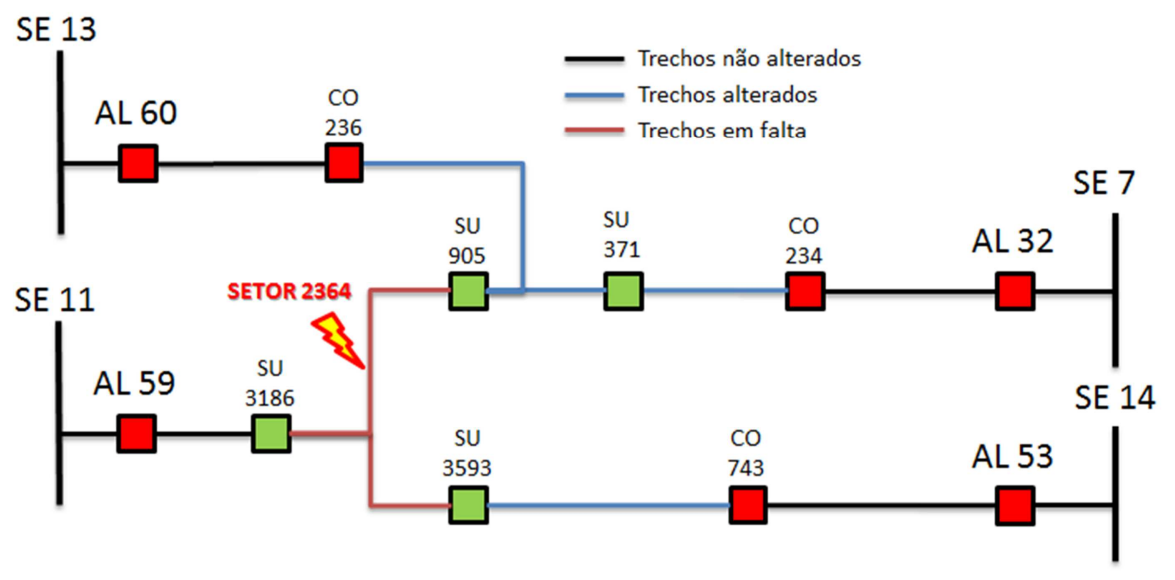

Figura 44. Representação Gráfica do indivíduo da geração 3.768

Ao realizar as manobras que dão origem ao indivíduo da geração 3.768 , elimina-se os "efeitos de queda de tensão" causados pelas manobras de restabelecimento. Com isso, volta-se ao valor de queda de tensão do sistema antes da falta $(2,48 \%)$, que é observada no alimentador 45 . Vale lembrar que o individuo da geração inicial caracteriza uma solução factível, assim mesmo com os ganhos advindos do indivíduo da geração 3.768, os Operadores do COD provavelmente não executariam as operações sugeridas tendo em vista o incremento no número total de manobras.

As manobras que dão origem ao indivíduo da geração 9.689 não envolvem o alimentador 45, com isso, o ganho para o sistema fica restrito à redução de perdas. Já as manobras que dão origem ao indivíduo da geração 12.493, conforme apresentado na Figura 45, apresentam uma redução do trecho do alimentador 45 que é transferido para o alimentador 47. Com isso o valor da queda de tensão do sistema é reduzido para 2,28\%. 


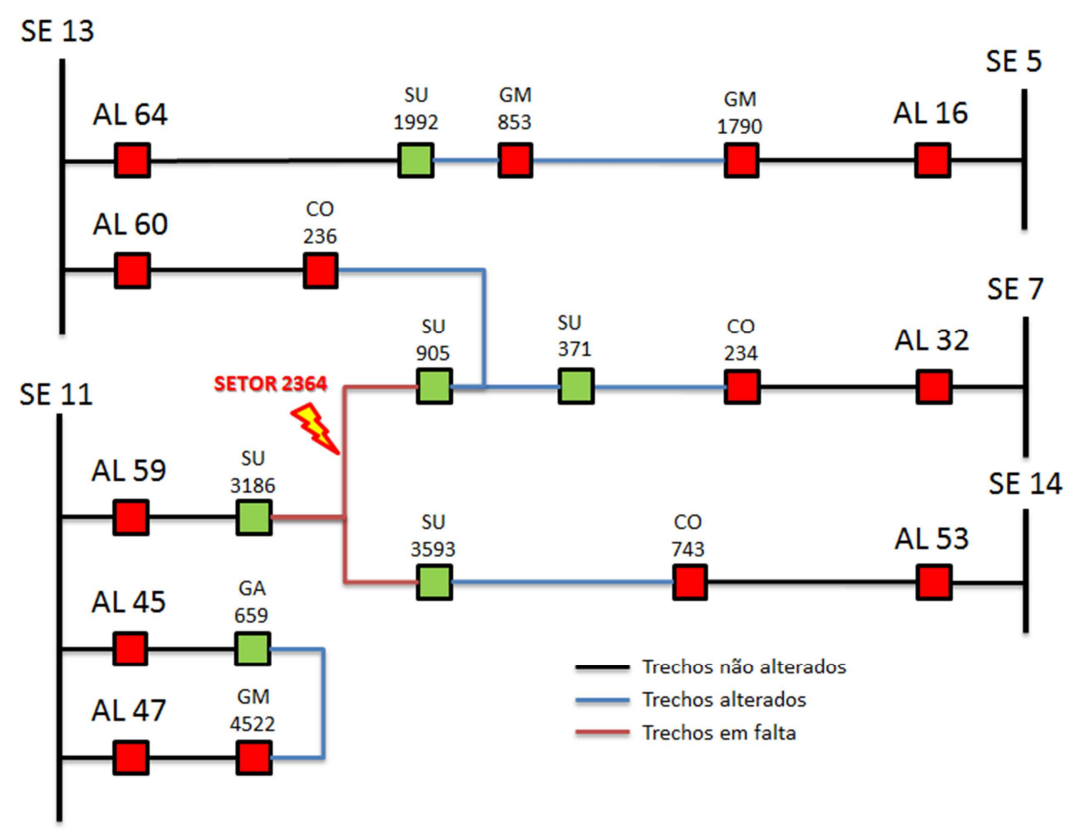

Figura 45. Representação Gráfica do indivíduo da geração 12.493

Por fim, as manobras que dão origem ao indivíduo da geração 54.452 (geração final) reduzem parte do trecho do alimentador 16, reduzindo consequentemente a queda de tensão do sistema para 2,26\%. Importa destacar que a quantidade de manobras sinalizadas não sofre alteração, isto porque a manobra envolvida nesta geração "anula" a necessidade de realização da manobra da geração 9.689. A Figura 43 apresenta a configuração do indivíduo da geração 54.452.

Um debate sobre as manobras apresentadas no processo evolutivo do AEMT-H, desde a geração inicial até a geração 54.452 , leva a refletir sobre a real necessidade e mesmo viabilidade da realização das manobras propostas. Observase que um processo de restabelecimento de energia busca sempre a ação realizada com maior velocidade (menor número de manobras) e atendendo os critérios de carregamento e nível de tensão. Assim, conforme exposto, conclui-se que o COD provavelmente não realizaria as 06 manobras supracitadas, executando apenas as 05 manobras da configuração inicial.

A sugestão observada para este problema (identificada como "Sugestão 3") é a de registrar, na variável que aponta as restrições (carregamentos e nível de tensão), somente os valores dos alimentadores que estejam envolvidos na manobra de restabelecimento de energia. No exemplo da Figura 41, seriam atribuídos somente os valores dos alimentadores 59,32 e 54 . Os resultados dos demais 
alimentadores seriam utilizados conforme ocorressem manobras envolvendo seus trechos primários.

Outra sugestão a ser avaliada é alterar a heurística utilizada no AEMT-H. Atualmente $\mathrm{o}$ algoritmo ranqueia os alimentadores conforme os respectivos níveis de tensão. A proposta é que as manobras possam ocorrer prioritariamente nos alimentadores que possuem interligação com o(s) trecho(s) em falta. Assim, conforme a evolução dos indivíduos, um número maior de alimentadores seria priorizado como opção de manobra. Esta sugestão foi identificada como "Sugestão $4 "$.

\subsection{OUTRAS SIMULAÇÕES}

A fim de validar as quatro sugestões apresentadas na seção 6.2, foram realizadas simulações de falta única em outros 02 (dois) setores de alimentadores distintos.

Inicialmente foi escolhido o alimentador 1 (setor 2 em falta), cuja queda de tensão apresenta um dos menores valores do sistema em estudo. Neste caso, selecionamos a $49^{a}$ simulação para detalhamento das gerações. A Figura 46 apresenta o indivíduo da geração inicial desta simulação.

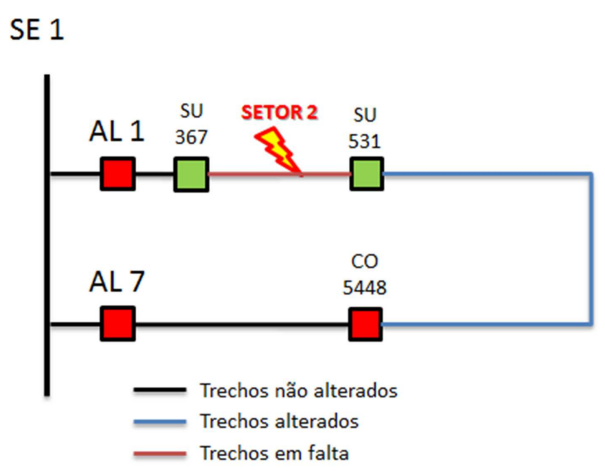

Figura 46. Indivíduo da geração inicial para falta no setor 2

O que se pode observar é que a transferência total das cargas à jusante da falta para o alimentador 7 implica em uma queda de tensão no "pior trecho" do alimentador 7 de cerca de $0,85 \%$. A corrente deste alimentador, mesmo com a transferência citada, não ultrapassa $50 \%$ das limitações dos equipamentos da rede. Comparando o valor de queda de tensão com o dos demais alimentadores, foi verificado que o alimentador 7 ocupa a 23를 colocação dentre os 64 alimentadores 
existentes (considerando uma classificação "ranqueamento" da maior para a menor queda de tensão). Com isso, e lembrando que a heurística envolvida seleciona os 32 piores alimentadores, verifica-se que o alimentador 7 pode ser escolhido para gerar novos indivíduos, no entanto, considerando-se o critério evolutivo no qual somente os melhores indivíduos "entram" nas tabelas do AEMT-H, é pouco provável que manobras envolvendo o alimentador 7 sejam perpetuadas para as gerações futuras.

Neste panorama a "Sugestão 1" terá impacto significativo no desempenho da metodologia. Por se tratar de um caso de restabelecimento de um alimentador com pequena carga, ao se testar todas as possibilidades de manobra para a geração inicial, a probabilidade de obtenção de uma solução inicial factível será elevada.

Com a aplicação da "Sugestão 1", espera-se que as "Sugestões 3 e 4" tenham relevância somente para necessidade de melhoria nos valores de queda de tensão e carregamento da rede encontrados na geração inicial. Ao reduzir o espaço de busca, há um aumento da probabilidade de obtenção de configurações com as melhorias esperados.

Em um segundo momento foi escolhido o alimentador 45, cujo valor de queda de tensão na configuração anterior à falta é a pior entre os alimentadores estudados $(2,48 \%)$ e cuja corrente na saída do circuito é superior à $300 \mathrm{~A}$. Foi selecionado ainda o setor 1784 para simulação da falta (setor com profundidade 1).

Seguem os resultados da configuração inicial apresentada na $1^{\text {a }}$ simulação do setor 1784 em falta. Conforme pode ser observado na Tabela 14, a configuração apresentada é factível (radial e restabelece todos os setores "sãos"), porém a solução não é factível (pois não respeita a restrição do carregamento da rede).

Tabela 14. Características do indivíduo da $1^{\text {a }}$ geração para falta no setor 1784

\begin{tabular}{|l|c|}
\hline & Sistema em Estudo \\
\hline Perdas Ôhmicas (kW) & 1206,46 \\
\hline Queda de Tensão (\%) & 5,35 \\
\hline Carregamento da Rede (\%) & $\mathbf{1 0 6 , 5 5}$ \\
\hline Carregamento da Subestação (\%) & 53,77 \\
\hline Quantidade de Manobras & 3 \\
\hline
\end{tabular}


A Tabela 15 sintetiza os resultados de perdas ôhmicas e das restrições operacionais obtidos pelo AEMT- $\mathrm{H}$, considerando os indivíduos de todas as 50 simulações presentes nas tabelas de 0 a 6 pares de manobras e de soluções "nãodominadas" $F_{1}$. Foram incluídos ainda os valores do tempo de processamento.

Tabela 15. Síntese dos resultados das 50 simulações para a falta no setor 1784

\begin{tabular}{|l|c|c|c|c|c|}
\hline & $\begin{array}{c}\text { Perdas } \\
\text { Ômmicas } \\
(\mathbf{k W})\end{array}$ & $\begin{array}{c}\text { Queda de } \\
\text { Tensão (\%) }\end{array}$ & $\begin{array}{c}\text { Carrega- } \\
\text { mento da } \\
\text { Rede (\%) }\end{array}$ & $\begin{array}{c}\text { Carrega- } \\
\text { mento da } \\
\text { Subestação } \\
(\%)\end{array}$ & $\begin{array}{c}\text { Tempo de } \\
\text { Processa- } \\
\text { mento (s) }\end{array}$ \\
\hline Mínimo & 949,70 & 1,95 & 79,54 & 49,02 & 9,75 \\
\hline Média & $\mathbf{9 9 6 , 9 3}$ & $\mathbf{2 , 3 2}$ & $\mathbf{8 0 , 3 4}$ & $\mathbf{5 3 , 6 6}$ & $\mathbf{1 3 , 8 6}$ \\
\hline Máximo & 1342,48 & 5,78 & 133,06 & 57,03 & 18,91 \\
\hline Desvio Padrão & 30,90 & 0,36 & 4,81 & 0,57 & 2,44 \\
\hline
\end{tabular}

Nota-se que o tempo médio de processamento foi superior ao obtido nas simulações para falta no setor 2384 , porém o valor médio se manteve abaixo dos 180 segundos (sustentando a consideração sobre a aplicação do algoritmo em atividades do tempo real).

Com relação ao número de manobras, apresentado na Tabela 16, novamente foram considerados os resultados de 50 simulações realizadas na metodologia em questão, utilizando apenas os indivíduos presentes na tabela de soluções "não-dominadas" $F_{1}$.

Tabela 16. Número de manobras para a falta no setor 1784

\begin{tabular}{|l|c|}
\hline & Sistema em Estudo \\
\hline Mínimo & 3 \\
\hline Média & $\mathbf{1 0}$ \\
\hline Máximo & 27 \\
\hline Desvio Padrão & 4,36 \\
\hline
\end{tabular}

O indivíduo da geração inicial é apresentado na Figura 47, nele ficam evidenciadas as 03 (três) chaves manobradas para isolar o setor em falta e restabelecer os demais setores "sãos" do alimentador. 


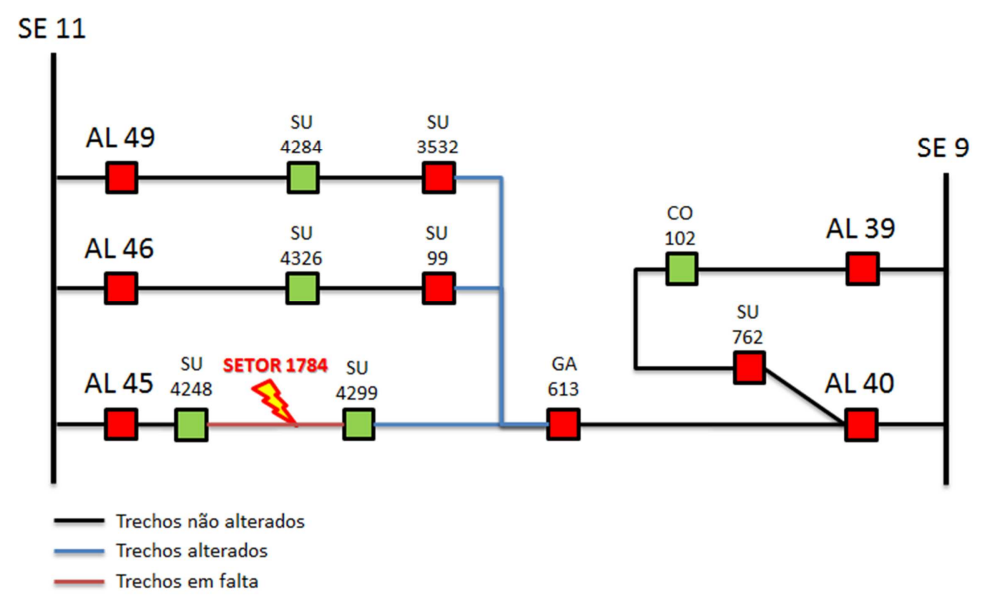

Figura 47. Indivíduo da geração inicial para falta no setor 1784

Vale destacar que este indivíduo, ao utilizar uma chave do tipo "CO" para o restabelecimento dos setores à jusante do setor em falta (chave operável com carga), atende ao disposto na "Sugestão 2" porém não caracteriza uma solução factível (isto porque ele não respeita as restrições operacionais).

Assim, para validar a "Sugestão 2", foi selecionado um indivíduo da $1^{\text {a }}$ simulação, presente na tabela de soluções "não-dominadas" $F_{1}$ e com menor valor de queda de tensão dentre os indivíduos ali presentes. $O$ indivíduo selecionado possui, portanto, uma queda de tensão de 2,27\%, sendo gerado através de 11 manobras no sistema em análise. Este indivíduo é o da geração 16.434, cujos resultados de perdas ôhmicas, número de manobras e demais restrições operacionais são apresentados na Tabela 17.

Tabela 17. Resultados do indivíduo da geração 16.434

\begin{tabular}{|l|c|c|c|c|c|}
\hline & $\begin{array}{c}\text { Perdas } \\
\text { Ôhmicas } \\
(\mathbf{k W})\end{array}$ & $\begin{array}{c}\text { Queda de } \\
\text { Tensão (\%) }\end{array}$ & $\begin{array}{c}\text { Carrega- } \\
\text { mento da } \\
\text { Rede (\%) }\end{array}$ & $\begin{array}{c}\text { Carrega- } \\
\text { mento da } \\
\text { Subestação } \\
(\%)\end{array}$ & $\begin{array}{c}\text { Número de } \\
\text { Manobras }\end{array}$ \\
\hline Indivíduo 16.434 & 1046,00 & 2,27 & 79,54 & 53,77 & 11 \\
\hline
\end{tabular}

A Figura 48 apresenta a configuração do indivíduo da geração 16.434 , considerando somente as alterações realizadas no sistema inicial. 

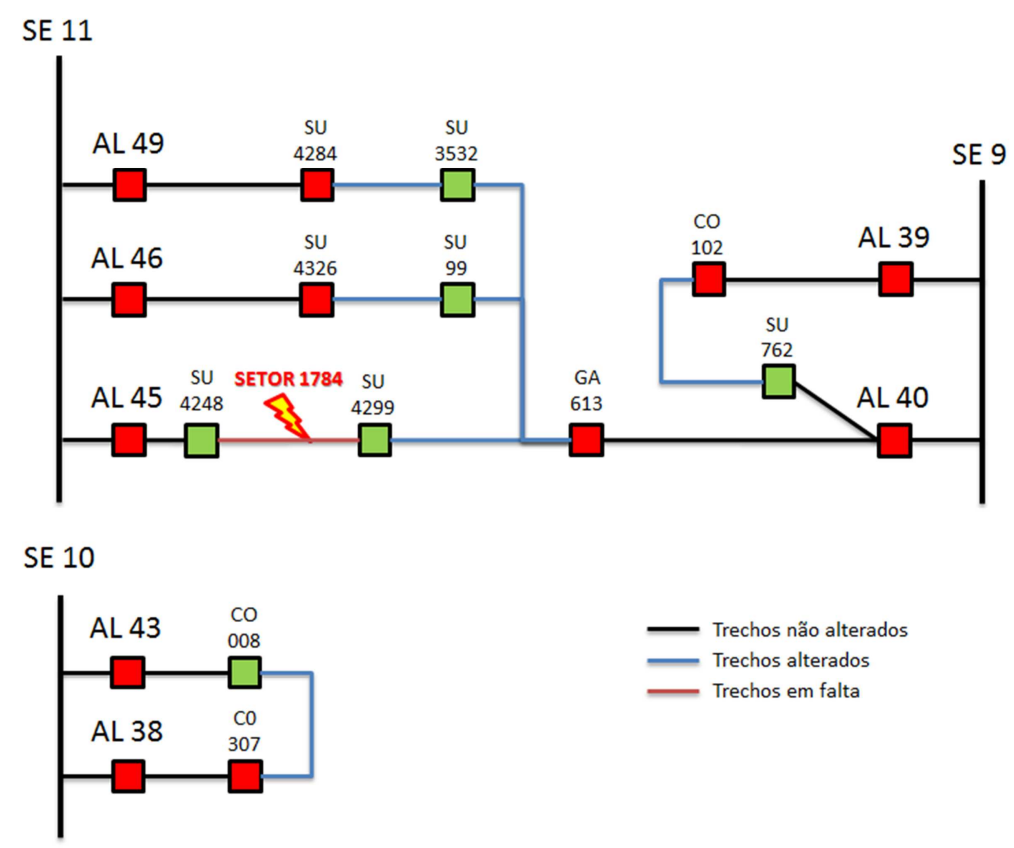

Figura 48. Representação Gráfica do indivíduo da geração 16.434

Em uma análise imediata do sistema da Figura 48, observa-se que a manobra envolvendo as chaves 008 e 307 (alimentadores da SE 10), não faz parte do "contexto do restabelecimento". Observa-se ainda que a manobra em questão não traz qualquer benefício aos valores do sistema. Esta geração só criou novos indivíduos por se tratar de uma geração próxima à geração inicial, ocorrida em um "momento" no qual as tabelas do AEMT-H não estavam completamente "preenchidas". Por ser semente de diversas outras gerações, esta manobra se "perpetuou" até o resultado final do algoritmo. Destaca-se que através da "Sugestão 4" esta manobra certamente não seria proposta.

Tabela 18. Resultados desde a geração inicial até a do indivíduo 16.434

\begin{tabular}{|l|c|c|c|c|c|}
\hline & $\begin{array}{c}\text { Perdas } \\
\text { Ohmicas } \\
(\mathbf{k W})\end{array}$ & $\begin{array}{c}\text { Queda de } \\
\text { Tensão (\%) }\end{array}$ & $\begin{array}{c}\text { Carrega- } \\
\text { mento da } \\
\text { Rede (\%) }\end{array}$ & $\begin{array}{c}\text { Carrega- } \\
\text { mento da } \\
\text { Subestação } \\
(\%)\end{array}$ & $\begin{array}{c}\text { Número de } \\
\text { Manobras }\end{array}$ \\
\hline Geração Inicial & 1206,46 & 5,35 & 106,55 & 53,77 & 3 \\
\hline Geração 6 & 1234,18 & 5,35 & 106,55 & 53,77 & 5 \\
\hline Geração 2.528 & 1229,40 & 5,31 & 106,55 & 53,77 & 7 \\
\hline Geração 4.446 & 1054,03 & 2,62 & 79,54 & 53,77 & 9 \\
\hline Geração 16.434 & 1046,00 & 2,27 & 79,54 & 53,77 & 11 \\
\hline
\end{tabular}


Analisando a evolução das demais gerações é observado que os pares de manobras envolvendo as chaves 762 e 102, 99 e 4326 e 3532 e 4284 reduzem os valores de queda de tensão e carregamento da rede, porém é possível observar que a mudança mais significativa ocorre da geração 2.528 para a 4.446 , quando o trecho à jusante da chave 3532 é transferido para o alimentador 49. Assim, os setores à jusante ao setor em falta são restabelecidos em uma solução factível e através de apenas 05 (cinco) manobras no sistema (abertura das chaves 4248 e 4299 para isolação da falta, abertura da chave 3532 para divisão do trecho a ser restabelecido e fechamento das chaves 4284 e 613 para restabelecimento dos trechos "sãos"). Estas manobras não foram identificadas entre os indivíduos das 70.000 gerações da Simulação 1.

Assim, imagina-se que a implantação das "Sugestões 1, 3 e 4" resulte em um número menor de possíveis configurações resultando em um aumento da probabilidade de seleção da solução factível com pequeno número de manobras. No entanto, para este tipo de problema (restabelecimento considerando uma carga elevada presente nos setores "sãos"), o impacto destas sugestões não será significativo.

Ao analisar as gerações das demais simulações, notou-se que existe uma alternativa de solução factível, utilizando apenas 03 (três) manobras. Esta solução foi observada em 23 das 50 Simulações e é apresentada na Figura 49.

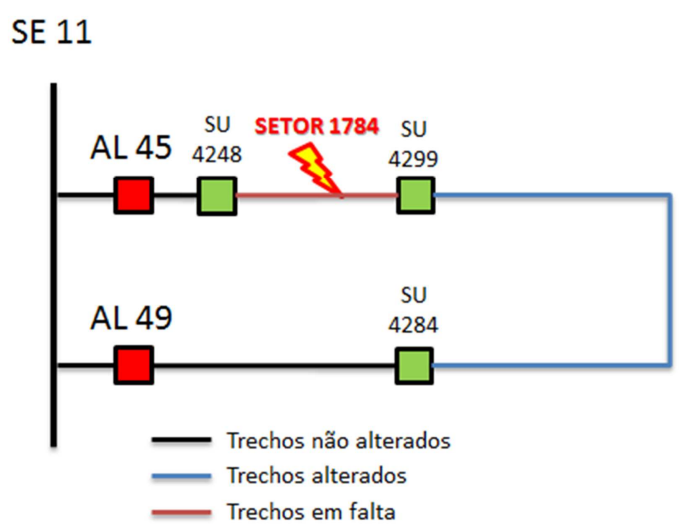

Figura 49. Representação Gráfica do indivíduo da 2ª Simulação, Geração 7.408

A Tabela 19 apresenta os valores de perdas ôhmicas, número de manobras e demais restrições operacionais do indivíduo da $2^{2}$ Simulação, Geração 7.408 . 
Tabela 19. Resultados do indivíduo da 2ª Simulação, Geração 7.408

\begin{tabular}{|l|c|c|c|c|c|}
\hline & $\begin{array}{c}\text { Perdas } \\
\text { Ôhmicas } \\
(\mathbf{k W})\end{array}$ & $\begin{array}{c}\text { Queda de } \\
\text { Tensão (\%) }\end{array}$ & $\begin{array}{c}\text { Carrega- } \\
\text { mento da } \\
\text { Rede (\%) }\end{array}$ & $\begin{array}{c}\text { Carrega- } \\
\text { mento da } \\
\text { Subestação } \\
(\%)\end{array}$ & $\begin{array}{c}\text { Número de } \\
\text { Manobras }\end{array}$ \\
\hline Indivíduo 7.408 & 1029,17 & 2,79 & 79,54 & 53,77 & 3 \\
\hline
\end{tabular}

O indivíduo da geração 7.408 enfatiza a importância da "Sugestão 1" desta dissertação, no entanto vale destacar que o valor apresentado para o percentual de carregamento da rede leva em consideração apenas o limite de corrente admissível dos condutores e das chaves da rede (elementos disponíveis atualmente no banco dados do AEMT-H). No entanto, tendo em vista a existência de conexões entre os condutores (neste caso condutores de alumínio de bitola 336), na prática há uma restrição para o limite de corrente de cerca de 420 Amperes. Neste caso uma nova sugestão é apresentada (identificada como "Sugestão 5"), na qual o valor máximo da corrente seja limitado à ampacidade dos cabos e chaves e ao valor de 419 Amperes (para o caso de condutores de alumínio 336). Desta forma indivíduo da geração 7.408, que possui uma corrente de carga de 415,21 Amperes, é uma solução factível, uma vez a restrição de carregamento da rede não é violada, porém o valor correto do carregamento da rede é de $99,10 \%$.

Vale destacar que não foram realizadas validações adicionais para a "Sugestão 2", tendo em vista o conceito envolvido não necessitar de exemplos para sua validação. 


\section{CONCLUSÕES}

Tendo em vista a necessidade cada vez mais inerente do rápido restabelecimento de energia quando da ocorrência de faltas no SDR, a presente dissertação buscou avaliar a metodologia para restabelecimento de energia denominada AEMT-H, que se baseia em algoritmos evolutivos multi-objetivos e na estrutura de dados RNP. Esta avaliação ocorreu através da aplicação do AEMT-H para obtenção de planos de restabelecimento de energia após a ocorrência de faltas simples no sistema COPEL da cidade de Londrina.

De uma forma geral o AEMT-H apresentou resultados bastante satisfatórios e coerentes com os presentes nos trabalhos [72] e [1], principalmente quando da observação do tempo médio de resposta do aplicativo computacional (em torno de 13 segundos). A principal razão dessa eficiência computacional é a utilização da estrutura de dados RNP e de seus operadores. Pois os operadores da RNP geram apenas "configurações factíveis", cujas barras que são armazenadas na RNP de acordo com o MPF, que é necessário para execução de um fluxo de carga de varredura direto e inversa. Com isso não há necessidade de ferramentas adicionais para o teste e verificação da conectividade e para ordenação das barras no MPF, após a realização da proposição das manobras.

Através da aplicação do AEMT-H em um sistema real e com análise de profissionais da área, foi possível validar a consistência dos resultados obtidos pelo AEMT-H, cujas configurações finais apresentaram soluções factíveis e ainda próximas ao esperado pela área (COD). No mesmo contexto foi possível identificar algumas possíveis melhorias na metodologia, melhorias estas que buscam trazer o resultado cada vez mais próximo ao esperado pelas concessionárias de energia. Dentre as sugestões se pontua a necessidade de uma avaliação de todas as configurações possíveis para o indivíduo inicial ("Sugestão 1"). Com isso se busca o aumento da probabilidade da identificação de indivíduos com quantidade de manobras reduzida.

Outra sugestão apresentada foi quanto à necessidade de considerar as características de operação de diferentes tipos de chaves seccionadoras (existência de telecomando, possibilidade de abertura com carga e/ou em curto circuito, etc.) serem manobradas nas redes de distribuição ("Sugestão 2"). O resultado almejado busca uma otimização na velocidade da execução das manobras (utilizando, por 
exemplo, chaves com comando e controle remotos) e ainda uma redução da quantidade de consumidores afetados (através da utilização de chaves operáveis com carga que evitam a abertura momentânea de alimentadores para manobras).

Sugeriu-se ainda a mudança na filosofia de atribuição do valor da queda de tensão e carregamentos ("'Sugestão 3") e ainda uma nova heurística na qual a priorização dos alimentadores a serem escolhidos para as manobras ocorra de acordo com a conectividade elétrica destes com o alimentador em falta ("Sugestão 4"). Estas sugestões buscam limitar o espaço de busca à região próxima ao setor em falta evitando a geração de manobras em alimentadores que não contribuam para o processo de restabelecimento de energia.

A "Sugestão 5", por sua vez, apresenta uma necessidade de utilização, para os valores de limite de corrente dos condutores de energia, do valor limite dos conectores existentes nas redes de distribuição.

Por fim, vale destacar que a presente dissertação é parte de um projeto de Pesquisa e Desenvolvimento da ANEEL - Agência Nacional de Energia Elétrica (PD 2866-0272/2012). O projeto está em andamento e conta com a participação de pesquisadores da USP, UTFPR (Universidade Tecnológica Federal do Paraná), UFG (Universidade Federal de Goiás) e COPEL. Neste projeto as melhorias propostas nesta dissertação serão estudadas e, conforme entendimento, aplicadas na metodologia a ser desenvolvida. 


\section{REFERÊNCIAS}

[1] SANTOS, A. C.; DELBEM, A. C. B.; LONDON, JR., J. B. A. ;BRETAS, N. G."Node-Depth Encoding and Multiobjective Evolutionary Algorithm Applied to Large-Scale Distribution System Reconfiguration". IEEE Transactions on Power Systems, v. 25, p. 1254-1265, 2010.

[2] NETO, A. C.; PACHECO, Marco Aurélio. "Alocação Ótima de Banco de Capacitores em Redes de Distribuição Radiais para Minimização das Perdas Elétricas", Revista da Inteligência Computacional Aplicada, Vol. X, No. Y, pp. 1-10.

[3] GOMES, F. et al. A new distribution system reconfiguration approach using optimal Power flow technique and sensitivity analysis for loss reduction. Proceedings of the Power Engineering Society General Meeting, pp. 897-901, 2005.

[4] CHEN et al. "Feeder reconfiguration for distribution system contingency by object oriented programming". Proceeding of the Power Engineering Society Summer Meeting, p. 431-436, vol.1, 2000.

[5] MANTOVANI, J.R.S.; CASARI, F.; ROMERO, R.A. "Reconfiguração de Sistemas de Distribuição Radiais Utilizando o Critério de Queda de Tensão", SBA Controle \& Automação, vol. 11, pp. 150-159, 2000.

[6] STROGATZ, S. H. "Exploring complex networks", Nature, vol. 410, pp. 268-276, Março, 2001.

[7] PIGATIN, V. N. ; LONDON , J.B. A. "Análise da Eficiência Computacional de Métodos para Cálculo de Fluxo de Carga". In: Seminário Internacional de Iniciação Científica da USP, 2009, São Carlos. Anais do Seminário Internacional de Iniciação Científica da USP, 2009.

[8] KUMAR, Y.; DAS, B.; SHARMA, J. "Multiobjective, Multiconstraint Service Restoration of Electric Power Distribution System With Priority Customers", IEEE Transactions on Power Delivery, vol. 23, pp. 261-270, January, 2008.

[9] DEB, K. "Multi-Objective Optimization Using Evolutionary Algorithms". Chichester, UK: Wiley, 2001.

[10] MENDOZA, F.; BERNAL-AGUSTIN, J. L.; DOMINGUEZ-NAVARRO, J. A. "NSGA and SPEA Applied to Multiobjective Design of Power Distribution Systems", IEEE Transactions on Power Systems, vol. 21, pp. 1938-1945, November, 2006.

[11] Carvalho, A. P. L. F.; DelBem, A. C. B.; SIMÕES, E. V.; TELLES, G.; ROMERO, R. "Computação Bioinspirada", Anais XXIII Jornada de Atualização em Informática, JAI4-2248, 50pp, 2004.

[12] FOGEL, G. B.; CORNE, D. W. "Evolutionary Computation in Bioinformatics”, Mogan Kaufmann, São Francisco, CA, USA, 2003.

[13] FUKUYAMA, Y.; CHIANG, H. D.; MIU, K. N."Parallel genetic algorithm for service restoration in electric power distribution systems", International Journal of Electrical Power \& Energy Systems, vol. 18, pp. 111-119, February. 1996.

[14] BACK, T.; FOGEL, D. B.; MICHALEWICZ, Z. "Handbook of Evolutionary Computation" New York: Oxford Univ. Press and Institute of Physics, 1997.

[15] AUGUGLIARO, A.; DUSONCHET, L.; RIVA SANSEVERINO, E. "Multiobjective service restoration in distribution networks using an evolutionary approach and fuzzy sets", International Journal of Electrical Power \& Energy Systems, vol. 22, pp. 103-110,February, 2000. 
[16] HSIAO, Y. T.; CHIEN, C. Y. "Enhancement of restoration service in distribution systems using a combination fuzzy-GA method", IEEE Transactions on Power Systems, vol. 15, pp. 1394-1400, November, 2000.

[17] TOUNE, S.; FUDO, H.; GENJI, T.; FUKUYAMA, Y.; NAKANISHI, Y. "Comparative study of modern heuristic algorithms to service restoration in distribution systems", IEEE Transactions on Power Delivery, vol. 17, pp. 173-181, January, 2002.

[18] SHIN, D. J.; KIM, J. O.; KIM, T. K.; CHOO, J. B.; SINGH, C. "Optimal service restoration and reconfiguration of network using Genetic-Tabu algorithm", Electric Power Systems Research, vol. 71, pp. 145-152, October, 2004.

[19] DelbeM, A. C. B. ; CARVAlHO, A. C. P. L. F. ; BRETAS, N. G. "Main Chain Representation for Evolutionary Algorithm Applied to Distribution System Reconfiguration". IEEE Transactions on Power Systems, v. 20, n. 1, p. 425-436, 2005.

[20] BENAYOUN, R.; MONTGOLFIER, J.; LARITCHEV, O. "Linear programming with multiple objective functions: Step method (stem)”, Journal Mathematical Programming 1(1): 366-375, 1973.

[21] CARRENO, E. M.; ROMERO, R.; PADILHA-FELTRIN, A. "An efficient codification to solve distribution network reconfiguration for loss reduction problem", IEEE Transactions on Power Systems, vol. 23, N.4, pp. 1542-1551, November, 2008.

[22] Delbem, A. C. B.; Carvalho, A. C. P. L. F.; Policastro, C.; PInTO, A. K. O.; Garcia, A.; HONDA, K. "Node-depth Encoding for Evolutionary Algorithms Applied to Network Design", Genetic and Evolutionary Computation Conference, 2004.

[23] DEB, K.; SUNDAR J. "Reference Point Based Multi-Objective Optimization Using Evolutionary Algorithms", Proceedings of the 8th annual conference on Genetic and evolutionary computation, pp. 635 - 642, 2006.

[24] MANSOUR, M. R. "Algoritmo para obtenção de planos de restabelecimento para sistemas de distribuição de grande porte”. São Carlos: USP, 2009. Dissertação (Mestrado) - Programa de Pós Graduação em Engenharia Elétrica, Escola da USP - São Carlos, São Carlos, 2009.

[25] GOLDBERG, D. E. "Genetic algorithms in search, optimization, and machine learning". Boston, MA: Addison-Wesley Longman Publishing Co., Inc., 1989.

[26] GRADSHTEYN, I. S. ; RYZHIK, I. M. "Tables of integrals, series, and products". San Diego, CA: Academic Press, 6th ed, 2000.

[27] BROWN, R.E., "Impact of Smart Grid on distribution system design", Power and Energy Society General Meeting - Conversion and Delivery of Electrical Energy in the 21st Century, 2008 IEEE, pp.1-4, 20-24 July 2008.

[28] DAVIS, K.; "SMART talk Directly from the DOE", Utility Automation \& Engineering T\&D, vol.14, no.1, pp.30-34, January 2009.

[29] KADAR, P.; "Multi Objective Optimization of Smart Grid Structure", Intelligent System Applications to Power Systems, 2009. ISAP '09. 15th International Conference on Intelligent System Applications to Power Systems, pp.1-5, 8-12 Nov. 2009.

[30] BERNARDON, D. P. ;GARCIA, V. J.; SPERANDIO, M. ; RUSSI, J. ; DAZA, E. ; COMASSETTO, L. "Smart Grid Concepts Applied to Distribution Networks Operation". In: 45th International Universities' Power Engineering Conference, 2010, Cardiff. UPEC 2010. 
[31] DELBEM, A. C. B. et al. "Node-depth Encoding for Evolutionary Algorithms Applied to Network Design". Proceedings of the Genetic and Evolutionary Computation Conference (GECCO), Lecture Notes in Computer Science. Heidelberg, Part I, p.678-687, 2004.

[32] SANTOS, A. C. "Algoritmo Evolutivo Computacionalmente Eficiente para Reconfiguração de Sistemas de Distribuição". São Carlos: USP, 2009. Tese (Doutorado) - Programa de Pós Graduação em Engenharia Elétrica, Escola da USP - São Carlos, São Carlos, 2009.

[33] LIMA, T. W. "Estrutura de Dados Eficientes para Algoritmos Evolutivos Aplicados a Projetos de Rede”. São Carlos: USP, 2009. Tese (Doutorado) - Programa de Pós Graduação em Ciências da Computação e Matemática Computacional, Escola da USP - São Carlos, São Carlos, 2009.

[34] GROSS, J.L.; YELLEN, J. "Handbook of graph theory”. CRC Press, 2004.

[35] VALIENTE, G. “Algorithms on trees and graphs". Secaucus, NJ, USA: Springer-Verlag New York, Inc., 2002.

[36] ATALLAH, M.J.; FOX, S. "Algorithms and tree theory of computation handbook". Boca Raton, FL, USA: CRC Press, Inc., produced By-Suzanne Lassandro, 1998.

[37] REZENDE, S. O. "Sistemas inteligentes: fundamentos e aplicações”. Barueri, SP: Malone, 2003.

[38] DE JONG, K. A. "Evolutionary computation: A unified approach". Cambridge, MA: MIT Press, 2006.

[39] EIBEN, A. E.; SMITH, J. E. "Introduction to evolutionary computing". Natural Computing Series. Berlin: Springer, 2003.

[40] GABRIEL, P. H. R.; DELBEM, A. C. B. "Fundamentos de algoritmos evolutivos, Relatório técnico". Notas Didáticas do ICMC-USP, 75, 2008.

[41] TEUSCHER, C., MANGE, D.; TEMPESTI, G."Bio-inspired computing tissues: Towards machines that evolve”, Grow, and Learn, BioSystems 68: 235-244, 2003.

[42] BALLARD, D. H. “An introduction to natural computing”. MIT Press, 1999.

[43] SAIT, S. M.; YOUSSEF, H. "Iterative Computer Algorithms with Applications in Engineering: Solving Combinatorial Optimization Problems". IEEE Computer Society Press, Los Alamitos, CA, USA, 1999.

[44] FOGEL, L. “Autonomus automata”. Industrial Research, v. 4, n. 1, p. 14-19, 1962.

[45] KOZA, J. R. "Genetic programming: On the programming of computers by means of natural selection”. Cambridge, MA: MIT Press, 1992.

[46] KRISHNAKUMAR, K. “Micro-genetice algorithms for stationary and non-stationary function optimization”. SPIE: Inteligent Control and Adaptative Systems, v. 1196, p. 289-296, 1989.

[47] LARRAEÑAGA, P.; LOZANO, J. "Estimation of distribuition algorithms: A new tool for evolutionary computation”. Kluwer Academic Publishers, 2001.

[48] TICONA, W. G. C.; DELBEM, A. C. B. "Algoritmos evolutivos para otimização multi-objetivo", Relatório técnico. Notas Didáticas do ICMC-USP, 76, 2008.

[49] HAIMES, Y.; LASDON, L.; WISMER, D. "On a bi criterion formulation of the problems of integrated system identification and system optimization", Systems, Man and Cybernetics, IEEE Transactions on 1(3): 296-297., 1971. 
[50] SCHAFFER, J. "Multiple Objective Optimization with Vector Evaluated Genetic Algorithms". Genetic Algorithms and their Applications: Proceedings of the First International Conference on Genetic Algorithms, Lawrence Erlbaum, p. 93 - 100, 1985.

[51] HAJELA, P.; LIN, C. Y. "Genetic search strategies in multicriterion optimal design". StructuralOptimization, v. 4, p. $99-107,1992$.

[52] FONSECA, C.; FLEMING, P. "Genetic Algorithms for Multiobjective Optimization: Formulation, Discussion and Generalization". Forrest, S., ed. Proceedings of the Fifth International Conference on Genetic Algorithms, University of Illinois at Urbana-Champaign, San Mateo, California: Morgan Kau man Publishers, p. 416 - 423, 1993.

[53] SRINIVAS, N.; DEB, K. "Multiobjective Optimization Using Non dominated Sorting in Genetic Algorithms". Evolutionary Computation, v. 2, n. 3, p. 221 - 248, 1994.

[54] HORN, J.; NAFPLIOTIS, N.; GOLDBERG, D. "A Niched Pareto Genetic Algorithm for Multiobjective Optimization". Proceedings of the First IEEE Conference on Evolutionary Computation, IEEE World Congress on Computational Intelligence, Piscataway, New Jersey: IEEE Service Center, p. 82 - 87, 1994.

[55] LAUMANNS, M.; RUDOLPH, G.; SCHWEFEL, H. "A Spatial Predator-Prey Approach to MultiObjective Optimization: A Preliminary Study". Eiben, A. E.; Schoenauer, M.; Schwefel, H.-P., eds. Parallel Problem Solving From Nature I PPSN V, Amsterdam, Holland: Springer-Verlag, p. 241 - 249, 1998.

[56] RUDOLPH, G. "Evolutionary Search under Partially Ordered Fitness Sets". Proceedings of the International NAISO Congress on Information Science Innovations (ISI 2001), ICSC Academic Press: Millet/Sliedrecht, p. 818 - 822, 2001.

[57] DEB, K.; AGRAWAL, S.; PRATAB, A.; MEYARIVAN, T. "A fast and elitist multiobjective genetic algorithm: nsga-ii". Evolutionary Computation, IEEE Transactions on, [S.I.], v.6, n.2, p.182 197, apr 2002.

[58] ZITZLER, E.; THIELE, L. "An Evolutionary Algorithm for Multiobjective Optimization: The Strength Pareto Approach". Relatório Técnico 43, Computer Engineering and Communication Networks Lab (TIK), Swiss Federal Institute of Technology (ETH), Zurich, Switzerland, 1998.

[59] ZITZLER, E.; LAUMANNS, M.; THIELE, L. "SPEA2: Improving the Strength Pareto Evolutionary Algorithm". Relatório Técnico 103, Computer Engineering and Networks Laboratory (TIK), Swiss Federal Institute of Technology (ETH) Zurich, Gloria strasse 35, CH-8092 Zurich, Switzerland, 2001.

[60] KITA, H.; YABUMOTO, Y.; MORI, N.; NISHIKAWA, Y. "Multi-Objective Optimization by Means of the Thermodynamical Genetic Algorithm". Voigt, H.-M.; Ebeling, W.; Rechenberg, I.; Schwefel, H.-P., eds. Parallel Problem Solving from Nature|PPSN IV, Berlin, Germany: Springer-Verlag, p. 504 - 512 (Lecture Notes in Computer Science, v.1), 1996.

[61] KNOWLES, J.; CORNE, D. "The Pareto Archived Evolution Strategy: A New Baseline Algorithm for Multiobjective Optimization". In: 1999 Congress on Evolutionary Computation, Washington, D.C.: IEEE Service Center, p. 98 - 105, 1999.

[62] VELDHUIZEN, D. V. "Multiobjective Evolutionary Algorithms: Classifications, Analyses, and New Innovations". Tese de Doutoramento, Department of Electrical and Computer Engineering. Graduate School of Engineering. Air Force Institute of Technology, Wright-Patterson AFB, Ohio, 1999. 
[63] COELLO, C.; VELDHUIZEN, D. V.; LAMONT, G. "Evolutionary algorithms for solving multiobjective problems". Genetic algorithms and evolutionary computation; 5. New York: Kluwer Academic, 2002.

[64] CORNE, D.; KNOWLES, J.; OATES, M. "The Pareto Envelope-based Selection Algorithm for Multiobjective Optimization". Schoenauer, M.; Deb, K.; Rudolph, G.; Yao, X.; Lutton, E.; Merelo, J. J.; Schwefel, H.-P., eds. Proceedings of the Parallel Problem Solving from Nature VI Conference, Paris, France: Springer., p. 839 - 848 (Lecture Notes in Computer Science, v.1917), 2000.

[65] CORNE, D.; JERRAM, N.; KNOWLES, J.; OATES, M. "PESA-II: Region-based Selection in Evolutionary Multiobjective Optimization". Spector, L.; Goodman, E. D.; Wu, A.; Langdon, W.; Voigt, H.-M.; Gen, M.; Sen, S.; Dorigo, M.; Pezeshk, S.; Garzon, M. H.; Burke, E., eds. Proceedings of the Genetic and Evolutionary Computation Conference (GECCO'2001), San Francisco, California: Morgan Kaufmann Publishers, p. 283 - 290, 2001.

[66] DEB, K., MOHAN, M.; MISHRA, S. "Evaluating the e-domination based multiobjective evolutionary algorithm for a quick computation of Pareto-optimal solutions". Evol. Comput. 13(4): 501-525, 2005.

[67] KAGAN, N.; OLIVEIRA, C. C. B.; ROBBA, E. J. "Introdução aos Sistemas de Distribuição de Energia Elétrica", vol. 1. $1^{\text {a }}$ ed. São Paulo: Edgard Blucher, 2005.

[68] DAS, D.; NAGI, H.S.; KOTHARI, D.P. "Novel method for solving radial distribution networks", IEE Proceedings-Generation, Transmission and Distribution, vol. 141, pp. 291-298, Julho, 1994.

[69] HAQUE, M. H.; "Efficient load flow method for distribution systems with radial or mesh configuration", IEE Proceedings-Generation, Transmission and Distribution, vol. 143, pp. 33-38, Janeiro 1996.

[70] SHIRMOHAMMADI, D.; HONG, H. W.; SEMLYEN, A.; LUO, G. X. A.; “A compensation-based power flow method for weakly meshed distribution and transmission networks". IEEE Transactions on Power Systems, vol. 3, pp. 753-762, Maio, 1988.

[71] MONTICELLI, A. J. "Fluxo de Carga em Redes de Energia Elétrica”. São Paulo, SP: Edgard Blcher, 1983.

[72] SANCHES, D. S. "Algoritmos Evolutivos Multi-Objetivo para Reconfiguração de Redes em Sistemas de Distribuição de Energia Elétrica". São Carlos: USP, 2013. Tese (Doutorado) Programa de Pós Graduação em Engenharia Elétrica, Escola da USP - São Carlos, São Carlos, 2013.

[73] N. KHAN, D. E. GOLDBERG, AND M. PELIKAN. Multi-objective Bayesian optimization algorithm. IlliGAL Report No. 2002009, University of Illinois at Urbana-Champaign, Illinois Genetic Algorithms Laboratory, Urbana, IL, 2002.

[74] MARTINS, J. P.; SOARES, A. H. M.; VARGAS, D. V.; DELBEM, A. C. B. Multi-objective Phylogenetic Algorithm: Solving Multi-objective Decomposable Deceptive Problems. In: Sixth International Conference on Evolutionary Multi-Criterion Optimization (EMO 2011), 2011, Ouro Preto. Proceedings Series: Lecture Notes in Computer Science. Springer Heidelberg Dordrecht : Springer, 2011. v. 6576. p. 285-297.

[75] MARCO LAUMANNS, JIRI OCENASEK. Bayesian Optimization Algorithms for Multi-objective Optimization, Proceedings of the 7th International Conference on Parallel Problem Solving from Nature, p.298-307, September 07-11, 2002. 
[76] C. WANG, H. Z. CHENG, "Optimization of network configuration in large distribution systems using plant growth simulation algorithm", IEEE Transactions on Power Systems, vol. 23, pp. 119-126, Fevereiro, 2008.

[77] Goldberg, D. D. Genetic Algorithm in Search, Optimization and Machine Learning. AddisonWesley Longman Publishing Co.,Inc. Boston, MA, USA, 1989. 